\title{
Seeping Ugly
}

\section{Charles Louisson}

A thesis submitted in fulfilment of the requirements for the degree of Master of Arts in Criminology

Institute of Criminology

School of Social and Cultural Studies

Victoria University of Wellington

November 2020 


\begin{abstract}
This thesis examines the human experience of encountering manifestations of historical pollution from the Houghton Bay legacy landfill in Wellington New Zealand. While much scholarship has already been dedicated to researching the broad characteristics of environmental victims, there exists a gap within the literature regarding the specific human experiences of historical pollution within urban contexts. This thesis tells the experiential stories of the Houghton Bay residents and their encounters with the landfill and examines their efforts to have overseeing institutions acknowledge their victimization. Through the examination of institutional documents, scientific evidence, visual illustrations and ten qualitative interviews with Houghton Bay residents, the research constructs a holistic view of how a deliberately confused and obfuscated informational landscape concerning a case of historical pollution can not only inhibit institutional acknowledgement of the experience of becoming and living as an environmental victim, but exasperate it. The thesis concludes that the human experience of historical pollution within urban settings is complicated by means of state and corporate propagated agnosis and ainigmology, and that in that process the question of 'who is responsible' becomes evident.
\end{abstract}


Dedicated to my loving mother Jeanette Louisson, and grandmother Noelene Hartridge. Without your unwavering love and support this thesis would never have been possible. 


\section{Acknowledgements}

There are many who have supported me over the course of this thesis and while some may not be mentioned here, know that I am grateful to each and every one of you.

First and foremost, to my primary supervisor, Sarah Monod de Froideville, I extend the sincerest of thanks. Being not only a nation leading expert in her respective field, Sarah has been an unlimited pool of motivation, inspiration and passion that has kept me working even when times were at their most trying. In addition to the day-to-day admin tasks that come along with supervising, Sarah's positive attitude and belief in me that I could finish this project, a belief I myself did not share at times, was perhaps what I came to acknowledge most. Without the role of Sarah as my primary supervisor I have no doubt in my mind this project would have remained a proposal. You'll continue to be a source of passion and inspiration to me for a long time to come, thank you.

To my co-supervisor, Simon Mackenzie, I also extend great thanks. On many occasions throughout the thesis Simon has offered unique insight and advice often leading the thesis into new areas of inquiry that had not yet been considered. Many of the conversations we have shared throughout the duration of this thesis have had a long-lasting impact on how I think about the world and of course, for the thesis itself, thank you.

This thesis would not have been possible without the contribution from my interviewees. You all took the time to speak with me about your experiences encountering manifestations of historical pollution and the subsequent victimisation that followed. Your experiences and resolve gave me additional determination and motivation to finish this project to a standard where it may become useful in enacting some form of positive change within Houghton Bay's environment. Your stories inspired me and kept me motivated to see this project through to the end, thank you.

To the fellow postgraduate students on the $9^{\text {th }}$ floor: Angus, Max, Daniel, Jordan, Sally, Maryam, Audrey and to everyone else I have missed, thank you for making the $9^{\text {th }}$ floor a friendly collegial environment in which to work. Angus, you've been a rock in what has been 
a very stormy period, your work ethic and conscientiousness has inspired me throughout the course of this program, thank you. Max, your fierce intellect and experience within academia has provided me with valuable insight while completing this thesis and moving forward, thank you.

To the office ladies, Gill, Suzanne and Debbie, thank you for always enthusiastically helping me with a myriad of requests ranging from finding the staples to extending my thesis. No matter the request, you all go out of your way to help others and for that, I thank you. 


\section{Contents Page}

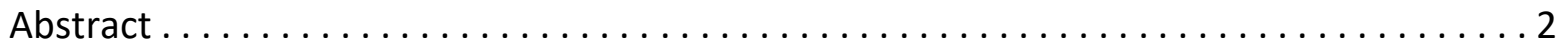

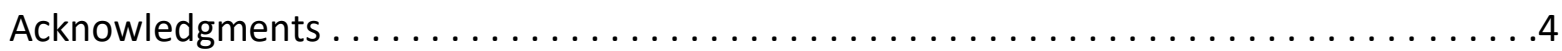

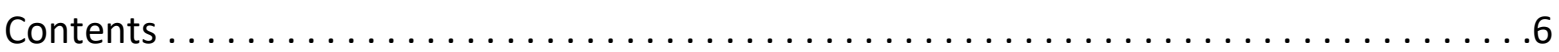

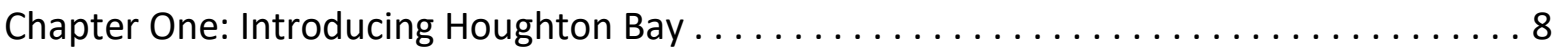

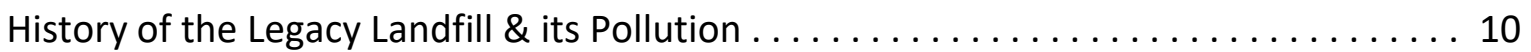

Theoretical Assumptions . . . . . . . . . . . . . . . . . . . . . . . 12

The Pollution's Capacity for Harm . . . . . . . . . . . . . . . . . . . . . . . 13

Chapter Two: Literature Review . . . . . . . . . . . . . . . . . . . . . . . . . 16

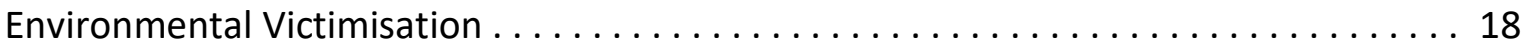

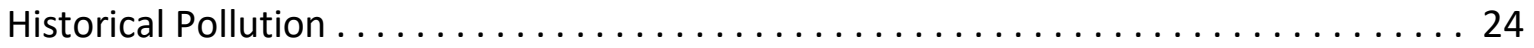

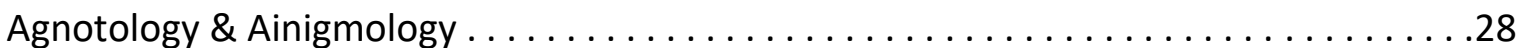

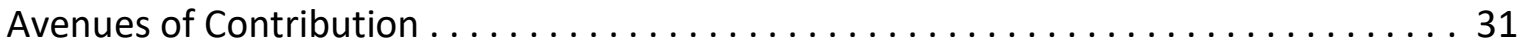

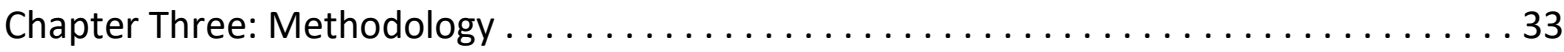

Theoretical Worldview: Eco-Marxism \& Eco-Sociology . . . . . . . . . . . . . . . . . . . 34

Methodology \& Methods: Using the Correct Tool for the Task ............ 38

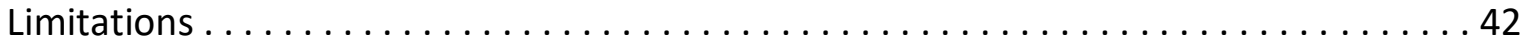

Chapter Four: Environmental Attraction to Houghton Bay $\ldots \ldots \ldots \ldots \ldots \ldots \ldots \ldots$

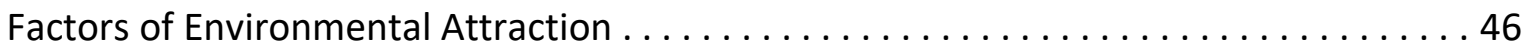

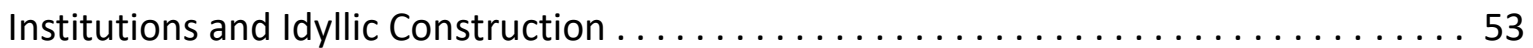

Chapter Five: The Human Experience of Urban Pollution . . . . . . . . . . . . . . 60

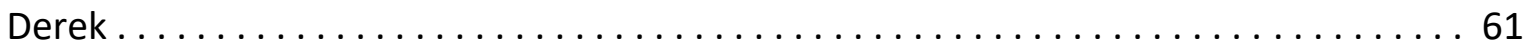

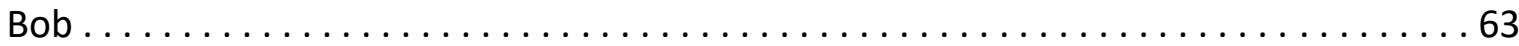

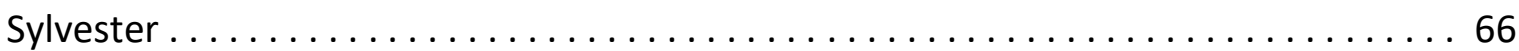

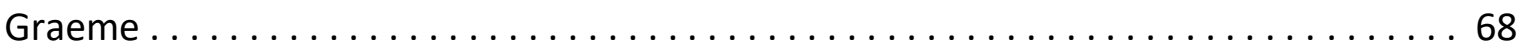

Chapter Six: Orchestrated Agnosis . . . . . . . . . . . . . . . . . . . . . 76

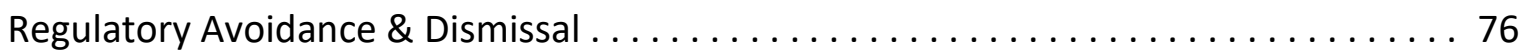

Institutional Dismissal of Community Science . . . . . . . . . . . . . . . . 79

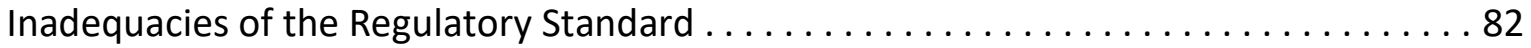

Treadmill of Law Protecting the Treadmill of Production . . . . . . . . . . . . . . 84

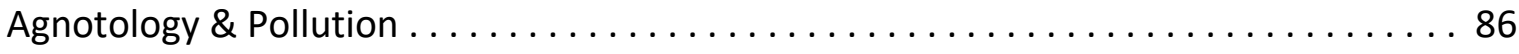




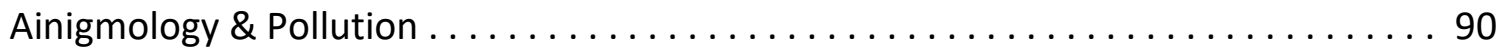

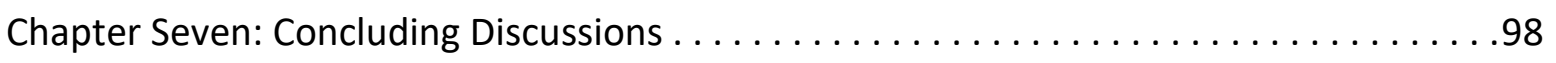

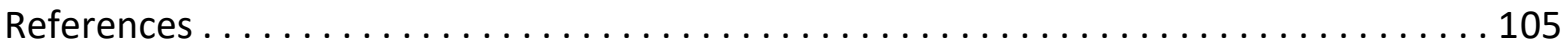

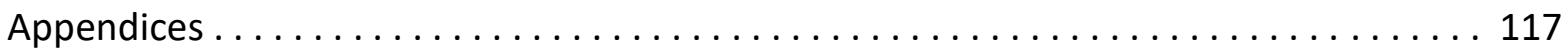




\section{Chapter One: Introducing Houghton Bay}

Houghton Bay (HB) is a suburb located on the southern coastline of Wellington, New Zealand (NZ). Walking through the area of $\mathrm{HB}$, one cannot help becoming entranced by its serenity. Beginning at the coastline at the bottom of the suburb's hilly valley, the wild, untamed HB beach, sun-washed and kissed by the ever-present sea breeze, offers what appears to be a pristine environment in which to live and enjoy. On a nice day the bay is almost always populated by surfers enjoying the rolling swells which come surging in. Clear waters break upon jaded gothic rocks, worn down by centuries of the sea slowly eroding the stones with each passing wave. Sounds of families laughing and the echo of birdsong hangs constantly in the air. As one makes their way up the valley from the beach, the wild coastline scenes transition into native bush that abuts the eastern side. Bushwalk tracks promising scenic experiences litter the area, offering opportunities to more closely admire the secluded aspects of this environment's beauty.

Continuing up the valley from the beach, one encounters leveled sections covered in grass in a staircase-like formation. On these sun-swept plains of green, playgrounds for children, basketball courts and park benches can be found. Mothers herd their children to these playgrounds where they can relax knowing their children are playing in what is a picturesque and obviously safe environment. Continuing further up the valley, one sees families having picnics on the grassy flat surfaces while pet dogs chase around and frolic in the sun-bathed paradise. The coveted Houghton Valley School (HVS) is situated on the largest of these levelled grassy surfaces and appears to be an urban representative of the quintessential country school with its open expanses, grassy fields, cross country track and proximity to the bush. During recess times the fields around the school are swarmed with energetic children playing games and interacting with their environment in a number of diverse ways.

Upon reaching the top of the valley near the border of Sinclair Park, the view looking back down towards the coast is nothing short of awe inspiring. The wild southern coastline, thick native bush, glistening grassy surfaces, all complimented by a unique typography, HB encapsulates the untamable, wild, bucolic NZ ideal. This ideal is the NZ equivalent of the 'American dream', a commonly shared aspiration across NZ society and culture to live somewhere reminiscent of NZ's rural environment. In this sense, HB is truly an idyllic 
environment. However, while walking back down the valley towards the beach, one notices a series of concrete manholes, cracked and rusted and protruding from the flatness of the grassy areas. A man-made feature that is incongruent with the picturesque natural environment. As one continues to walk down the valley, one starts noticing these concrete manholes are aplenty. What are they there for? Why has this infrastructure been buried beneath these leveled grassy surfaces? As the mind tries to make sense of what the eye records, a foul odor characterized by notes of petroleum and oil wafts up from between the cracks of the manholes. The smell throws one into a state of concern and confusion. How is it that such an environmentally wondrous area boasting some of the most idyllic and picturesque environmental features within a NZ context can exhibit a proliferation of unexplained concrete manholes accompanied by a horrid smell? One looks around the area for some notification, a sign perhaps, explaining the origin of the offensive smell or the function of the manholes but alas, no such notification is found. Finally arriving back at the beach, one notices the massive pipe, big enough for an adult to walk through if crouched, discharging what appears to be a lurid orange-tinged liquid bearing the same offensive petroleum-based smell previously detected further up the valley. One watches helplessly as the unsavory liquid oozes across the sand before it enters the sea, forming a large unsettling orange 'plume' within the bay.

Something insidious is buried here beneath this idyllic environment, something that has been literally covered up but still poses significant harms for the people of HB, the nonhuman inhabitants and the physical environment itself. Something buried but not entirely forgotten. This is the HB legacy landfill.

This thesis investigates the HB legacy landfill through the experiences of residents living within the area. This research, through conducting 10 semi-structured interviews with residents of $\mathrm{HB}$, describes in detail the specific manifestations of environmental victimisation through exposure to instances of historical pollution. It investigates the relationship between states of awareness regarding harms associated with legacy waste and the amendment of personal behaviors upon encounters of pollution. This is the experiential aim of the thesis. The research additionally identifies the methods employed by national and local authorities to obscure and confuse the potential for harms associated with the 
legacy landfill pollution (Natali, 2017), adopting agnotological and ainigmological frameworks, which describe the processes by which ignorance, confusion and obfuscation are produced, to do so. It attempts to advance the issue of attributing responsibility and culpability within instances of historical pollution, a line of causation that is fettered by the passage of time and subsequent changes in bureaucratic structures. Having outlined the research intentions, this introductory chapter will next give a history of the HB legacy landfill, followed by a description of the motivations which precipitated this research. The harmful potential of the pollution occurring within the area, as demonstrated by testing for the presence of heavy metals and organic compounds, will form part of that discussion.

\section{History of the Legacy Landfill \& its Pollution}

A legacy or historic landfill is a location where various forms of waste were stored without adequate environmental safeguards in place, such as plastic liners, due to absence of relevant legislation. The HB landfill is one such landfill. In 1950, the landfill was officially opened by Wellington City Council and the Ministry of Education (Purchas, 1998; Wellington Water, 2015). During its operation the HB landfill collected various forms of general waste such as plastics, metals, wood, newspapers and gas-works material but there is still much conjecture as to what exactly was put in it (Purchas, 1998). The HB valley was filled in two sections with the initial section beginning in the lower reaches and extending up to the Houghton Valley School situated approximately halfway up the vale (Purchas, 1998). This lower section of the landfill at its greatest depth is said to be 18 metres and holds somewhere in the region of 698,000 cubic metres of waste (Purchas, 1998).

After the lower section of the landfill was totally utilised, work began on extending the fill towards the top of the valley from the Houghton Valley School up to the border with Sinclair Park (Purchas, 1998). This upper section of the fill began accepting waste in 1963 and was the final section of the fill to be utilised until its closure in 1971 (Purchas, 1998; Wellington Water, 2015). At its greatest depth this upper section is approximately 36 metres and holds 764,550 cubic metres of waste (Purchas, 1998). The HB landfill was constructed without any environmental considerations in mind due to the absence of any legally binding environmental legislation pertinent to the issue of leachate and waste disposal (Purchas, 1998). All the legally enforceable regulations pertinent to landfills such as stipulations concerning what type of soil they are built into, required plastic liners and 
drainage systems did not exist during the landfill's operation or decommission (Ministry for the Environment, 2018; Purchas, 1998; Wellington Water, 2015).

In the absence of legislation, such as the Resource Management Act 1991 (RMA), landfills such as the one in Houghton Valley were decommissioned with no additional environmental safeguards installed to protect the surrounding ecosystems or species in the years to come (Ministry for the Environment, 2018; Wellington Water, 2015). Inadequately sealed landfills are responsible for the generation of leachate (Christensen, Cossu and Stegmann, 1992; Christensen et al., 2001; Van Duijvenbooden and Kooper, 1981). Leachate itself is created through quantities of water percolating down through the compacted layers of waste within the landfill (Christensen et al, 2001; Van Duijvenbooden and Kooper, 1981). As the water percolates down through each layer of waste various chemical, microbial and physical processes transfer pollutants into the water whilst it soaks through the landfill (Christensen et al 2001; Van Duijvenbooden and Kooper, 1981). The exact chemical composition of the pollutants absorbed is closely linked to the contents of the landfill itself, therefore each case of leachate will differ slightly in chemical composition and will therefore differ in its effects upon introduction to an environment (Christensen et al 2001;

Christensen, Cossu and Stegmann, 2012; Van Duijvenbooden and Kooper, 1981). This means that each suspected case of landfill leachate must be examined on a case-by-case basis to formulate effective responses in reducing the pollutants unique to a specific landfill (Barrett and White, 2017; Christensen et al., 2001).

The decommissioned HB landfill is the source of the leachate pollution infiltrating the HB environment (Jayaratne et al., 2015; Wellington Water, 2015; Purchas, 1998). The impact of leachate contamination on any environment is nothing short of abominable (Lisk, 1991). Research shows that landfill leachate is incredibly toxic for luminescent bacteria and zooplankton in aquatic environments which are vital on a microbial level for decomposing organic material and creating nutrients for other lifeforms (Lisk, 1991; Plotkin \& Ram, 1984). Though the impacts on these non-human victims is beyond the scope of this project, I acknowledge them here as a way of appreciating the scope of the environmental harm occurring at HB. Effects of landfill leachate contamination do not exist in isolation for a single species or ecosystem, as each system is affected by leachate contamination the harms and pollutants are continually transferred to the following system and so on (Lisk, 1991; Plotkin \& Ram, 1984). Eventually, pollutants are transferred into ecosystems and 
environments where they can negatively affect humans (Lisk, 1991: Plotkin \& Ram, 1984). Consumption of contaminated animals is only one manifestation how leachate contamination can affect humans but typically, adverse effects of leachate contamination in humans results from exposure to pathogens created by conditions inside the landfill itself (Donnelly, Scarpino \& Brunner, 1982; Lisk, 1991; Pahren \& Clarke, 1987). Conditions within landfills are favourable for the development of harmful pathogens and bacteria such as leptospirosis and even isolated cases of the poliovirus (Lisk, 1991; Peterson, 1974) both of which pose serious health risks to humans. Scientific affirmation regarding the potential harms associated with legacy landfill pollution, and the known existence of pollution occurring in $\mathrm{HB}$ informs much the motivations that precipitated this research.

\section{Theoretical Assumptions}

This research adopts an eco-Marxist theoretical worldview combined with the ecosociological 'treadmill of production' theory, since transplanted into criminological research concerning environmental crimes (Giddens, 1971; Foster, Clarke \& York, 2010; Benton, 1996; Schnaiberg, 1980; Lynch \& Stretesky, 2014). The aforementioned theories encapsulate my unstated assumptions regarding how the world operates and also accounts for the initial construction of the landfill and why the production of waste is necessary for capitalist based economies to function viably (Benton, 1996; Foster, Clarke \& York, 2010). These theories shall be unpacked and connected back to the research in full during the methodology chapter, while here I articulate the main implications from this theoretical grounding.

Eco-Marxism argues that there is an inherent contradiction within capitalist states between political economy and the environment (Benton, 1996; Foster, Clarke \& York, 2010). The perceived infinite growth of capitalism based on the finite resources of the natural world places the environment on a trajectory towards total destruction in the name of capital accumulation (Benton 1996; Foster, Clarke \& York, 2010). Simply put, the infinite growth capitalism pursues begins with the conversion of finite natural resources into commodities, a conversation capitalism seeks to replicate until the end of time. This anticapitalist doctrine extends to the researcher's incorporation of the eco-sociological treadmill of production theories which have since been transplanted into green criminological considerations (Lynch, Stretesky \& Long, 2018; Lynch \& Stretesky, 2014; 
Schnaiberg, 1980). The treadmill of production theory characterises the relationship between the world's natural resources and capitalism though what are referred to as 'additions' and 'withdrawals' (Schnaiberg, 1980). 'Withdrawals' refer to the input of natural resources demanded by capitalism in order to maintain and increase production in the name of profit accumulation while, 'additions' refer to what is placed back into the natural environment as a by-product of intensive production processes (Schnaiberg, 1980). These by-products manifest themselves in many forms, but of interest for this research are the industrial wastes and consumer wastes which are then introduced back into the environment in the form of rubbish. This research explains the HB legacy landfill's existence as facilitating those environmentally adverse 'additions' by servicing the heightened state of consumption required by capitalists in order to successfully amass capital. In this sense, landfills serve as an essential capitalist tool necessary in order to provide a consumption obsessed society with somewhere to dispose of unwanted commodities in order to purchase more, thus creating situations like that of HB.

\section{Pollution's Capacity for Harm}

Before introducing and summarising the function and content of the following chapters, I shall address the harmful quality of the pollution occurring within HB. This is in anticipation of claims that without objective proof evidencing the harmful potential of the pollution occurring in $\mathrm{HB}$ it is fallacious to view those who have encountered the pollution as potential victims. In other words, how do I know that the pollution entering HB is harmful? To do so accurately meant conducting some form of scientific analysis of the pollution occurring in HB. A methodology for the tests conducted, the full results and the associated limitations, can be found in the appendices.

Tests were of water and solid samples drawn at the beach of HB. Lead was found to be present within both the water and solid samples and at its highest level tested at 28.2ugL. This result breached all contamination guidelines for both freshwater and marine water according to the Australian and New Zealand Environment and Conservation Council (ANZECC) guidelines (ANCECC, 2000). Lead's capacity for harm upon exposure to humans, non-humans and the environment has been extensively researched and in humans can lead to hyperextension, renal impairment, immunotoxicity and a strata of behavioural impacts (WHO, 2019). It should also be noted that there is currently no known level of lead exposure 
that does not yield some form of health complication: in other words, any level of lead exposure is potentially harmful (WHO, 2019). Lithium, another heavy metal, was also present within each sample and at its most concentrated tested at 18.2ug/L. Lithium has also been shown upon exposure to cause abdominal pain, acidosis, renal tubular acidosis and acute kidney injury (PubChem, 2020a). These are only two results from the 31 different non-organic elements tested and only represent a small fraction of the total results that breached respective ANZECC limits, results that can be found in the appendices.

The research also tested for the more commonly overlooked organic pollutants present within the HB pollution. The tests employed here indicate the presence or absence of compounds rather than their exact quantity. Benzyl butyl phthalate, used to increase the flexibility of plastics, was found within the pollution samples. This compound has been proven to cause acute headaches, nausea and drowsiness upon human exposure (PubChem, 2020b). Butyric Anhydride, commonly used within cosmetic and chemical manufacturing, was also found present within the HB pollution and has been shown to cause severe damage to the respiratory system and eyes upon exposure (PubChem, 2020c). Like the inorganic test, these two organic test results represent only a fraction of all those which exceeded relevant guidelines and can be found in the appendices. These tests provide objective verification that the pollution entering HB has the capacity to cause harm to humans who are exposed to it. This allows the discussion to move away from proving the capacity of the pollution's harm, to a place where the pollution's harm and resulting experiences of victimisation are assumed. These tests unequivocally illustrate the harmful capacity of HB's pollution, and the associated implications upon exposure.

A short summary of the upcoming chapters shall now be articulated. The next chapter, Chapter Two, establishes where this research shall be conceptually situated amongst similar literature. This is achieved through a discussion on the pertinent principals associated with green criminology, environmental victimisation, historical pollution, agnotology and ainigmology. Chapter Three, the methodology, discusses the research's epistemology, theoretical worldview, adopted methodology and the specific methods employed to obtain the data. Chapter Four begins the conceptual journey by investigating why people are attracted to live in HB despite the contamination and the establishment of what is termed an 'idyllic construction' concerning the perception held by residents of the area. Chapter Five examines how interactions with manifestations of pollution effects the 
strength of the area's 'idyllic construction' and whether these encounters cause changes in interviewee awareness of the pollution, followed by the amendment of personal behaviours and environmental interaction. Chapter Six examines the interviewee experience of engaging with presiding institutions in attempting to have their experiences of victimisation formally acknowledged in addition to the role national and local authorities play in confusing and obfuscating the harms associated with the pollution, thereby accruing those institutions with the respective organisational rewards. This is then followed by Chapter Seven, where the conclusions from the thesis are stated and all lines of argument are brought to a close. 


\section{Chapter Two: Literature Review}

Green criminology has had over thirty years of academic development and in that time has evolved considerably from being a sub-discipline that sat on the very periphery of criminological inquiry that has now become an integral component of many criminological schools around the world today. The term 'green criminology' was coined by Michael Lynch in his 1990 essay entitled 'The Greening of Criminology' (Lynch, 1990; South, Eman \& Mesko, 2014). Lynch (1990) advocated for a more ready adoption of an environmental perspective within the realms of more traditional criminological inquiry and research. In a sense, Lynch (1990) was making an announcement to all other criminologists globally to incorporate an environmental perspective within traditional lines of criminological inquiry advocating for the examination of environmental crimes.

Lynch then incorporated eco-sociological literature concerning what is referred to as 'the treadmill of production' with that of the newly established 'green criminology' (Lynch, 1990; South Eman \& Mesko, 2014; Schnaiberg, 1980). The 'treadmill of production' (ToP) was a theory found in Schnaiberg's 1980 work 'The Environment: From Surplus to Scarcity' where he connects the modern industrial process such as the layers of production required to facilitate the western consumer life-style to the negative effects this 'treadmill' has on environments (Schnaiberg, 1980; South Eman \& Mesko, 2014). Lynch argued that this 'treadmill' is responsible for the majority of environmental crime and degradation currently occurring (South, Eman \& Mesko, 2014). Schnaiberg's ToP theory has also been connected to the eco-Marxist schools of thought and it is the eco-Marxist notion of ecological disorganisation that informs the theoretical worldview of this research insofar as I will examine the HB landfill as a negative environmental 'addition' (Benton, 1996; Foster, Clarke \& York, 2010).

The next significant contribution to the conceptual development of green criminology was from the work of Piers Beirne (Beirne, 1995; Beirne, 1999, South, Eman \& Mesko, 2014). Beirne began to discuss environmental criminology with a focus on the implication for non-human species that evolved from examination of wildlife trafficking practices and other forms of animal abuse occurring at that time (Beirne, 1995; Beirne, 1999). Bernie's work criticised criminology's inflated focus on anthropocentric dimensions of environmental crime and argued that the harm endured by non-human victims within 
instances of environmental crimes is often much greater in extent and should therefore be deserving of criminological attention (Beirne, 1995; Beirne, 1999). Beirne's contention that environmental harm can extend beyond the anthropocentric is a key idea that underpins much of what this present thesis protests. However, while Beirne's contribution here is undoubtedly significant, it must be reiterated that ideas are not formulated in a vacuum.

Rob White has been credited with codifying, collating and organising the various green criminological concepts, philosophies and frameworks that have ultimately become the standard mode to which effective green criminological research is conducted today (South, Eman \& Mesko, 2014; White, 2008). His work has established typologies, orientations and frameworks that one can adopt to organise how specific environmental crimes are researched (Heckenberg \& White, 2014; South, Eman \& Mesko, 2014; White, 2008). Therefore, White has been instrumental in organising various epistemologies regarding different forms of human interaction with environments such as biocentrism, anthropocentrism and ecocentrism, and connecting these to the relevant green criminological frameworks of ecological justice, environmental justice and species justice (White, 2008; White \& Heckenberg, 2014). These three eco-philosophies (anthropocentric, ecocentric and biocentric) defines the philosophy of one's relationship to their environment and has important implications for researchers of green criminology and policy makers alike (White \& Heckenberg, 2014). For example, policy makers who subscribe to an anthropocentric eco-philosophy will prioritise the protection of human health and wellbeing above that of non-humans and physical environments (White \& Heckenberg, 2014) These eco-philosophies naturally align themselves with the three eco-justices (ecological justice, environmental justice and species justice) that give different considerations to what is harmful and how we value what is being harmed, for example, an ecological justice values the sustainability of eco-systems and recognises humans has simply being one small component of a much larger set of ecosystems (White \& Heckenberg, 2014).

White's (2008) organisation helps a green criminological researcher locate their line of inquiry and it also helps to highlight the divisions between different forms of victimisation across a strata of life forms and even to physical environments themselves (White $\&$ Heckenberg, 2014). This project, due to its focus on the human experience of urban pollution, sits primarily under the anthropocentric environmental justice framework (White \& Heckenberg, 2014). This does not eliminate the project's consideration of the nonhuman 
and physical environment but situating this project within an environmental justice framework reinforces the research's primary concern towards understanding and collating the human experience of environmental harm.

White is also credited with the development of the three categorisations of environmental issues, these being 'Brown', 'Green' and 'White' (White, 2008; White, 2010; White \& Heckenberg, 2014). 'White' issues refer to the impact of modern science and the development of new technologies and includes environmental issues such as nanotechnologies, animal experimentation and genetically modified organisms (White, 2008, 2010; White \& Heckenberg, 2014). 'Green' issues refer to the destruction of wildlife habitats, deforestation, acid rain and the loss of wildlife (White, 2008, 2010; White \& Heckenberg, 2014). Finally, and of most relevance to this project, is the 'brown' classification of environmental issues which include air pollution, oil spills, disposal of hazardous/toxic wastes, pollution of urban storm water and the pollution of beaches (White, 2008, 2010; White \& Heckenberg, 2014). The present research fits into the 'brown' classification of environmental issues.

\section{Environmental Victimisation}

The field of 'environmental victimisation' was born out of the cross pollination between the sub-disciplines of victimology and green criminology. Frederick Wertham established the sub-discipline in order to research and study those who were affected by criminal acts in 1949 (Hall, 2013). From its initial inception up until the 1970's, victimology was primarily focused with examining 'the precipitation question' that referred the potential role a victim plays in actually precipitating their own victimisation (Zaykowski \& Campanga, 2014). The 'precipitation question' has since been harshly critiqued in regard to perpetuating victim blaming ideologies and has been largely departed from by mainstream criminological inquiry. Scholarship researching the 'precipitation question' remained the predominate line of victimological inquiry up until the late 1970's where the work of academics such as Nils Christie, who began to examine the way criminal justice systems throughout the world actually prevent the accommodation and acknowledgement of certain victims (Christie, 1977; Hall, 2013; Maguire, 1991). The focus of traditional victimology subsequently began to shift away from the formative arenas of victimisation and its disciplinary parameters were widely expanded. 
This expansion of victimology's conceptual boarders now permitted the study and research of victims that were unacknowledged by criminal justice systems throughout the world. Christopher Williams saw an opportunity for the integration between the two schools of victimology and that of green criminology and subsequently published 'An Environmental Victimology' (Williams, 1996). Williams saw the need for the development of a sub-discipline dedicated to researching the complex origins and lived experiences of the environmental victim, a genesis and experience that had slipped between the fingers of academic scrutiny and understanding for too long. It is from his influential 1996 work where the first working definition of an 'environmental victim' was posed:

"Those of past, present or future generations who are injured as a consequence of change to the chemical, physical, microbiological or psychosocial environment, brought about by deliberate or reckless individual or collective, human act or omission." (Williams, 1996, pg. 35)

This definition encapsulates many important concepts pertinent to the issues of environmental crime and degradation such as the idea of 'intergenerational victims' (Williams, 1996). According to this definition, those who would be intergenerational victims are included under the term 'future', based on the idea that we as the current generation who presides over the environment have a duty to maintain a minimum standard of quality and to operate sustainability in order for those who come after us to have the same quality and access to environment in the same manner we did (Williams, 1996). This article also includes much discussion on formulating this definition with specific legal considerations in mind, evidenced by the terms 'deliberate' and 'recklessness' (Williams, 1996). This is important because at the time of his writing environmental crime was only considered so by law if the outcomes of the activity which precipitated the event referred to as the crime were 'reasonably foreseeable', so where companies and corporations could prove that they were unable to know of a specific outcome, if they were unable to 'reasonably foresee' the impacts that followed, then the court would not classify the transgression as an environmental crime (Williams, 1996). By including the term 'recklessness', the court could recognise inherently dangerous and risky activities, activities where a specific negative outcome might not have been reasonably foreseeable but because of the blatant disregard 
for the dangerous nature of the practice, can be included under this definition as a 'reckless' act and therefore those who suffer as a result can be accommodated as environmental victims (Williams, 1996).

Williams' conceptualisation of environmental victims is grounded in a legal perspective and much of his article is dedicated to incorporating and drawing from international law. It is a view of victims that has been criticised by some as being too anthropocentric (Hall, 2017; Hall, 2013; Skinnider, 2011). This is due to the omission of the non-human and physical environments that can also become victimised through various process of environmental degradation. I agree with the anthropocentric criticism insofar as there needs to be a definition of environmental victims that possesses the conceptual flexibility to include the victimisation of beings and spaces that extend beyond that of the human, however, such an encompassing definition would most likely prove too impracticable for meaningful use by criminal justice systems as they are presently configured (Williams, 1996). Williams did note his definition was not intended to be a "catch all" and was primarily constructed as an initial "starting point" (Williams, 1996, pg. 21) to which future environmental victimisation research could then add to. Williams further defended his definition by arguing that the defining of such concepts should be conducted in a way that makes them readily implementable into existing legal frameworks (Williams, 1996). A definition is of more practical assistance to environmental victims if so.

An interesting position to consider with regard to the legal practicality of conceptual definition are the views of Hall, Lynch and Stretesky who are critical of how effective the same system that creates the "legally ambiguous" (Hall, 2013, pg. 14) arena can ever be at remedying the consequences of the very practices it facilitates (Hall, 2013; Lynch \& Stretesky, 2014). It has been well verified that existing legal frameworks lack not only the flexibility to accommodate indirect forms of victimisation, but also protect the process of production that precipitate and are responsible for much of the environmental degradation the earth's ecosystems are currently experiencing (Lynch \& Stretesky, 2014; Lynch, 2019; Lynch Stretesky \& Long, 2018). I will demonstrate in this thesis how this point is evidenced by the way that New Zealand's Resource Management Act 1991 (RMA), the legislative vehicle designed to protect the country's unique flora and fauna, actually aids in the perpetuation of the very environmentally destructive practices it espouses to combat. 
The next significant contribution to the body of environmental victimisation literature comes from Eileen Skinnider's 2011 report concerning environmental victims from a Canadian perspective (Skinnider, 2011). Skinnider sets out and discusses the broad characteristics of environmental victims and provides a few different typologies to organise and study those respective environmental victims (Hall, 2013; Skinnider, 2011). Her report addresses the concept of environmental victims from a legal perspective with much of the report's discussion alluding to the specific statutory framework of Canada including Canadian definitions and interpretations of related concepts such as 'environment' and 'victim' that are not overly useful for the present research situated within a New Zealand jurisprudence (Skinnider, 2011). What is useful from her report is the second section entitled "Range and Types of Environmental Victims" (Skinnider, 2011, pg. 6), referred to by Matthew Hall, a prominent green victimological scholar, as being "the most systematic review of environmental victims... available" (Hall, 2013, pg. 26).

Skinnider discusses the difficulties in quantifying the scope of environmental victimisation (Skinnider, 2011). The first is that in many instances of environmental crime, especially in cases where exposure to contaminates over time results in harm akin to the present situation in $\mathrm{HB}$, the victims are often unaware of the contamination taking place and therefore would never even think to consider themselves as an environmental victim (Skinnider, 2011). She goes on to state other difficulties as follows. Quantifying the exact extent to which someone has been victimised in a situation like the one described above where the physical manifestations only become apparent after prolonged exposure is complex. Does each single instance of exposure constitute its own offence or is it only the final accumulation that need be prosecuted against? (Skinnider, 2011). She goes on to say that even in certain situations where there are clear manifestations of environmental harm, those suffering those harms are still reluctant to report these 'crimes' to the respective authorities and therefore prevents classifying oneself as the victim of an environmental crime. This is similar to 'self-silencing' identified by studies of victims of sexual violence that have found that, for a number of reasons, victims feel like their experiences will not be formally acknowledged or believed and so become reluctant in reporting such offences (Jordan, 2012; Skinnider, 2011).

Skinnider (2011) also collates the common characteristics of environmental victims. She notes that part of the reason the development of such characteristics has been fettered 
over the course of victimology's development is that victimisation surveys have only recently have begun to incorporate environmental crimes and the associated victimisations (Skinnider, 2011). The characteristics of environmental victims as collated by Skinnider are as follows:

I) Environmental victims are not always aware of the fact they have been victimised (Skinnider, 2011).

II) The process of environmental victimisation is often delayed with the victim usually becoming aware of their victimisation after the environmental crime has been committed (Skinnider, 2011).

III) It is usually unclear to environmental victims who or what exactly is responsible for the environmental conditions that cause their victimisation (Skinnider, 2011).

IV) The severity of environmental victimisation usually comes from the mass victimising nature of environmental crimes rather than seriousness of an individual experience of victimisation (Skinnider, 2011).

V) Environmental victimisation can also include repeat offences (Skinnider, 2011).

While collating these common characteristics constituted a gargantuan advancement within environmental victimisation literature, Skinnider herself noted, "Further study is required to get a better understanding of this type of environmental victimisation and how it differs from other types of victimisation" (Skinnider, 2011, pg. 25). These general characteristics of environmental victims are important for the green criminological environmental victimisation researcher as they attempt to generally distinguish the experience of victimisation with regard to environmental crimes between experiences of victimisation with regard to other forms of crime. This distinction creates somewhat of an environmental victim 'identity' that scholars can look for amongst all victimisation experiences. Skinnider's general characteristics of the environmental victim shall be looked for within the present research's data to explore the universality of the characteristics and test their applicability across different geographical regions.

The next substantial contribution to the field of environmental victimisation comes from the scholarship of Matthew Hall. Hall (2013) responds to the Skinnider's 2011 work and offers his own contribution in advancing the environmental victimisation literature. 
With regard to Skinnider's work, Hall argues that the report was somewhat descriptive and her analysis inextricably linked to the Canadian perspective of environmental victimisation (Hall, 2013). Hall moves to advance Skinnider's (2011) characteristics by developing a "typology of the forms of harms such victims might experience" (Hall, 2013, pg. 27). Halls typology of harms environmental victims may experience are as follows:

I) Health Impacts. This is the most immediate and recognisable form of harm that an environmental victim may endure (Hall, 2013). Hall uses the harms associated with air pollution and climate change in order to illustrate the pervasive nature and scope at which environmental crimes can victimise people with regard to compromising their health (Hall, 2013).

II) Economic Impacts. Hall argues the financial impacts of environmental degradation constitute a form of environmental victimisation (Hall, 2013). This is evidenced though examination on the predicted impact of climate change on the earth's global agricultural industry as well as discussions on the financial impact the 2010 British Petroleum (BP) Deep Water Horizon oil spill had on local Louisiana shrimp fishermen thereby illustrating a financial dimension to environmental victimisation (Hall, 2013).

III) Social and Cultural Impacts. Hall poses that in addition to the financial and health impacts, environmental victimisation can precipitate harms in the realm of social and cultural (Hall, 2013). Hall cites research discussing the impacts of climate change, specifically rising sea levels, with regard to the people living in the Maldives (Hall, 2013; Morner, Toolie \& Possnert, 2004). The rising sea-levels will negatively impact the traditional cultural practices and society of the Maldives people, forcing them to abandon their traditional culture and society in favour of adopting an escape from the harms wrought by climate change (Hall, 2013).

IV) Security Impacts. Hall articulates the link between environmental degradation and an increase in the scarcity of resources at the individual, national and global level (Hall, 2013). Of particular note is the impact climate change is expected to have on the world's food production due a rise in temperatures, desertification and a loss of biodiversity (Hall, 2013). This may cause the demand for food to sharply rise which has already been shown to 
precipitate riots and other forms of associated civil unrest (Hall, 2013; Schanbacher, 2010). Transferring the idea of security to environmental contexts thus incurs a consideration toward forces that undermine said security (Hall, 2013).

Hall's typology concerning the harms associated with environmental victimisation provides this research with a set of characteristics that can be sought after within the data for a sense of replication within an urban NZ context. Yet none of the examples provided stem from the context of historical pollution within an urban setting. This provides an avenue of contribution for the present research as manifestations of harm within the experiences of those afflicted by historical pollution can empirically illustrate that these specific forms of harm are applicable outside of the contexts and examples Hall described.

\section{Historical Pollution}

From the broad perspective of green criminology, to the 'brown' issues of environmental harm as according to White's typology (2008), and then within that, the arena of environmental victimisation with the general characteristics of specific forms of harm associated with environmental victimisation (Skinnider, 2011; Hall, 2013), the next and final rung most closely associated with the present research's line of inquiry shall now be reviewed. This area of literature is referred to as 'historical pollution' and is a form of 'brown' crime according to White's typology (Centonze \& Manacorda, 2017; South, 2016; Wyatt, 2016; White, 2008).

Lorenzo Natali has been credited by other historical pollution scholars such as Centonze and Manacorda as being essential in developing and calling for empirical research within the realm of historical pollution (Centonze and Manacorda, 2017). Much scholarship in this field has been dedicated to creating a working definition of the term historical pollution so that researchers are able to clearly delineate between similar cases of other brown environmental crimes. The task for the present researcher is to situate the present research as a study of historical pollution. For the purpose of the present research, historical pollution shall be defined as: 
"the pollution of sites and natural resources (intended as the relevant behaviour), which started or took place in the past, due to industrial activities or other production-related activities. Historical production usually entails the emergence-or the persistence-of contamination of sites and natural resources (meant as the effect of such conduct) a long period of time after the original pollution took place" (Rotolo, 2017, pg. 61).

There are two very important appendages built into this definition that are essential for appreciating and accounting for historical pollution's complexity, time and causation (Rotolo, 2017; Natali, 2017). According to established scholarship, the temporal dimension of historical pollution refers to the chronological distance in time between the beginning of the polluting behaviour and the point at which this behaviour is observed or acknowledged (Rotolo, 2017). This is one of the unique features of historical pollution that distinguishes the phenomena from other forms of environmental crime. This temporal distance is exhibited by the present research's case study of HB. The HB landfill was officially closed in 1971, yet it was not until 1990 that Wellington City Council (WCC), in conjunction with Wellington Water, officially observed the issues of leachate and gas contamination and only then began monitoring procedures and an investigation into the feasibility of possible solutions (Purchas, 1994; WCC \& Wellington Water, 2018). This is a period of almost two decades of regular polluting from both the landfill gases and leachate, that continued unobserved in any officially capacity thereby providing the contaminates with the opportunity to affect the local environment, wildlife and human residents over time.

The second important appendage of historical pollution refers the specific consequences and impacts of said pollution (Rotolo, 2017). The 'specific consequences' refer to the contamination of places and natural resources as the primary consequence, and human and non-human harms that stem from the pollution of the physical environment as secondary (Rotolo, 2017). This is an issue of establishing causality. It is establishing the connection between a specific instance of pollution and resulting harms that are then experienced by humans, the non-human and the physical environments (Rotolo, 2017; Natali, 2017). Due to the length of time that passes and the number of individual instances of pollution contained within that time period makes this connection increasingly difficult to make, especially in the legal arena where the exists a devotion to the more quantitative and 
scientific forms of evidence that to encapsulate these temporal notions would require a significant investment in time, resources and expertise (Scott, 2016). Some of the harms experienced by the interviewees, examined within the findings chapters, stems from this difficulty in establishing, in an official capacity, a direct causational link between the specific instances of pollution and the resulting harms that, in an anthropocentric sense, manifest themselves as health, social, cultural, economic and environmental security impacts (Hall, 2013; Skinnider, 2011).

There has also been much scholarship conducted within the field of historical pollution regarding the use of the term 'historical pollution' itself. Rotolo discusses how many other terms bearing similar connotations to the term 'pollution' have employed to refer to the issue of historical pollution such as 'impurity', 'contamination' and 'defilement', to name a few (Nagle, 2009; Rotolo, 2017). These terms, especially the terms pollutant and contaminant, have been used interchangeably within the arena of historical pollution (Rotolo, 2017). Debate has naturally ensued from this in which the terms 'pollution' and 'contamination', with respect to the term 'historical pollution', have been distinguished from each other. Understanding this distinction is essential in making strides within the subdiscipline towards complete uniformity and consistency in how issues of historical pollution are discussed amongst researchers. Nagle (2009) argued that contamination as a concept is wider than that of pollution on the basis that contamination can occur without explicit human involvement, whereas pollution requires some form of human conduct that then precipitates the contamination (Nagle, 2009). It has also been argued that the term 'pollution' can be thought of with reference to the "human behaviours" (Rotolo, 2017, pg. 64) that precipitate the specific manifestations of environmental harm and that the term 'contamination' refers to the effect of the pollution (Rotolo, 2009). The present research shall refer to the aforementioned concepts using the established terms as to increase in consistency of terminology used within the sub-discipline, thereby creating greater cohesion between the present research and the body of literature it seeks to be situated within.

Two final points from the historical literature shall now be considered. Natali (2017) describes three famous cases of historical pollution including the 1978 Love Canal, the Caffaro industry contamination in Brescia, Italy and finally the pollution concerning the town of Huelva, Spain. He briefly recounts each cases' historical progression and development followed by a comparative analysis where specific recurring themes between the cases are 
discussed alongside a three step process where it is argued that to "deal adequately with the toxic legacies left behind by the industrial past it is necessary to turn our attention to" (Natali, 2017, pg. 39),

1) Changes in the production process over the course of time (industrial history) (Natali, 2017)

2) Areas where the industries and their waste are located (geographical dimensions) (Natali, 2017).

3) Changes in social awareness and in environmental legislation (Natali, 2017). Natali (2017, pg. 39) argues that a "historical-geographical reconstruction" is essential in developing a solution to an instance of historical pollution due to the changes in production and the development of different production materials and processes over time (Natali, 2017). As the means of production change, so to do the commodities which are produced, the changing processes of production consequently precipitates different forms of pollution that will then effect the environment and its inhabitants differently. An example of this change in production and commodities can be found from the adoption of chemical and fossil fuel based modes of production that characterised many post World War II capitalist economies (Lynch, Stretesky \& Long, 2018). Plastics such as polyethylene and polypropylene through changes in the modes of production, were put into mass production in the 1940-50's during the post War World II era (Andrady \& Neal, 2009). Prior to the development of the aforementioned compounds, these plastics would not have been present in any landfill and or the wider environment and so knowing how to combat the impacts of pollution associated with these two compounds remained undeveloped. After the development and introduction into mass production, a new set of environmental implications arose pertaining both to the new methods used to produce the plastics, and the impact the introduction of the plastics has on the environment.

This illustrates the importance of Natali's suggestion in developing a 'historicalgeographical reconstruction' for an area subject to historical pollution. Natali (2017) also discusses the scale of developing such a history for a given area, a history that would need to recount the industrial progression of a country from the beginning of the 1900's up until the present day, in addition to the varying social, cultural and legal contexts. This, as put by Natali, is a "huge task" (2017, pg. 39) and one that falls beyond the scope of this research. 
The final point of discussion from the historical pollution literature relevant to this present research is a discussion regarding the social awareness and experience of historical pollution (Natali, 2017). Natali asserts that:

"...living in a polluted environment is, in fact, an extremely complex experience built from many interacting spheres... the result of this interaction is often a slow, gradual process of attuning, though which the inhabitants of these places, with the passage of time, negotiate the contaminated reality, though still in conflict about how to interpret it, its seriousness, and the responsibilities related to it." (Natali, 2017, pg. 36)

This complex experience partially stems from the multitude of different "spheres" (Natali, 2017, pg. 36) that intersect with those experiencing historical pollution and includes the social, cultural and political. This thesis aims to contribute to this intersection, specifically with regard to how the involvement and actions engaged in by manifestations of the political sphere, such as governmental institutions and subsidiaries, impact the official acknowledgment of the environmental victim. The result of this complex interaction is confusion regarding the pollution's severity and danger pertaining to both human health and the health of the physical environment (Natali, 2017).

Remaining with this notion of confusion, Natali argues that "state, mass media, local and national newspapers, local and national authorities - have the power to achieve an effective work of obfuscation and confusion concerning the issue of contamination" (Natali, 2017, pg. 44). This is where the primary contribution of the present thesis comes to light. This thesis seeks to develop and expand upon the influence 'local and national authorities' exert on cases of historical pollution and the resulting difficulties in attaining formal acknowledgement for the experiences of the environmental victims through the examination of the HB legacy landfill.

\section{Agnotology and Ainigmology}

From the discussion above, a precedent concerning the role of confusion and obfuscation regarding issues of historical contamination has already been established (Natali, 2017; Auyero \& Swistun, 2009). This thesis vies to integrate the relevant teachings 
found within the disciplines of agnotology and ainigmology as a way to understand and recognise the processes of confusion and obfuscation engaged in by local and national authorities in cases of historical pollution. What follows is a discussion of the relevant agnotological, ainigmological principals that this thesis argues should be employed by researchers and other scholars attempting to assess the influence, impact and process, often from local and national authorities, that incur the confusion and obfuscation of the experience of historical pollution and the accommodation of the subsequent victims.

Agnosis is the noun for the term 'agnotology' which is the formal study of ignorance and examines the processes, the how and the why, that can make individuals and collective populations acquiescent and ignorant towards phenomena and developments that are against their interests (Stanley \& Mihaere, 2018; Proctor, 2008). Agnotology is a rich body of literature that deals with ignorance and its origins in a wide array of situations such as how ignorance is experienced by individuals at a micro level and the various stages of ignorance one can fall into beginning at the innocently naïve stretching to the complete internalisation of false information (Barton, Davis \& White, 2018; Smithson, 1990). What is of analytical relevance to the present research concerning the field of Agnotology is how this ignorance is generated and maintained by government institutions and subsidiaries. That is to say, what are the specific process and practices engaged in by institutions, with respect to the HB landfill, that enables the manufacture and injection of informational confusion? This answer to this question lies within the scholarship of Agnosis.

It has already been firmly established by Agnotological scholars that there exists a multitude of strategies in which the establishment of ignorance can occur with the purpose of said confusion typically attempting to "maintain states of ignorance about risks and harms associated with an activity or product to ensure the latter can continue" (Barton, Davis \& White, 2018, pg. 16). Transposing this to an examination of HB, this research seeks to examine the role of the WCC, Greater Wellington Regional Council (GWRC) and Wellington Water in establishing and maintaining an agenda to confuse and obfuscate the leachate and gas harms associated with the landfill in HB as to justify their response characterised by management rather than perusing a permanent solution.

The type of ignorance that typically accrues and institution with specific organisational rewards, in addition to the rewards mentioned prior, has been termed 'strategic ignorance' (McGoey, 2012, 2019). Strategic ignorance is defined as "any actions 
which mobilize, manufacture or exploit unknowns in a wider environment to avoid liability for earlier actions" (McGoey, 2019, pg. 3). It should also be noted that the term 'strategic ignorance' is also used in reference to the amplification of falsehoods in order to justify future political action in addition to its previously stated function (McGoey, 2019). This research applies the notion of 'strategic ignorance' to the actions engaged in by the WCC, GWRC and Wellington Water with regard to the HB legacy landfill and its associated pollution.

According to the pertinent literature, there are two specific organisational benefits that an institution might accrue form perusing an agenda of strategic ignorance (Barton, Davis \& White, 2018; McGoey, 2012, 2019). Firstly, as alluded to in the definition of 'strategic ignorance', a successful propagation of ignorance will permit the continuation of harmful albeit lucrative practices (Barton, Davis \& White, 2018; McGoey, 2012, 2019). This organisational benefit is more readily applicable to situations where the production process of an associated commodity incurs a level of harm on the environment as a by-product of its production, yet this organisational reward can also refer to the benefits of maintaining an inadequate process of management within the realm of historical pollution. Through perusing an agenda of ignorance, this may enable the continuation of inadequate landfill management procedures thereby avoiding meaningful change through the implementation of permeant solutions that would only come of great cost to the institution.

The second organisational reward resulting from a successful propagation of agnosis is the retention of plausible deniability (Barton, Davis \& White, 2018; McGoey, 2012, 2019). In situations where the ignorance produces ample doubt, should harms materialise, the organisation will leave itself the opportunity to avoid liability and culpability by claiming that the harms were unforeseeable (Barton, Davis \& White, McGoey, 2012, 2019). Through adopting an agenda of confusion, organisations and institutions are able to provide themselves with a way to circumvent responsibility, and within the context of historical pollution, to avoid significant remedial actions while providing defence for a policy of management rather than solution. This research seeks to illustrate the usefulness of strategic ignorance with regard to the institutions that are changed with managing the complications associated with the HB landfill, specifically the WCC, GWRC and Wellington Water. 
Ainigmology, similar to agnotology, is another discipline employed by the current research as a way to analyse the practices of obfuscation engaged in by local authorities such as the WCC, GWRC and Wellington Water with respect to the HB landfill. Ainigmology works in the same sphere as agnotology dealing with the propagation of confusion and obfuscation of information (Stone, 2013, 2014). Where the two concepts differ is with the implication of the artificial information. Agnosis, through manufacturing a sense of confusion, seeks to establish those falsehoods as the dominating narrative concerning a given issue, whereas a case of ainigmology only seeks in install general confusion and not necessarily cement a given falsehood as a dominating narrative (Stone, 2013, 2014). From wider reading, it appears the concept of ainigmology is far less developed than its agnotological cousin with academic publications cornering the concept being sparse at best but despite its underdeveloped state, this concept can be used within the realm of historical pollution to analyse the practices of national and local authorities which instil a sense of general confusion and obfuscation concerning the risks associated with HB's landfill.

\section{Avenues of Contribution}

A large portion of the current thesis's contribution to the literature is the employment of agnotological/ainigmological frameworks in researching and examining cases of historical pollution. The existence of a relationship between instances of historical pollution and the role of confusion (agnotology/ainigmology) has already been noted by historical pollution scholars in that "state, mass media, local and national newspapers, local and national authorities - have the power to achieve an effective work of obfuscation and confusion concerning the issue of contamination" (Natali, 2017, pg. 44). The contribution of this thesis, serves as a detailed expansion into the processes, specific manifestations and implications towards environmental victims that come as a result of national and local authorities cultivating agnosis with reference to the legacy pollution occurring in HB. This thesis argues that the incorporation of agnotological frameworks in examining cases of historical pollution is essential in developing some form of meaningful recommendation for effected environmental victims.

This thesis also aims to contribute to the issue of culpability with regard to cases of historical pollution and organisations. Criminal law tends to favour single actors operating under a direct line of causality over a line of causality that is diffused across a multitude of 
different agents. When dealing with organisations comprised of many different individuals, establishing culpability to a single individual within said organisation is an issue that plagues questions of remediation concerning historical pollution (Centonze \& Manacorda, 2017). Indeed, it is asserted that "the identification of the person who should be burdened with the payment of damages and of the costs relating to clean-up remains a key aspect of the complexity of the regulation of this field" (Centonze \& Manacorda, 2017, pg. 13). This issue of attributing responsibility within organisations comprised of many individuals is made even more complicated by the unique qualities instances of historical pollution exhibit, specifically with regard to time. As time progresses within the context of historical pollution, so to do the relevant legal, social, cultural, technological and organisational frameworks and actors thereby making the establishment of singular responsibility even more complex (Centonze \& Manacorda, 2017). The present research makes a contribution towards solving this issue through arguing that those contemporary actors who play a role in cultivating an agenda of confusion be made culpable for obscuring the paths for environmental victims.

The final avenue of contribution lies within the replication of Hall's typology of harms concerning environmental victims within an urban context of historical pollution (Hall, 2013). This research stands to provide specific examples of the various harms of environmental victimisation articulated by Hall, those referring to health, economic, social, cultural and environmental security within the context of historical pollution (Hall, 2013). By collating the specific experiences of those living within an area afflicted by historical pollution, this enables researchers to develop a more comprehensive understanding of what living in a polluted environment is like, something that is currently "an extremely complex experience" (Natali, 2017, pg. 36). Through in-depth analysis concerning the experiences of interviewees living in $\mathrm{HB}$, may serve to erode some of this complexity as what the specific experiences, feelings and emotions were contracted by the environmental victims shall be presented, discussed and collated here. This shall provide other scholars looking to investigate the lived experiences of those in urban contexts experiencing historical pollution with a set of experiences to look for within their own data sets. More accurately understanding the lived experiences of those within urban contexts experiencing historical pollution might additionally help presiding institutions towards developing more practical solutions to the issue of pollution itself and a more effective accommodation and acknowledgement of those who become victimised by similar circumstances. 


\section{Chapter Three: Methodology}

Cresswell and Poth (2018) argue that the first step of the methodological process should be to discuss and understand both the explicit and implicit biases and assumptions that an individual researcher brings to the project (Cresswell \& Poth, 2018). Only after the researcher has explored the various ways in which their personal biases and assumptions may impact the research can discussions regarding other methodological concerns commence. Crotty (1998) however does not regard this conversation of the researcher's biases to be an inalienable component of a methodology and argues that examining the epistemological concerns first is an equally valid and acceptable approach. The impact of the personal biases of the researcher on this project remains an important discussion, however, and will be conducted in the limitations section of the methodology rather than the beginning. In adopting this structure, the interaction between the epistemology, theoretical framework, methodology and methods can be more clearly illustrated and explored.

Social constructivism will be the epistemological grounding for this current research. Social constructivists contend that knowledge and meaningful realities are solely reliant on interactions between human beings and the natural world and that through these interactions with the world meaningful realities are constructed and transferred socially and culturally (Crotty, 1998). The function of the constructivist viewpoint contents that "meaning is not discovered but constructed" (Crotty, 1998, pg. 42), implying that we use 'tools' or 'social and personal materials' like personal experiences, biases and cultural conditioning to assemble and construct meaning. Social constructivism is not limited to how social phenomena are constructed and can be used to interpret objects within the natural world like a forest or a lake. Nothing about the forest nor the lake are inherently social, but it is how culture and society influence my interpretations, even influence what I choose to not see and how these values are transmitted from person to person in a social manner (Crotty, 1998). This encapsulates the function of social within social constructivism (Crotty, 1998). Social constructivism is an epistemology that combines the personal interpretation and assembly of meaning, interpretation that is shaped and transmitted from person to person with society by social forces (Creswell \& Poth, 2018; Crotty, 1998). 


\section{Theoretical Worldview: Looking at the Landfill through an Eco-Marxist Lens}

A combination of Eco-Marxist and Eco-criminological/sociological theories encapsulate my underlying assumptions regarding how the world operates and creates a theoretical backdrop for the current research. Jacques Derrida in his 1994 work Spectres of Marx (as cited in Livens, 2010), described the teachings of Marx as "a patchwork quilt of concepts, theories, practices and experiences... and that we need to be selective and creative in our handling of this legacy" (Derrida, 1994; Lievens, 2010, pg. 5). The first of Marx's intellectual 'quilts' that shall be discussed in relation to the current research's assessment of the ecological situation in HB is the concept of 'metabolic rift' (Livens, 2010; Giddens, 1976). Marx was initially exposed to this idea of metabolism through the works of renowned German chemist by the name of Justus von Liebig who wrote disputatiously of the (at the time) modern agricultural practices occurring in Britain (Livens, 2010). Liebig argued that produce that was being grown in one area (rurally) and then transported to another geographically distant area and consumed (in an urban setting) interrupts the natural cycle of elements and minerals leading to nutritionally depleted soil (Livens, 2010). Liebig wrote both extensively and harshly of British agriculture in this respect arguing that the nutrients in the food produced was unable to make its way back into the soil from where it was grown in the countryside and additionally, where the food is consumed, incorrect disposal of unwanted produce leads to instances of pollution such as the Thames in London at the time (Lievens, 2010). While Marx was researching for his work Capital he came across the work of Liebig and used the German Chemist's observations to inform his own social commentary (Livens, 2010). Marx argued that the industrialisation of modern agricultural practices "disturbs the circulation of matter between man and the soil" (Marx, 1974, pg. 474) and goes on to argue that "capitalist agriculture is a progress in the art, not only of robbing that labourer, but of the soil" (Marx, 1978).

Marx argues that at each and every level of production there should exist a metabolic equilibrium that is reached between material production and the natural world but under modern capitalist agricultural practices the metabolic exchange is made unbalanced (Foster, 2000; Livens, 2010). Capitalism interrupts this natural cycle and also compounds this interruption by exporting it all over the world as the unbalanced processes of production becomes globalised (Livens, 2010). The further removed these processes of production become from a sense of metabolic equilibrium, the more incompatible these 
commodities become with natural world. This research incorporates and expands this notion of metabolic rift from pertaining to an agrarian capitalistic mode of production to the entire system of capital itself. Each commodity that is being produced by this system of capital becomes more complex in its design making the product incapable of being readily assimilated back into the world through the natural process of decomposition. Unable to be readily incorporated back into the natural world, this perspective or rather, this 'selected Marxian quilt' suggests that perhaps landfills like Houghton Bay are the result of what happens when the metabolic rift becomes too great? As the systems of production produce more complex and artificial commodities that are unable to be reintroduced back into nature unless subjected to additional manufacturing processes, landfills become the method for disposing of these unwanted commodities produced in utter metabolic disproportionality. According to a 1998 government report, the HB landfill was, in addition to many other things, filled with considerable concentrations of metals, plastics, gas works materials and other forms of industrial hydrocarbons (Purchas, 1998). These materials, due to the metabolic rift in which they are produced, destine themselves to be deposited in a landfill like HB. The adoption of an Eco-Marxist perspective illuminates' part of the possible explanation for why the landfill exists in the state it does today.

This state of production characterised by metabolic drift is only one of the many disastrous ecological ramifications created by the capitalist mode of production and is connected to the concept of 'alienation' (Giddens, 1971; Livens, 2010). Marx noted that workers begin to become strangers to themselves, what they produce and the natural world around them, and he described this feeling of becoming a stranger as 'alienation' (Giddens, 1976; Livens, 2010; Marx, 1975). Though Marx described different forms of 'alienation' that befall people in capitalist societies (Giddens, 1971), the form that is of most interest to the current research is that which pertained to the relationship humans share with their natural world. Marx argued that the alienated processes of production, in addition to the other forms of alienation, separate man from the natural world alienating him from nature (Giddens, 1971; Livens, 2010).

Today, it is nearly impossible to argue with Marx regarding the alienation from nature as meaningless commodities that serve no other purpose but to extract exchange value from markets plague production lines around the world (Foster, 1999). The capitalistic lifestyle characterised by gross over-consumption in each aspect of our lives distances us 
from the natural world, not only in how we consume but in how we live, how we work and how we interact with what little of the natural world we are exposed to and is left. This level of alienation between mankind and nature creates the opportunity for nature to be abused as we are now so disconnected from the world that we are not able to associate the cause and effects of our own ecologically disastrous behaviours even when the visible ramifications surround us. This is rather ironic because the same system of capital that precipitates disturbing levels or environmental degradation is also entirely reliant on the environment for natural resources to begin the process initially (Foster, 1999; Livens, 2010). As the system of capitalist production expands, the creation of waste during the industrial process becomes more prevalent and researchers with an Eco-Marxist inclination have wrote on this matter.

Heather Rogers is one such writer. She argues that waste is built into the modern capitalist production process and is of far greater determent to the environment than is 'household' waste (Rogers, 2010). She argues that if all of the 'household' waste in American homes was to vanish, then we would still be left with over $98 \%$ of the total amount of waste generated here on earth (Rogers, 2010). The modern system of capitalist production cannot function without the necessary production of waste and as production continues to increase so too does the industrial waste produced (Rogers, 2010; Livens, 2010). Following in this vein, it could be argued that the leachate contamination occurring in Houghton Bay is the result of an inherently wasteful system of production that has been allowed to run unchecked. It is this grating between the perceived infinite growth of capitalism and the finite resources within the environment which is at the core of the EcoMarxist critique as to grow and expand, capitalist systems of production must ultimately destroy the environments in which they extract resources and additionally environments where waste is destined to go (Foster, 2000).

These ideas at the core of Eco-Marxism bear many strong resemblances to green criminological concepts, the most striking of which is the Treadmill of Production Theory or (ToP) (Schnaiberg, 1980). The ToP theory began as an Eco-sociological idea created from observations of the American system of post-world war II production and the responses to these changes in production and later reproduced in relevant green criminological literature (Lynch, Stretesky \& Long, 2018; Lynch \& Stretesky, 2014; Schnaiberg, Pellow \& Weinberg, 2000; Schnaiberg, 1980). The theory begins by observing the increase in social mobility and 
income for a growing middle class in America during the post-world war II period, but this increase in wages and social mobility came at the expense of the environment (Schnaiberg, Pellow \& Weinberg, 2000; Schnaiberg, 1980). This system of post-WWII production was characterised by new energy and chemical technologies that upon being developed were shown to greatly increase production while simultaneously bringing labour costs down, further maximising profits (Lynch, Stretesky \& Long, 2018). This new production system that was taking shape created two very important developments for the environment which in the ToP theoretical literature are referred to as 'withdrawals' and 'additions' (Schnaiberg, Pellow \& Weinberg, 2000; Schnaiberg, 1980).

'Withdrawals' refers to the increased input of natural resources required from nature to satisfy the now intensely efficient modern factories (Schnaiberg, Pellow \& Weinberg, 2000; Schnaiberg, 1980). Not only do 'withdrawals' see the environment become robbed of ever-increasing quantities of natural resources, the modern factory requires large, complex systems to maintain a state of constant surplus and as a result, necessitate increases in the provision of power (Schnaiberg, Pellow \& Weinberg, 2000; Schnaiberg, 1980). Factories of the post-WWII era employ transformative machine, chemical and energy processes that alter the composition of raw 'inputs' into either wholesale products used in the manufactured of other commodities or is marketed as the final product (Schnaiberg, Pellow \& Weinberg, 2000; Schnaiberg, 1980). However, this change in the adoption of more efficient chemical, machine and energy intensive production processes brought with it a nefarious set of environmental issues like pollution and waste management. Schnaiberg called these 'additions' (Schnaiberg, Pellow \& Weinberg, 2000; Schnaiberg, 1980).

These 'additions' and 'withdrawals' work in tandem to create what is termed as 'environmental disorganisation'. The increased level of surplus production of the post-world war II capitalist system demands an increase in the energy required to facilitate this level of over-production (Lynch, Stretesky and Long, 2018). This sees energy becoming extracted from the natural world in ways that compromise the longevity and reproductive ability of the natural biospheres and ecosystems from where the energy is extracted (Lynch, Stretesky \& Long, 2018). This creates the 'environmental disorganisation' amongst those natural systems. The connections between these ideas and the current situation with the Houghton Bay landfill are very strong. The landfill, according to Schnaiberg (1980) can be viewed as one massive 'addition', as the landfill is the place where all the waste and undesired 
products created by the over-productive ToP are sent. Not only can the physical entity of the landfill itself be considered an 'addition' according to ToP theory but the leachate plumes and leaking gas emanating from the landfill are 'secondary' and 'tertiary additions' resulting from the 'primary addition'. Perhaps the term 'compounding additions' might be applied here to encapsulate this idea of one primary instance of pollution (the creating and filling of the HB landfill) that then creates if other forms of pollution (such as the leachate and gas contamination) that result from the initial 'addition'.

\section{Methodology \& Methods: Using the Correct Tool for the Task}

I had a choice between two possible avenues of inquiry that presented as relevant for the current research: narrative or phenomenological. Both methodologies have much overlapping theory and are very similar in operationalisation. I decided that this project aligned most succinctly with phenomenology. This decision was made upon finding subtle yet important substantive differences that I will briefly discus as justifications for my decision. A phenomenologist takes a phenomenon or 'a happening' and then seeks to describe and understand the lived experiences of those who are subjected to the phenomenon. After examining the lived experiences of several individuals, the phenomenologist should strive to develop holistic descriptions of those lived experiences across all individuals (Creswell, 2014; Moustakas, 1994). Moustakas described this process as being one that should strive to capture the 'essence' of the experience across all the individuals involved with the phenomenon (Creswell, 2014; Moustakas, 1994). Phenomenology fits in exceptionally well with the case study of historical pollution occurring in $\mathrm{HB}$. The phenomenon under investigation is the historical pollution that manifests itself as leachate contamination and gas contamination occurring within the area. As one of the primary research objectives of the current project is to create an understanding of the lived experiences of those who encounter the phenomenon of historical pollution within an urban context, the adoption of a phenomenological inquiry both permits and facilitates such discussions.

Phenomenology allowed me to develop the participant's experiences of the contamination holistically and to draw conclusions from across all the participants interviewed. Designing the research from a phenomenological perspective calibrated the focus onto people's experiences of the historical contamination and also allowed me to 
draw across each participant to form conclusions regarding how the interviewees as a collective experienced this phenomenon.

With a focus on the lived human experience of historical pollution it is crucial to have a method of data analysis that is going to facilitate and curate an opportunity for the participants to share as much of that experience as possible. The correct method of data collection shall secure the freedom for the participants to share every aspect of their experience regarding the phenomenon but will also retain a fictional level of rigidity to ensure the participant shares mostly relevant material avoiding tangential topics. The method of data collection that would satisfy these stipulations and mesh perfectly within the phenomenological framing are semi-structured interviews.

A semi-structured interview allows an interviewee to move between topic and concept at their own pace while also allowing them a degree of autonomy with regard to how long they answer and what they want to talk about (Harrel \& Bradley, 2009). This is an advantage because each interviewee will have a uniquely personalised interpretation and impression of the phenomenon so employing a method of data collection that will facilitate this will be of incalculable value. However, this freedom presents a potential issue for the research in that without a rigid set of questions how are the interviewees going to be stopped from discussing irrelevant material should they move beyond the parameters of what research seeks? Each interview had a set of fifteen open-ended questions that were to be discussed by the participant at their own pace but were also to be used as prompts by the interviewer to try and usher the interviewee back to topic should they stray into irrelevant material (Harrell \& Bradley, 2009). This loose structure also enabled discussion between the two parties in an informal manner relaxing the interviewees making it easier for them to share an develop their experiences and also allowing the researcher to ask pertinent questions should they arise. It is for these reasons why semi-structured interviews were employed for data collection.

Interviewees were recruited with pamphlets that were dropped into mailboxes around HB. The pamphlet contained my contact information, a brief summary of the scope of the research and why involvement was important. Ten people were willing to be interviewed for the project. For seven of the ten interviews I travelled to the interviewee's place of residence to conduct the interview. The final three were conducted at each 
interviewee's place of employment. Each interview was audio-recorded and transcribed before the analysis stage.

Another aspect of the methodology employed by the present research was photo elicitation (Natali, 2019). Photo elicitation is where an interview is organised around a set of preselected images (Natali, 2019). Although the interviews were not entirely organised around a selection of photographs, participants were shown photographs of the pollution during the interview where relevant to act as a recollection prompt (see Figure I pictured below). I found that having a visual representation on hand to show the interviewees acted as a tool that enhanced the recollection of the participant of something relevant to the research that they were then able to discuss in more detail. The majority of those who live within contaminated environments navigate a complex set of perceptions and conflicting versions of reality (Natali, 2019). Photo elicitation can prove to be powerful tool in getting interviewees to discuss the conflict between what might be a distorted version of the contamination within their own subjectivities with the objective reality of their situation (Natali, 2019). During the present research however, photo elicitation proved to more of a 'heuristic research tool' (Natali, 2018, pg. 651) that reminded interviewees of other relevant topic of discussion to the research that could then be explored further.

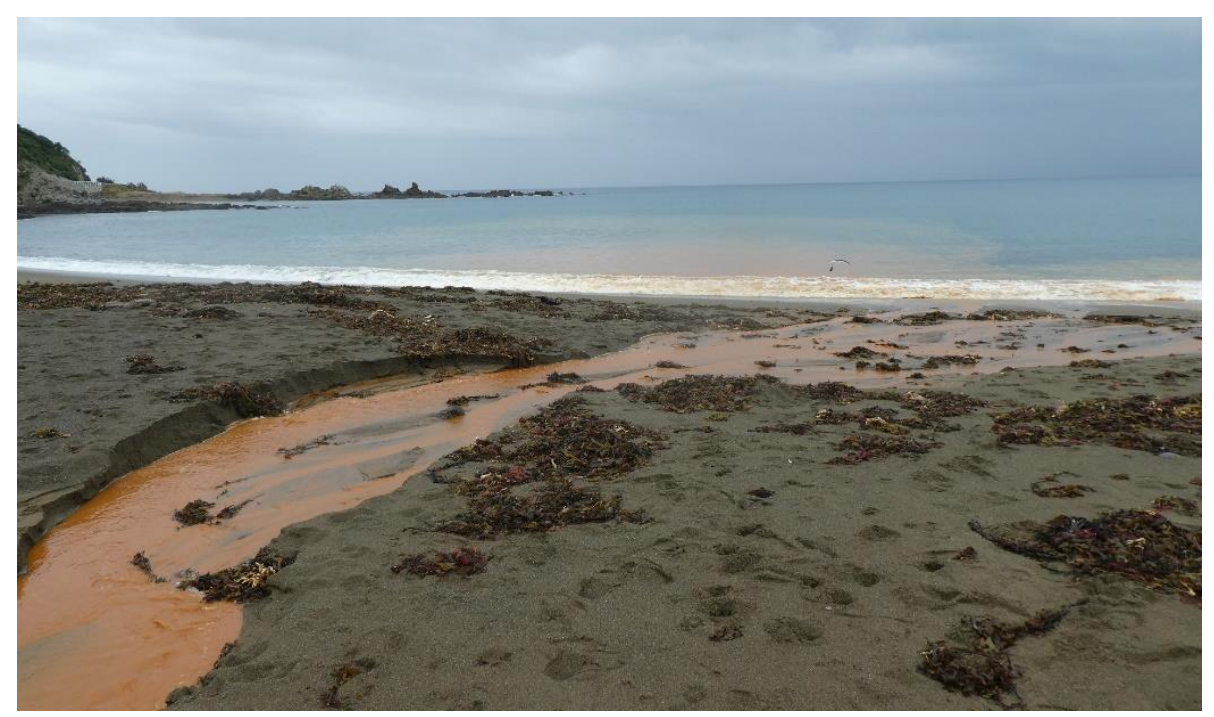

Figure I: Leachate flow into Houghton Bay

I wanted to employ the use of an interpretation strategy that was going to permit me the freedom to analyse concepts as they arose in the interviews without being methodologically shackled. I turned to the technique of thematic analysis. Braun and Clarke 
(2006) argue that thematic analysis has a universal quality to it and can be employed across a number of different methodologies. Others such as Bernard and Ryan (2000) argue that thematic analysis has a historical precedent to only be used where thematic analysis has been traditionally employed such as in grounded theory. I agree with Braun and Clarke as many of the techniques used within thematic analysis can be transposed to other styles of research while to silo the technique off to only the forms of research which align with the historical precedent for the technique seems disingenuous.

I had to decide on what type of thematic analysis I would employ, what types of themes I was going to be looking for and what type of coding I would use to find these themes. Theoretical thematic analysis was best suited to this research because it allowed me to spool through my data and focus on aspects of it that were of interest to either myself or the research project (Braun \& Clarke, 2006). In this way I would not be constricted by limiting myself to discussing only what was said in the data taking it at face value such as in inductive thematic coding (Braun \& Clarke, 2006). Under an inductive coding regime, the focus is on drawing conclusions solely from the data gathered despite how distant conceptually the information might be from the questions and aims of the research. Wanting to retain the ability to search for ideas and nodes of interest to me and the research, theoretical thematic coding was adopted as the style of data interpretation.

The next decision to be made regarded how I was going to identify the themes within my data (Braun \& Clarke, 2006; Boyatzis, 1998). Would I look for interpretive, latent, explicit or semantic themes? Or some others? (Braun \& Clarke, 2006; Boyatzis, 1998). Examining potential themes in a latent style fit most succinctly with the design and aims of the project because it allowed me to look beyond the interview data conceptually (Braun \& Clarke, 2006). Searching for themes at the latent level enabled me to investigate the underlying assumptions, perceptions and mentalities of those who experience the issue of historical contamination providing a greater level of depth in the analysis that would not have been achieved if the themes were examined in another fashion.

The final decision that had to be made regarded the style and process of coding that would ultimately deliver the themes of the research. 'Coding' and 'codes' are terms that are commonly thrown around within the arena of qualitative research and it is easy to become bogged-down in the semantics of defining the terms. To avoid such confusion, I opted for Saldana's succinct description, "coding is the transitional process between data collection 
and more extensive data analysis" (Saldana, 2009, pg. 4). This simply means that the act of coding is a process that allows the researcher to move from a raw database to the themes of what will become their narrative. Saldana also argues that coding is an interpretive process so what might be considered 'codes' within a particular data set by one research might not be considered 'codes' by another. This difference can also be attributed to differing epistemologies, theoretical frameworks and methodologies between examples of research (Saldana, 2009). This means a 'code' can be anything from the data set that the research finds interesting, poignant, revealing or salient with regard to the aims of the research and what the research wants to focus on during the narrative. In essence, a 'code' is something inextricably linked to what the researcher deems salient and noteworthy within the data set. Codes are then combined where conceptual overlap occurs to form 'sub themes' that are then combined with other 'sub themes' to form a 'theme'. This is the process in which the 'themes' are created thereby creating the narrative of the research.

\section{Limitations}

Focusing on the decommissioned landfill meant straying into fields of natural scientific inquiry such as ecotoxicology, organic and non-organic chemistry, and biology, as well as a number of others. With all of my formal education and training being criminological in nature, acquiring, understanding and explaining various scientific principals and their relevance to green criminology and the project was something exceptionally challenging. Yet the project also demanded adequate levels of scientific discussion surrounding exactly what landfill contaminates are entering the environment, their effects on local ecosystems and possible solutions. This naturally called for a degree of scientific analysis and data acquisition.

Straying beyond the comfortable and familiar green criminological literature is necessitated both by the nature of its inquiry as a sub discipline and in its operationalisation when conducting empirical research such as the present. This manifested itself in me finding myself away from the serenity of the university library and instead kneeling over a putrid smelling landfill outfall diligently collecting water samples for scientific analysis. Lacking the knowledge to interpret such information correctly I sought the assistance of specialists with the appropriate knowledge who were able to process and provide guidance of said information. This kind of collaboration between faculties, schools of thought and 
institutions is not only crucial for the creation of significant research but is also important for the implementation of environmental initiatives by society's governing institutions (Natali \& McClanahan, 2017).

The present research commissioned two different sets of scientific testing on the contaminates emanating from the landfill outfall: non-organic trace element and organic contamination tests. The specific methodologies and limitations of each test are available in the appendices. I sought out an organic chemist at Victoria University of Wellington who kindly offered his time to aid in the processing and explanation of the organic test results. During these interactions he was able to communicate the process through which the tests were conducted as well as how to most correctly interpret the results. The organic tests were completed through the use of what is called a Gas Chromatograph Mass Spectrometer (GCMS) (Sparkman et al, 2011).

At its most basic level, the GCMS compares unknown compounds within the sample being tested to a computer database of known compounds (Sparkman et al, 2011). As the machine processes each unknown compound it will attempt to match it with a known compound within reference library (Sparkman et al, 2011). Rarely is a 100\% match attained, as this excerpt from water sample \#1 (in Fig. II, pictured below) illustrates: 


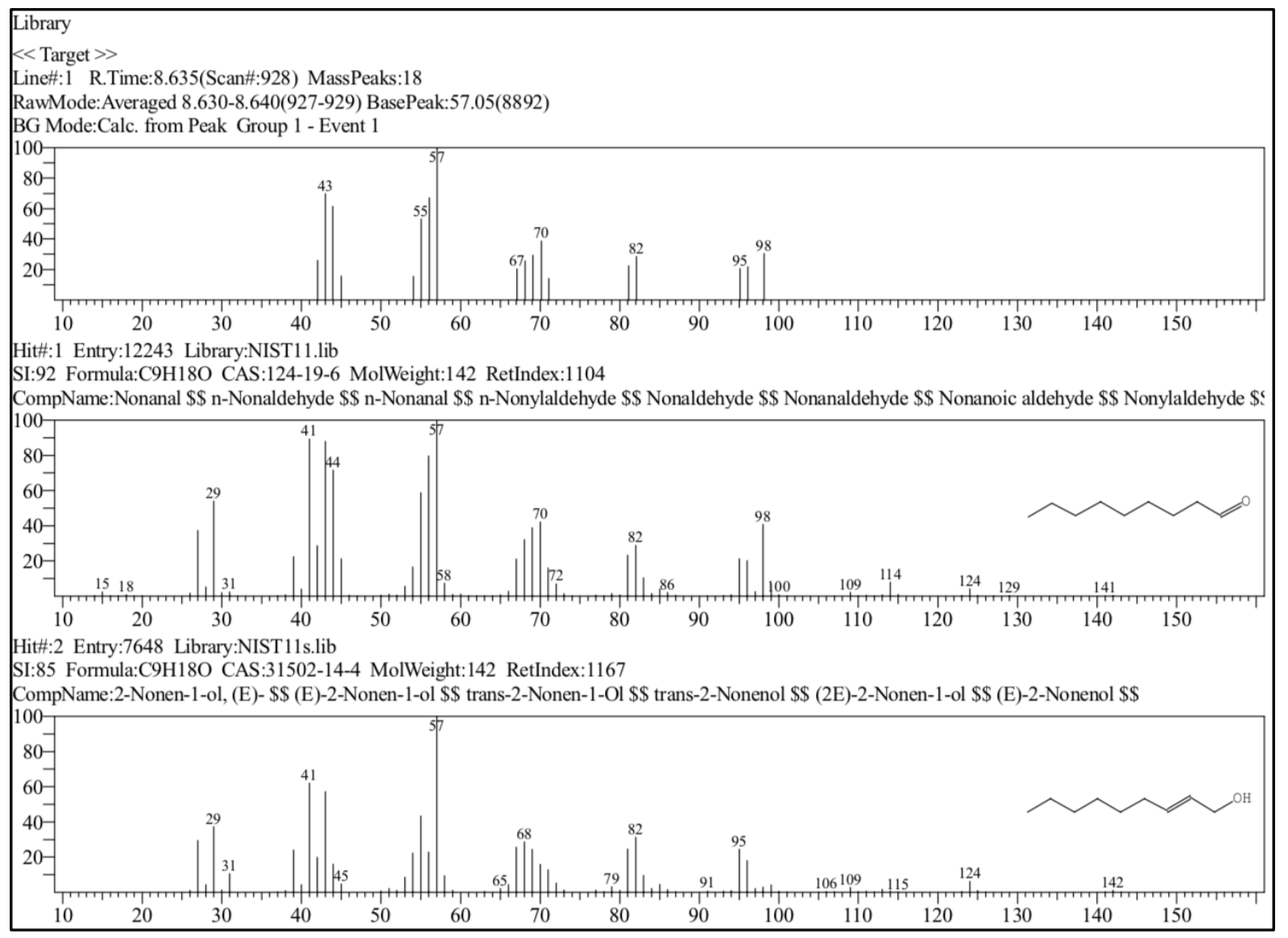

Figure II: GCMS analysis of water sample \#1

The three chromatograms in Fig II above include the top two 'hits' from line one in the water sample with the top chromatograph being the sample tested referred to as 'line \#1. Pay attention to the 'SI' number on the top left of each chromatogram. This stands for 'similarity index' but may also be referred to as 'scores' and 'matches' by different manufacturers but they all seek to achieve the same goal of providing an indication of how similar the tested compound is to one within the database. We can see that the middle chromatogram reads $92 \%$ indicating that the sample tested is a $92 \%$ match with the database compound. The third chromatogram has an $85 \%$ similarity with that of the unknown compound. Of the two hits, the $92 \%$ similarity index is a high enough result that we can reasonably assume that the unknown compound from this line within water sample $\# 1$ is the compound n-Nonaldehyde or $\mathrm{C}_{9} \mathrm{H}_{18} \mathrm{O}$.

Assuming the identity of the unknown compound, I took the chemical formula and used a service called 'PubChem' provided by the 'U.S. National Library of Medicine' that provides, with reference, information pertaining to a compound's toxicity and effects upon 
human exposure. PubChem pools its data from three primary sources: government agencies, chemical manufactures and journal articles making it a fairly reliable tool for the purposes of this project (PubChem, 2020d). Upon searching n-Nonaldehyde $\mathrm{C}_{9} \mathrm{H}_{18} \mathrm{O}$ in the PubChem resource I found that the compound will cause skin and eye irritations upon exposure. It also a combustible liquid so it must be kept away from sources of ignition (PubChem, 2020e). According to the Globally Harmonised System of Classification (GHS) the compound is 'harmful to aquatic life with long lasting effects' and has the potential to accumulate within aquatic organisms (United Nations, 2019). Documentation from PubChem also states that there has been little to no conclusive research conducted on the human effects of exposure but from the information already available it seems appropriate to stipulate that the compound's presence within the environment of HB is going to be negative. This process was repeated for all of the results from both the non-organic trace element and organic contamination testing. However, this process is not without its limitations. Results can only act as 'likely indicators' of what the compound in question could be, and the classifications of harm and the potential danger each compound poses are not universal.

Another major challenge presented by the use of scientific data was the sheer amount of it that needed to be processed. Of the eight samples that were run through the GCMS, over 400 pages of chromatographs and other scientific information was generated, all requiring interpretation through unfamiliar scientific jargon. The green criminological researcher must be conceptually flexible when in search of answers. Scientific inquiry within green criminological research can be used to lay the initial foundation of concern and to establish harm. As I would discover, however, establishing harm involves far more than a scientific test can provide. 


\section{Chapter Four: Environmental Attraction to Houghton Bay}

This chapter deals with the issue of why people would choose to live in HB (Houghton Bay), even though parts of it are contaminated. The chapter examines the different sources of agnotological and ainigmological information that contribute to the establishment of an 'idyllic construction' of the area, and the way in which this construction is reflected in the minds of the residents. It establishes what it was about the area that attracted and enticed participants to live there. It will retrace the development of the 'idyllic construction' of HB's physical environment from the various institutions labelling it as a desirable place to live, and how this construction manifests itself in lived experiences of interviewees. It illustrates how $\mathrm{HB}^{\prime}$ s environment possesses many attractive qualities that are coveted amongst the wider New Zealand population, termed 'factors of environmental attraction'. In the NZ context include things such as a rural-esque country aesthetic, native wildlife, marine reserves and the rejuvenation of native species as well as others. These factors of environmental attraction, in conjunction with examination of New Zealand's 'clean and green' marketing campaign, in turn redirect interviewees' awareness and acknowledgement of environmental pollution. I argue the redirection of attentions constitutes forms of both agnosis and ainigmology. This idyllic perception justifies residents' decisions to purchase a house in a polluted area. In turn, because they have invested financially and emotionally into HB, they adopt the idyllic construction of the area. This idyllic perception - as it is created and lived out - produces environmental agnosis.

\section{Factors of environmental attraction}

There were a variety of reasons given from participants that accounted for their decision to purchase a home in Houghton Bay. Interviewees Charlie and Gertrude cited moving into the area for reasons of proximity to family and to the community respectively. The remainder of the interviewees fell into one of two categories: affordability of housing or environmental appeal. Interviewees Stella, David and Mary all stipulated that the affordability of the houses in the area was the primary reason for their permanent residence. Stella said: 
"Originally it was the house prices because I bought the place in 2002, which was before the massive spike in house prices." (Stella, 2019)

David and Mary, in a similar vein, said:

"...in 1987 this was a section, these were all sections here, they were cheap, relatively cheap." (David \& Mary, 2019)

Another interviewee, Sam, stated that during the late 90's he was able to purchase a section within HB for $\$ 225,000$ NZD, a price considerably lower than that of property closer to Wellington's city centre at that time. Sam's statement suggests that living in HB was once considered to be a long way away from the city than it is today.

Contamination was part of the reason for the cheap section that David and Mary purchased:

"...at the time there was still a lot of sewage contamination on the coast... beach would be littered with debris and that kept the property values low." (David \& Mary, 2019).

The contamination specifically referred to by David and Mary was discharged from the nearby sewage plant in Moa Point that flowed onto the beach under certain tidal and wind conditions. This, in addition to leachate pollution from the decommissioned landfill, as well as litter on the beach, in their view, kept the real estate prices in the area low during that time. In fact, they were quite well aware of the environmental issues prior to moving to Houghton Bay. Regarding the leachate, David said he was "kind of aware that the land I was standing on was landfill..." (David, 2019). This suggests the cheap price of the section overrode David's concerns of the pollution, but as David was yet to spent considerable time within the area his level of pollution awareness at this stage had not been fully realised. Although the sewage pollution has long since been remedied, the issues caused by the leachate and gas pollution have not. Yet despite this, the median property value within HB has increased significantly. The current housing market within HB which currently boasts a median house value of nearly $\$ 900,000$ NZD, an increase in the median value by $50.91 \%$ 
over the last five years (OneRoof, 2020). What is of most significance for the current study is that these issues of environmental contamination did not deter these interviewees from moving into the area.

The remaining six interviewees, all of whom were aware of the contamination to one extent or another prior to moving there, all cited that the primary reason for moving into the area was due to what I am terming 'factors of environmental attraction'. Environmental attraction refers to the enticing and alluring qualities of the environment within a particular location, in this case $\mathrm{HB}$, that are deemed to be desirable and coveted within a local population. Many mentioned the coast:

"The attraction of living by the coast was very strong... living next to the coast is quite an idyllic place to live" (Sam, 2019).

"I was trying to find Wellington's version of Takapuna beach" (Mathew, 2019).

"It was just really charming and a lot of people don't know that it's there" (Jane, 2019).

"We wanted to be by the sea, we like the south coast... it's a nice sort of smooth beach... you've got wild beaches all around here" (Derek, 2019).

The common thread running through these quotes is that the area of HB becomes more desirable in the minds of the residents, and prospective residents, because of factors of environmental attraction, specifically the culturally coveted 'Takapuna-esque' beach within HB. Yet there were two co-existing narratives amongst interviewees when discussing the area: i) the narrative of the environmentally attractive factors that garner a sense of pride and exclusivity amongst the residents, and ii) a narrative concerning the state of environmental contamination within that same area.

Reasons why interviewees held living on and or near the coast in such high esteem are complex, and the result of a confluence of factors. The primary reason cited in the

\footnotetext{
${ }^{1}$ Takapuna beach is one famed within certain NZ contexts as being the perfect beach and place to live
} 
interviews was the coast's proximity to a large city centre, Wellington City. With the prospect of living in a city there comes with it an assumption that your residence will be a small box amidst a sprawling concrete jungle. In this respect, HB is certainly an exception (HB Progressive Association, 2020). Although the area has certainly become more urbanised in recent years, it does retain proximity to both coastal areas and the central business district (CBD) of a capital city enabling the enjoyment and use of coastal facilities while still offering all the amenities and conveniences of city living. In short, it provides the best of both worlds. As interviewees claimed:

"On a good day I am fifteen minutes from the city centre and would you believe you're in a major city sitting here?" (Derek, 2019)

"It is really close to Newtown" [Newtown being a bustling suburb of Wellington city with a high level of commercial and cultural activities] (Stella, 2019)

Another attractive aspect of HB's environment that was focused on during the interviews was in reference to the 'wild rural-esque' nature of the bushes, trees and landscape itself:

"It was nice having the trees and the bush and the scrub covered hills, the green" (Derek, 2019)

"I really loved that wild sort of country feel close to the ocean... it's gorgeous" (Jane, 2019)

"As you can see it is pretty bushy and that was quite appealing as well" (Sam, 2019).

The features of an untamed, wild and rugged landscape are reminiscent of a time when the landscape in a holistic sense remained largely untouched and uncorrupted by the activities of humanity. The Western side of Houghton Valley boasts a bush reserve each with numerous walking tracks throughout for the enjoyment of the residents (and other Wellingtonians). These tracks through the bush also enable appreciation and closer 
involvement with the environment, creating a greater sense union between people and the environment in which they reside. This combination of urban proximity and wild countrylike bushland, like its coastal location, that is something not shared by many other suburbs within the region. David and Mary attested to a sense of pride about their suburb on behalf of HB residents:

"They're [residents] proud of Houghton Valley (HV), being from here and how green it is and how much wide space and bush there is." (David \& Mary, 2019)

Manifestations of environmental attractiveness therefore appear to both entice and attract people into the area to settle, and then upon residency, they become factors that retain people's presence and form part of the basis for their pride and esteem. These feelings further solidified by a growth in the native wildlife population in the area that has seen a significant rejuvenation over the last decade. Interviewees spoke of a time when the area was inundated with pests, especially possums, and that due to the pest control efforts from the council and the Department of Conservation (DoC) possums have now been successfully eradicated. Native species, like the Tui, have reclaimed the bush. Sam recalled:

"I had possums jumping on my roof then suddenly one day there were no more possums and then the Tuis came back... In 2001 we heard the first Tui in this area and now it is just Tui galore, it's incredible around here" (Sam, 2019).

An environment in which the Tui can thrive in, bereft of pests such as possums, ultimately becomes another string in the bow of environmental attraction in HB. Witnessing positive environmental developments within one's physical environment has been shown to accrue a sense of what is termed 'environmental identity' where the positive aspects of one's environment, such as native wildlife like Tuis, can be internalised by residents into their sense of self (Clayton, 2003; Manzo, 2005; Scannell \& Gifford 2010, Stokols \& Shumaker, 1981). This is the process that can create a sense of environmental pride and attachment amongst interviewees regarding their physical environment, a process that begins with recognition of a factor of environmental attraction. 
Many interviewees discussed the benefits of the Taputeranga Marine Reserve that the bay is part of. The Conservation Act of 1987 gives authority to the Department of Conservation (DoC) for the establishment of marine reserves around New Zealand. These marine reserves strictly and expressly prohibit the activities of fishing or any other form of seafood collection as well as disturbing any marine life in any way shape or form (Conservation Act, 1987). What is also interesting to briefly note, and what will be discussed at length in a later stage of this thesis, is that the Conservation Act explicitly prohibits by law "allowing any contaminate to enter any such water" (Conservation Act, 1987, s 39, ss 3,4 \& 5) and if contravened will be liable for either two years imprisonment, $\$ 100,000$ fine or a $\$ 10,000$ per day fine for a continuing offence (Conservation Act, 1987). The prohibition of the aforementioned activities allows for the marine environment and aquatic organisms to replenish and rejuvenate their populations and gives the most degraded areas of the coast a chance to recover (DoC, 2015).

The Taputeranga Marine Reserve begins at its most western point below an old quarry located above Owhiro Bay Parade, stretches 3.8 kilometres (kms) eastward behind the eastern corner of $\mathrm{HB}$ and extends $2.3 \mathrm{kms}$ out to sea giving the reserve an approximate area of $8.74 \mathrm{~km}^{2}$. The process of the Marine reserve's genesis and its inclusion of the HB area was not a timely affair. Consultation with the community began in 1991 with the help of Royal Forest and Bird Protection Society of New Zealand and the South Coast Marine Reserve Coalition (DoC, 2015). This process spanned almost 20 years from beginning to end. After a collaborative effort between these parties and the Wellington Regional and City Councils, the reserve was officially established in 2008 where it has remained in place to the current day (DoC, 2015).

Mathew had this to say about the benefits of the reserve:

"There was this one-time, pre-marine reserve when the whole bay was full of fish and after about fifteen minuets the entire bay was filled with fishermen and people were filling sacks and wheel barrows, it was a Kahawai massacre that day. The thing with Kahawai is that you have to bleed them so the next day the entire beach was covered in fish heads, seagulls everywhere." (Mathew, 2019) 
The implementation of this reserve has changed people's behaviours and perceptions of the beach by demarcating between what is acceptable and unacceptable behaviour with respect to the sea and its inhabitants. Activities such as fishing in the bay and keeping an unlimited catch were once totally permissible forms of behaviour, both socially and legally, but the implementation of the reserve has helped to change this perception and indirectly, aided in the restoration of the aquatic environment (with the exception of the ongoing complications due to the leachate and gas contamination, of course).

The establishment of the marine reserve was another factor of environmental attraction discussed by the interviewees that drew people into the area of HB. Mathew said:

"I do a bit of snorkelling around here and it is full of fish and Pāua and sea life, you wouldn't believe it... I've got paddle boards now so in the summer I am out there every day... there are also dolphins that come into the Bay each morning... I go out there in the middle of the Bay and just tap my board then they all come over... I head to Princess Bay and they all start chasing me." (Mathew, 2019).

These interactions with the wildlife of the marine reserve serve as key environmental distinguishers for the area only adding to the factors of environmental attraction. The restoration efforts that have led to the comeback of the Tui's, beach and sea life also serve to enhance a sense of feeling attached to HB for interviewees. I will argue later, that these factors of environmental attraction, that once served as the primary interviewee motivation to become a permanent resident within $\mathrm{HB}$, then come to act as 'attention diverters' that coaxes residents into an agnotological negotiation between the manifestations of the landfill pollution and the manifestations of the idyllic construction. This notion of 'attention diversion' is similar to the forms of cultural and interpretive denial as espoused by Stanley Cohen (2001). The implication of this negotiation is that people's focuses and energies concerning the current landfill contamination and how to combat it, are ultimately redirected and/or neutralised, preventing acknowledgement of and meaningful redress for the environmental victimisation.

There are other sources and narratives which contribute to this agnotological negotiation. Houghton Bay is marketed by various institutions as an environmental haven, a 
quintessential habitat that offers the experience of the clean and green NZ ideal as described in Chapter One. It is the confluence of the agnotological negation from the factors of environmental attraction and the ideological narratives espoused from corporations and 'clean and green NZ' that cements and congeals the 'idyllic construction' of the area amongst the residents making reconciliation of the pollution from the landfill fettered. These ideological narratives are what shall be considered next.

\section{Institutions and idyllic construction}

No business, institutional entity or community advocate would discuss the complications associated with the landfill as a means to praise the area of HB. People want to be proud of where they live, and research has shown that certain types of physical environmental settings can accrue a sense of what is referred to as 'natural place attachment' in the minds of those who live there (Clayton, 2003; Manzo, 2005; Scannell \& Gifford 2010, Stokols \& Shumaker, 1981). Some of these physical environmental settings include the features of environmental attraction discussed by the interviewees in $\mathrm{HB}$ including but are not limited to forests, bush, parks and other features of natural environments (Clayton, 2003). As discussed, HB boasts a litany of these desirable environmental features which I argue coaxes residents into cultivating a strong sense of environmental attachment and the development of an 'environmental identity' (Clayton, 2003). The process of internalising positive aspects of one's physical environment that sees the incorporation of one's environment into their sense of self accounts for the attachment and sense of pride the interviewees in HB cultivate from their physical environment. However, this argument cannot be applied to that of the business or corporation.

Transferring the explanation of 'environmental identity' between an individual to a corporation is erroneous for a couple of reasons. Corporations do not internalise aspects of their physical environments in the same way that individuals grow and develop in a physical environment, nor are corporations physical entities in the sense that they are directly exposed to and affected by their physical environments like individuals are. There is a need for another explanation regarding the way in which corporations discuss and advertise environments like HB. This explanation can be found in the primary overriding goal, which is the drive for profit (Foster, Clark \& York, 2010; Marx, 1991). The provision of a quality good or service by a corporation that bears a high level of utility value for the consumer and 
wider society is rescinded by the pursuit of profit, insurance and deliverance of quality goods and services only stretch to the point where profit can be made, regardless of whether the consumable delivers the required level of utility (Foster, Clark \& York, 2010; Marx, 1991). Any factor or complication that has the potential to hinder this exchange in the pursuit of profit maximisation, such as disclosing information pertaining to the HB landfill would then logically be avoided and omitted by corporations.

This omission of details that will not serve the goal of profit maximisation for a respective corporation can be exemplified in the way real-estate corporations discuss and describe houses for sale in the area of HB. In February 2019, for example, successful Wellington based real-estate corporation Tommy's listed a vacant section of land on TradeMe, an online trading site in New Zealand. The section sat directly to the east of the landfill outflow, the point where contamination comes into contact with the beach. Yet the section was described as a "treasured and sacred position" and the area of HB as having "superior aesthetic qualities" (Tommy's, 2019). The listing described the parks which are built on top of sections of the landfill, sections containing waste that extends nearly 30 meters into the ground only covered with one third of a meter with topsoil and clay, as being "top class recreational facilities" (Purchas, 1998; Tommy's, 2019). The listing also advertises the close proximity to all the conveniences of living near a major city while at the same time retaining a wild, serene rural-esque environment as a place to call home saying "you can enjoy the stunning vistas of a world class marine reserve from your window and yet be at the office or airport within 10 minutes" (Tommy's, 2019). This type of corporate public relations syntax and language is entirely geared towards creating the most economically palpable representation of that specific area to arouse the interest and entice a potential bidder. The description makes no mention of the area's history with pollution seeping from the landfill, the leachate plumes, the landfill gas or the potential interaction with these complications one might experience as a resident of this area. In addition, the listing features an image of the section's view to HB beach that appears to have been altered, as no evidence of the stormwater pipe and its outflow is visible in the location it should be. While understanding that for the real-estate corporation openly advertising the area's history with leachate and gas contamination would not be a successful marketing strategy, corporate marketing that over-emphasises the features of environmental attraction only serve to reinforce and further entrench the palatability of adopting an idyllic 
construction in the minds of potential residents. This precipitates environmental victimisation occurring in the area.

The language used in corporate advertising possibly accelerates the construction of $\mathrm{HB}$ as an idyllic space. The factors of environmental attraction as discussed by the interviewees are also potentially cemented and solidified further by the advertising commissioned by Tommy's Real Estate. As factors of environmental attraction meet corporate dissemination, confirming the idyllic construction of the area within the minds of the $\mathrm{HB}$ residents, there could be increasing inhibition of environmental remediation. As the idyllic construction is confirmed, any sense of urgency and willingness to implement a remedy to the area's contamination stagnates because it would require an admission that the area is polluted to the extent where such a remedy is needed. This would then be incongruent with the idyllic construction of the area that has been shaped by the factors of environmental attraction and then cemented by the message disseminated by the local real-estate corporation. A tension is thus created between acknowledging the state of environmental contamination and the factors of environmental attraction leading to the construction of an idyllic space.

Institutions such as Wellington City Council (WCC) also play a central role in promoting the idyllic construction of HB in the minds of residents. Wellington City Council are responsible for the ensuring the closed landfill does not present a threat to residents, and for maintaining the grassy 'sports fields' sitting atop the landfill. The council also operate a website that people can use to make inquiries regarding work the council is doing within the area, or work that needs to be done in addition to a considerable variety of other services and information (WCC, 2019). Some of this information on their website pertains to recreational activities one can engage in when in or near Wellington City (WCC, 2019). Under the tab 'enjoy the outdoors' you will eventually find HB listed under 'beaches and coasts' (WCC, 2019). The website has a brief description of the area describing the walk from Sinclair park to Buckley road as having "outstanding views", and that the beach, including the area of sand where the contaminated flow from the culvert wreathes the nearby sand in pollutants, is suitable for "picnics" and "short walks" (WCC, 2019).

The WCC HB website page not only focuses on the more idyllic constructions of the area created from the factors of environmental attraction, such as the area's outstanding views and suitability for picnics, which have the effect of further entrenching the 
construction of the area as the embodiment of an undisturbed picturesque environment. Additionally, the WCC website is completely void of any information regarding the decommissioned landfill from HB (WCC, 2019). Like the real estate corporation, WCC undermines potential remedial efforts, despite having a legal and societal obligation to do the opposite. By not detailing any information regarding the history of the landfill and its pollution on their website, people both within the area and those outside thinking about frequenting it, should they use the WCC website for information, will not be able to learn and even become aware of complications and as a result may encounter contaminated sand, water or air.

This lack of information regarding the landfill on the website also suggests for those who are aware of the landfill that it and its associated complications do not warrant any level of concern (WCC, 2019). However, the website does mention a "dangerous undertow" and warns of the potential danger to swimmers should they become caught in the undercurrent and are subsequently carried out to sea (WCC, 2019). This demonstrates that the WCC has a degree of interest in protecting and ensuring the wellbeing of its constituents. Yet despite a litany of scientific, qualitative and visual evidence proving the landfill's capacity for pollution, no information is presented on the WCC HB page (WCC, 2019). This suggests the undertow ranks higher on the council's priority list than that posed by the contaminate-seeping colossus of a landfill. This failure to inform residents of the landfill's complications will be dealt with in much greater detail later during the development of the argument. At this stage, the council's role in perpetuating and fuelling the creation of an idyllic narrative through advertisement of the factors of environmental attraction and omission of landfill relevant information is what is of relevance.

Interviewees identified another institution that plays a role in perpetuating the idyllic construction of the area: Houghton Valley School (HVS). It came to light during the interviews that the HVS is thought of by many to be an exceptional and unique school for the Wellington city setting in which it resides. David said:

"...everyone always says the beautiful grounds... the grounds are so beautiful, they look amazing... the kids are so lucky to have all this land." (David, 2019) 
The 'beautiful grounds' being referred to here are of course the large flat spaces created as a result of the landfill being covered in clay and topsoil which was then levelled with the aid of heavy machinery (Purchas, 1998). Having this extra space that can then be used for various school activities, as well as the school being surrounded by native bush reserves, places this institution at the epicentre of HB's factors of environmental attraction.

The HVS website also makes it no secret that the school is unique in its environmental location and capitalises on the school's proximity to a major city centre while retaining a rural-esque small town community atmosphere, two aforementioned factors of environmental attraction. The website uses words and phrases encapsulating the factors of environmental attraction such as "nestled in the hills above Houghton Bay on the beautiful, wild South coast of Wellington", "to take advantage of all Wellington city has to offer, whilst sharing a warm sense of small school community" and finally "extensive grassed playing areas, bike track" (HVS, 2019). These quotes all speak of the area's factors of environmental attraction describing the area as being "beautiful" and "wild", advertising these coveted a highly desirable factors within a predominately urban environment. Houghton Valley School therefore actively markets itself as unique from other schools within the region, resulting in the high esteem afforded to it amongst current and potential parents.

The construction of the area of $\mathrm{HB}$ as being an idyllic environment is almost complete, but before examining the final piece of this puzzle it is important to quickly summarise the conceptual journey up until this point. The unique combination of bucolic lifestyle features with that of inner-city conveniences; the many picturesque factors of environmental attraction; corporate promotion of houses in the area; favourable descriptions of activities in the area by local authorities; and a quintessential country school in the city, all work together in tandem to create an idyllic construction of the area within the minds of $\mathrm{HB}$ residents. The final section of the discussion of the idyllic construction shall explore the role of NZ's 'clean and green' marketing campaign.

Scholars note the origins of NZ's 'clean and green' imagery go back to the colonial government's depiction of NZ as an agricultural arcadia in attempts to entice British settlers to $\mathrm{NZ}$, but the general consensus is that the most recent version came into being during the time of NZ's nuclear-free movement during the 1980's (Coyle \& Fairweather, 2004; Dew, 1999; Tucker, 2017). Some authors attach its genesis to that of the vessel the 'Rainbow Warrior' and its role in aiding NZ to become a nuclear-free state, others content that it was 
the combined efforts of marketers and businesses that wanted to create an economically viable international image of NZ in the interest of bolstering exports, the primary drivers being the tourism and agricultural sectors (Coyle \& Fairweather, 2004; Tucker, 2017; Bain \& Dandachi, 2015). Regardless of whether the saying was born out of economic or political motivation, the notion of a 'clean and green' backyard has been woven into the social and cultural framework of NZ society and has aided in the establishment of the 'Kiwi' landscape now renowned around the globe (Tucker, 2017; Dew, 1999).

The success of this national branding cannot be understated with massive growth seen in both the agricultural and tourism industries since its inception (Tucker, 2017; Bain \& Dandachi, 2015). The monetary success and wide dissemination of this 'clean and green' NZ image is also thought to have become culturally adopted by the collective NZ consciousness: "it may well be that tourism advertising influences New Zealanders as much as it influences tourists" (Coyle \& Fairweather, 2004, pg. 150). The leachate and gas contamination from the HB landfill threaten to distort this manufactured construction of reality as an environment that endures consistent spouts of industrial waste over a significant period of time cannot also be considered a 'clean and green' environment.

References to the types of images and language associated with the 'clean and green' construction and its wider overarching cultural implications were common throughout the interviews:

"The greenness of that area was part of the draw... it seemed like a batchy kind of green, sort of a little rough." (Stella, 2019)

"The bush and scrub covered hills, the green." (Derek, 2019)

"It's the perfect spot really." (Mathew, 2019).

These quotes indicate that the 'clean and green' ideal potentially has, as was suggested by Coyle and Fairweather (2004), been subconsciously internalised within NZ culture to the point where the features espoused in the ideal are now intertwined with people's personalities, perhaps part of their 'environmental identities'. A slice of the NZ 'clean and green' landscape acts as a cultural marker, of privilege. Living in an environment 
that exhibits the 'clean and green' ideal confirms their success. In the case of environments such as HB, the 'clean and green' ideal acts as 'cultural cement' that solidifies the already prevalent idyllic construction held by the inhabitants within the area.

It must be noted that not all the interviewees were so readily sold on the 'clean and green' NZ image, in fact some not only had their doubts regarding the truth to the image but blatantly called this 'truth' into question:

"Yes, NZ clean and green, more like clean and brown." (Derek, 2019)

David acknowledged the incongruity between NZ's marketing ideal and the sporadic contamination that they experience while living in HB. Others also made similar types of statements regarding the general hypocrisy and juxtaposition of their idyllic environmental construction and that of manifestations of historical pollution such as smelling the landfill gas or seeing the leachate plume. This juxtaposition between the two competing perceptions of reality for those living within HB will be examined thoroughly in the following chapter, but at this stage it is important to note that not every interviewee was convinced by the 'clean and green' ideal.

It is clear that for those living within the environment of HB there are conflicting constructions and interpretations of reality. This chapter has addressed the construction of the idyllic perception of HB's environment in the minds of the interviewees for the current study. The idyllic construction is a result of a confluence of factors that centre on the manifestations of features of environmental attraction: a lush pest-free bush-scape and close proximity to marine and terrestrial wildlife, all while retaining proximity to an urban centre. $\mathrm{HB}^{\prime}$ s factors of environmental attraction are then adopted and romanticised by corporations and local governmental institutions, while the HVS cultivates a sense of prestige and desirability amongst parents through its integration and location relative to $H_{B}$ 's factors of environmental attraction. Finally, the national 'clean and green' marketing ideal potentially cements and solidifies the adoption of what is an already very alluring idyllic construction within the minds of the residents. The following chapter will illustrate how the idyllic construction of HB can be threatened when pollution is experienced and how, in turn, this idyllic construction can inhibit acknowledgement and appreciation of the experienced contamination. 


\section{Chapter Five: The Human Experience of Urban Pollution}

This chapter argues that as the idyllic construction of HB's environment becomes congealed and cemented within the minds of those living within the area, it can serve to undermine remedial efforts and divert attentions away from the pollution. People's corporeal senses provide indications and confirmation that the socially constructed environment of HB is not as idyllic in reality. These corporeal indications create friction between two incongruent versions of reality that thrusts those who have experienced pollution into a form of agnotological tension between full contamination acknowledgement with behavioural amendment, and adherence to the idyllic construction with some contamination acknowledgement. However, the primary objectives for this chapter are phenomenological and experiential in nature. I shall first describe and collate people's lived experiences of living next to the landfill in HB. The chapter will then illustrate how corporeal experiences of pollution throw residents into the aforementioned agnotological tension, either eroding the idyllic construction of $\mathrm{HB}$ or strengthening it.

Smelling the petroleum-esque gas that emanates from below the landfill was a common finding across the interviews. Beyond encountering the smell, experiences were very individualised and unique to each respective interviewee. That being so, I present the testimony of just four interviewees in this chapter: each as a case that helps to illustrate the variations among the residents of $\mathrm{HB}$ and the ensuing threads to my argument.

Understanding the individual experiences of those who encountered the manifestations of pollution, what confronted them and how it impacted on their lives, and how they then navigated their lives around the contamination, forms the basis of the argument developed in this thesis. Fundamentally, it helps me to address the question at the centre of studies of historical pollution: who is responsible? Not only were people exposed to the pollution which prompted a re-evaluation of how to navigate their amended physical reality, additionally, they then faced the overly complicated and convoluted bureaucratic mechanisms available for seeking redress in instances of environmental victimisation. As I too would discover in my own searching for official information pertaining to this study, it becomes easier to navigate the contamination daily than it is to call out the idyllic perception as a lie. 


\section{Derek}

Derek encounters the smell "at least once a week" (Derek, 2019). He went on to explain that the "vents" on his property from whence the stench emanates were connected to two larger pipes that run underneath the entirety of the section. These two larger pipes were part of the landfill's flood management infrastructure that in the event of a deluge will divert the flow into the bay. He went on to say:

"So when it is really bad outside we try and avoid it really, like when you're at the forecourt filling up your car you don't stick your head close to the nozzle" (Derek, 2019).

Derek's property was situated right at the bottom of the valley at the lowest point other than the sea and additionally, lies right in the centre below the old landfill itself. This is a unique geographical position, an olfactory front-row seat for the experience of gas pollution. He went on to add that when people visit his property it is not uncommon for them to be concerned:

"'Oh I don't know if breathing those petrol fumes are good for you'? We've had people say this who have come in, have just been hit with it and have gone wow, to which we say, yea we don't hang around this spot by the backdoor because of the smell. It's not always there but on a bad day I just try to not breathe it in" (Derek, 2019).

It is clear that the confronting the sense of smell indicates that there may be a danger to one's health and wellbeing. When friends of Derek and his family visit they are immediately cautious of the smell without knowing exactly what it is and share a collective suspicion regarding the possible health implications upon inhaling it. This suggests that there is an almost automatic biological response that the body makes due to the unnatural and likely unhealthy potential of the smell. Derek is constantly forced to choose between possibly compromising his family's health and simply using their backyard as per their rights of private ownership. Derek interacts with his property and home environment in a different 
way than he had imagined he would. By not spending time near the rear of his property he can avoid the unpleasant and potentially toxic smell.

The leachate into the bay also prompted significant change to the way he interacted with other areas of the HB environment. As he recalled:

"Yes, absolutely so we don't go swimming when the Bay is like the photo you showed me, you obviously don't want to go swimming in that... I mean just look at that horrendous awful brown colour..." (Derek, 2019)

It is a terrible irony that Derek and his family were attracted to purchasing a house in HB for its picturesque environment, but that living there has meant they must limit their interactions with the physical landscape around their home and while on the nearby beach.

Derek's experience begins to illustrate the extent to which people within the area of HB must amend their normal and expected daily interactions with their environment. As I delved further into the experiences of those within the area, wisps of the tension in Derek's testimony between the idyllic construction of $\mathrm{HB}$ and the experiential reality of encountering the pollution became more apparent. Responses to the tension, however, varied. In some cases, an adherence to the idyllic construction of the environment served to divert or neutralise concern about having to change behaviour in relation to both the gas and leachate contamination. In others, it prompted collectivising with others to seek redress from those they deemed responsible.

Figure III depicts a spectrum that at one extreme captures those who were hopelessly indoctrinated and consumed with the idyllic construction, and at the other those who acknowledged the extent of pollution and acted to seek remedial efforts in addition to culpability: 


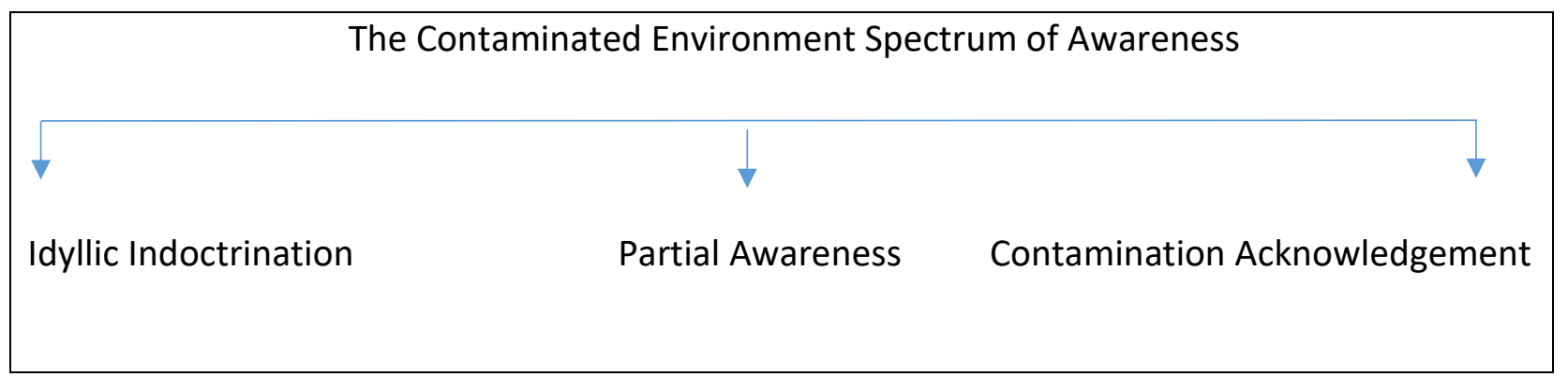

Figure III: The Contamination Environment Spectrum of Awareness

The employment of a spectrum to illustrate how interviewees navigated the tension between construction and reality helps in understanding that the human experience of pollution within the setting of historical urban pollution is not consistent. From Derek's responses, it is clear that he is both critical and aware of the pollution, even going as far as to amend his family's behaviour. This indicates that Derek acknowledges his proximity to and potentiality of pollution exposure to himself and his family. Derek would sit towards the right end of the spectrum as he appeared to have been somewhat detached from the idyllic construction of the area through experiences with the pollution.

\section{Bob}

There are important differences between the interviewees' lives that play into how they interact with the environment. For example: Derek had retired and at the time of the interview and his children had moved away from home. This meant that Derek did not need to be overly concerned about possible health implications regarding his children. Derek could be referred to colloquially as a 'senior citizen' whereas Bob was much younger and had two young children attending the local primary school. Keep these important distinctions in mind as Bob's experiences are discussed.

Like Derek, Bob's first physical interaction with the pollution was through the corporeal detection of smell, Bob stated:

"I've thought nothing of it [the landfill] until we moved down here and then you start noticing the smell... on a nice hot summers day you can be at the park and you get a whiff of it... it smells like a toxic diesel-like kind of smell, not very pleasant." (Bob, 2019) 
Bob lives in a different location to Derek which means that he will be experiencing and interacting with the pollution in different ways. Bob said that he did not really think about the landfill until he and his family detected it through their olfactory senses. Despite that the landfill has existed since the 1950's and there is much archival documentation pertaining to it (Purchas, 1998), neither Derek nor Bob paid it any attention until they could corporeally detect evidence of it themselves. Until the landfill made itself known through its odour, acknowledgement of its presence and its associated risks was not immediately available to these residents. This illustrates the insidious, invisible nature of historical pollution for those of the present day.

An element of invisibility also comes from the way the landfill itself is actually concealed within the area. As mentioned earlier, the landfill was officially closed in 1971 and was benched and compacted by heavy machinery to form the staircase like structure recognisable today (Purchas, 1998). These steps were then covered in a layer of top soil and grass was subsequently planted. In addition, a children's playground was installed on one of the lower layers, along with a basketball court. These developments will be further analysed in the following chapters but for now it is of note that the playground and the basketball court not only literally cover the landfill, but they offer the suggestion that this is a space that is safe for children. The landfill's physical nature is visually covered with a veneer. It is through the corporeal engagement with smell that the residents become privy to the possible danger that is lurking beneath the surface.

Bob's house was situated up the valley opposite the landfill. Nevertheless, he spoke of his frequent interactions with it:

"It's consistent, on hot days, funnily enough you'll smell it every other day, you can smell it especially around the playground area where that T-junction is on Hungerford road and HB road, maybe there is a particular drain there that is venting off more than other places, it's always bad there, a friend of mine up Hungerford road can smell it in his house... essentially from the park down you can almost continually smell it." (Bob, 2019)

Bob attests to the pervasive, widespread nature of the smell within the area. This has a number of important implications. Firstly, for this interviewee and their family, time spent together in the area around their home is a time where they may all be at risk of prolonged 
exposure due to inhalation of the landfill gases. Research has shown landfills produce a litany of potentially harmful gases with Hydrogen Sulphide being one of the more recognisable due to its olfactory resemblance to rotten eggs (ATSDR, 2001). In high enough concentrations, limited exposure can lead to acute symptoms including severe eye and respiratory complications and in high enough concentrations even death (ATSDR, 1999, 2001). Bob's young family engage with the environment in ways not shared by Derek. They must navigate a potential threat to their health whenever they venture down to the park to play and whenever they go down to the beach to run about or swim. Bob and his family are forced to negotiate a set of invisible, uncertain risks that others who live in HB do not to the same extent. Yet the link between the amendment of personal behaviour in light of the leachate contamination, especially towards himself, was not made so readily for Bob. On discussing the leachate plume, he had the following to say:

"Being a surfer there are certain times of year due to the weather when you don't go surfing because of the wash-off and you get a lot of toxins in the water and people say you don't want to surf there because you can get sick ... whether that is true or not I don't know." (Bob, 2019)

When asked whether he himself had ever been sick he claimed that he had not. Following on from the above passage, Bob claimed that he would go surfing "whenever there is a wave, whatever the conditions" (Bob, 2019). He said:

"I still go in there but some of my friends don't for that reason... I have a couple of friends say they have been sick after swimming and surfing in $H B$, in all conditions and who don't do it anymore, they think it's because of the leachate... I'm a bit silly really... my kids... I keep them away from the stream and the beach." (Bob, 2019)

These excerpts suggest that Bob is aware of the potential adverse implications associated with the leachate but at the same time is not prepared to amend his own surfing behaviours. He noted: "I'm bit silly really" (Bob, 2019), indicating a degree of self-realisation that by surfing in the bay with the leachate present he is putting himself unnecessarily in harm's way. 
In terms of the 'contaminated environment spectrum of awareness', Bob's case is interesting. There can be no argument that he is ignorant to the manifestations of contamination as he repeatedly notes the consistency of the smell, where he smells it, what it smells like and notes the periodic discharge of leachate into the bay. He is therefore unable to placed entirely in the 'idyllic construction' section of the spectrum. Yet Bob is also unable to be placed at the right section under 'contamination acknowledgement' insofar as his knowledge of the leachate plumes and corporeal indications of risk to his health does not deter him from engaging in recreational surfing in the bay.

Bob's concerns about the landfill become subsumed under the greater priority of engaging in recreational surfing: he can be said to slide along the spectrum depending on whether or not the surf is good.

\section{Sam}

Sam illustrated how factors of environmental attraction, the forebears of the idyllic construction, can become agnotological and ainigmological in function as they serve to divert concerns about the contamination and attention back towards favourable appreciation of specific factors of environmental attraction. Sam did not deny the extent to which the area is afflicted with the landfill contamination, and he was critical of the responsibility and work of WCC and Wellington Water regarding the monitoring of the landfill, but he would soon revert back to speaking favourably of work the council has done to improve other aspect of HB's environment. For example, Sam criticised WCC's prohibition against establishing communal gardens on the contoured areas of the landfill in lieu of removing the contamination. Yet almost immediately, Sam retreated back to favourably discussing the factors of environmental attraction that WCC have either directly aided in protecting or have avoided disrupting. Sam stated:

"It's not a completely black and white issue... the land was contoured has created space that is used by the HVS which is well known for having the best cross-country track of all the southern schools." (Sam, 2019)

Sam's reverting back to speaking favourably of the positive environmental initiatives conducted by WCC functions as a means to offset what is an abandonment of constituent 
obligation. Thinking favourably about the positive aspects of the WCC's environmental work within the area diverts concerns away from the contamination. This was evident again when Sam said:

"I would feel probably the council has taken an it's too hard and expensive kind of approach." (Sam, 2019)

A level of dissatisfaction regarding the WCC's procrastination towards implementing a permanent solution to the landfill pollution is thus implied. However, in the very next sentence Sam stated:

"... in 2001 we heard the first Tui in this area and now its Tui galore, it's incredible around here, and a lot of that is due to the council work trapping pests... we used to have possums around here and we haven't seen a possum for over ten years... the council is doing some good environmental initiatives." (Sam, 2019)

In the space of a couple of sentences, Sam's critical commentary that may have become the galvanising force to precipitate practical action towards WCC has now been diverted and absorbed by a retreat back towards a specific feature of environmental attraction and towards the idyllic construction itself. I argue that the idyllic construction here has a neutralising effect on Sam's initial critical reflection of the work, or lack thereof, conducted within HB by WCC, GWRC and Wellington Water. There exists a tension between acknowledging the presiding authorities' [WCC, GWRC and Wellington Water] lack of meaningful development towards a solution and the pro-environmental initiatives already conducted by said authorities. The Tui example illustrates that some of the proenvironmental initiatives conducted by pertinent authorities can create and maintain specific factors of environmental attraction. WCC's pest control within HB was essential in rejuvenating the Tui population, a factor of environmental attraction. This suggests these factors of environmental attraction, despite being objectively ecologically positive, can act to confuse, obfuscate and frustrate, akin to the function of agnosis and ainigmology, the efforts, concerns and attentions of residents such as Sam. 


\section{Graeme}

Graeme also highlights the unique aspects of experiencing environmental contamination, and introduces the social and cultural implications of being aware of the landfill within the affected community (Hall, 2013; Skinnider, 2011). Graeme proved to be fiercely knowledgeable regarding the history of $\mathrm{HB}$, including about the establishment of the landfill as well as the community efforts that appealed to WCC for assistance in remedying the problem (which I discuss further below). Graeme began by telling me about his understanding of the risks to the children who attended HVS:

"One of the big problems with the tip is methane, so the kids in the school are playing in a field where methane is being emitted... when I was walking down there [Hungerford and Houghton Bay Roads] to catch the bus and you go past the crates the smell is horrendous." (Graeme, 2019)

As mentioned earlier, the landfill was formed in layers as it progressed up the valley and this is what produces the staircase like arrangement of the levelled surfaces within the area. Graeme is alluding to the layer where the HVS is located. During recess, primary school students descend onto the large open field from whence landfill gases emanate. Knowing this put Graeme in an ethical conundrum. Given his knowledge of the landfill gas emanation and the inevitability of children being exposed, Graeme is potentially partially responsible for a possible case of human contamination if he peruses a course of inaction. To act meaningfully in this situation requires investment of considerable time and effort, in addition to the personal expenditure one must pay to be in a position to act selflessly, that culminates in an emotionally draining task. This type of decision constitutes an emotional conflict that Graeme must navigate, in addition to the spouts of physical pollution he must also navigate, when living in an area afflicted with historical pollution.

It is becoming clear that the implications of living in an environment afflicted with gas and leachate contamination poses risks that go beyond threats to human and environmental health and actually extend to potentially impacting residents' moral compass. People like Graeme are thrust into ethical minefields and are pressed into making difficult decisions that others need not concern themselves with. Such impacts have been the subject of lengthy academic debate and discussion (White, 2008, Skinnider, 2011, Hall, 
2013). Hall (2013, pg. 35) duly noted the "less tangible" quality of the social and cultural implications of environmental dilapidation when held up against the more objective verifiable implications of pollution such as health and economic impacts (Hall, 2013). Hall argues, and I agree, that this deficiency in tangibility should not decrease or impinge upon the responses of some form of remediation via legal mechanisms. Hall encapsulates this line of thinking by posing the question, "how, or whether, these systems can offer any kind of meaningful redress mechanism for this category of harm?" (Hall, 2013, pg. 35).

Unfortunately for Graeme, the criminal justice system in New Zealand would be unable to provide redress, for a number of reasons. Most prominently, the burden of attaining a causal link between the contamination within an area and specific health implications related to exposure is significant (Scott, 2015), and thereafter one would have to prove intent or recklessness (Trundle, 2020). The high standard of causal evidence demanded by legal mechanisms within the criminal justice system has been the topic of lengthy discussion within the green criminological community for some time and ought to be linked to the research data where possible (Hall, 2013; Scott, 2015, Shriver et al, 2019; Trundle, 2020; White, 2011; Williams, 1996).

Graeme was well aware of the almost unobtainable standard of proof expected. He said:

"... we know people who are suffering through health but is not that we have the evidence to say those health problems are caused by the tip...people are suffering, the link just hasn't been made." (Graeme, 2019).

Meanwhile, time marches on and residents continue to live within the afflicted space, continually being exposed to the landfill pollution which compounds their victimisation. Moreover, unaccommodating legal mechanisms of remediation potentially leave people feeling ignored by regulatory agencies and leads to feelings of disappointment, abandonment and frustration. What Graeme's reflections spoke to within the literature is that the manifestations of environmental victimisation, like the social, cultural and health implications, struggle to be processed or even acknowledged in any significant way by legal mechanisms. While examination of the nuances surrounding the failing of legal mechanisms to adequately address environmental victims falls well beyond the scope of the present inquiry, what Graeme's experience makes clear is that collating and examining examples of 
these less visible and legally unappreciated forms of environmental victimisation is imperative for unearthing the invisible struggles of those living within contaminated environments.

Unfortunately, this would not be the last situation in which Graeme was forced to navigate the social and cultural repercussions of environmental victimisation (Hall, 2013). The most confronting evidence of the landfill's presence is the outfall stream that directs the flow of the leachate onto the beach from where it then flows across the top of the sand down towards the sea. Many interviewees, as citations have indicated, are suspicious towards the safety and quality of the water, with all parents interviewed forbidding their children from playing in the stream of water from the outflow due to the fear of contamination. Graeme had this to say regarding the stream:

"There are definitely some nasties in there... that valve... its only meant to open under pressure from heavy rain fall... so there shouldn't be any pressure on that valve whatsoever but the fact is, even in the middle of summer there is still water trickling down to the beach." (Graeme, 2019)

What Graeme is describing above is the infrastructure that is meant to regulate the flow of the stream onto the beach through use of a pressure activated valve that should only discharge pollutants when the required pressure is met, usually under heavy rainfall. Yet for reasons that remain unclear to the council, residents and the current research, the pressure valve has been compromised resulting in almost a permanent flow of pollutants across the beach. Substantiating Graeme's explanation of the landfill's infrastructure is no simple feat. Official council documents related to the topic are buried underneath screeds of seemingly unimportant and irrelevant apparatchik administrative documents. Yet despite these nefarious efforts I was able to find some information pertaining to the HB outfall from the Greater Wellington Regional Council (GWRC). The document makes no mention of a pressure activated valve, yet also claims, "leachate contaminated storm water discharges to the receiving water only during extreme wet weather" (WCC \& GWRC, 2013, pg. 1). Yet in Graeme's account the flow across the beach is almost constant and certainly not limited to instances of 'extreme wet weather'. This was something that I also observed myself upon visits to $H B$. 
Graeme's testimony reveals there is a disconnection between the official understanding and acknowledgement of the pollution against the lived experience of pollution. This disconnection creates more opportunities for social and cultural harm within the contexts of environmental crime and situations of environmental dilapidation. Graeme's experience is illustrative:

"I have walked down there [the Houghton Bay outfall on the beach] and there has been a mum sitting beside that stream with her kids playing in the stream, many times, kids are playing in it. It's actually painful to see... So when I've approached people and said hey look I wouldn't let your kids play in there, it's toxic and stuff, sometimes they'll get angry and tell me to piss off. (Graeme, 2019)

The disconnection of information between institution and resident within the context of environmental crime and dilapidation creates an information dissonance. Like dissonance in a musical context, the separate and conflicting accounts and interpretations of the contamination clash jarringly with one another, resulting in people conducting themselves in different ways depending on which version or interpretation of events they choose to adopt. The differences between which interpretation people adopt will inform the respective amendments those people make to their behaviour. I suspect this can explain the harsh reaction Graeme encountered when attempting to voice his concerns regarding the child playing in the contaminated stream. Perhaps the child's mother had been influenced by one of the many conflicting information sources of questionable accuracy surrounding the landfill and as a result may have only considered the leachate an issue after heavy rain as purported by the GWRC (WCC \& GWRC, 2013), if, in fact, she had considered it at all.

The personal distress and upheaval experienced by Graeme upon seeing this was acute and profound. Similar to the earlier ethical conundrum, does inaction on Graeme's part mean that he is now somewhat indirectly culpable for any potential health implications the child might contract knowing there is reasonable cause to suspect the outfalls toxicity? Yet Graeme's altruistic actions in warning the mother and child resulted in Graeme being verbally accosted for his virtue. Aside from the emotional meat-grinder Graeme had to subject himself to, there is of course the question of whether the child was still permitted by 
its mother to play in the stream where it was potentially exposed to contaminates? Graeme did not elaborate on the outcome, although it may be implied in his utterance:

"It's actually really painful to see." (Graeme, 2019)

Graeme's dilemma constitutes a form of social victimisation taking place alongside the environmental victimisation that is occurring within the HB area (Hall, 2013). Graeme would sit towards the right end of the spectrum of contamination awareness evidenced by his efforts to amend not only his own personal behaviours but that of others within the area. There is a culture of engaging in recreational activities on the beach and in the water, as well as an overall engagement with the coastal marine environment. Surfing at HB is a popular pastime for some members of the community, like Bob, and there are many others who come in from outside the area to surf there too. Teenagers are known to hold 'beach parties' some evenings, complete with bonfires and fireworks on occasion. Taputeranga Marine Reserve, part of which encompasses $\mathrm{HB}$, is also a popular with walkers and snorkellers. At weekends, families with younger children can be found building sand castles on the beach. With respect to how the leachate contamination affects their activities on the beach, David had this to say:

"I think I have felt aggrieved about the stuff the comes out into the sea [the leachate from the outfall] because we take the kids down there and they quite often want to play in that [the outfall] because it's kind of a little stream but I've always been conscience it's not okay for them to play in... because it smells... there has always been a part of me that's thought they if the kids want to come to the beach and play the they should be able to plan anywhere on the beach they want... because it smells." (David, 2019)

From this excerpt it is clear that the leachate restricts residents' activities at the beach. The simple act of taking one's family down to the beach for those who live in or visit $\mathrm{HB}$ becomes more than recreation and an engagement with the sand and sea insofar as it also an interaction with an industrial hazard. Managing exposure and keeping safe from potential sources of contamination becomes an additional factor of a visit there. Nor do the 
risks and manifestations associated with the outfall on the beach remain constant as throughout the year seasonal changes create more risk and avenues for pollution. New avenues that people using the HB beach recreationally must become aware of in order to minimise exposure to pollution. Throughout most of the year, there is sufficient moisture in the area which creates the stream of water that runs across the beach from the outfall. During the later parts of the summer, the lack of moisture causes the stream to evaporate and the contaminate-soaked sandy stream bed becomes exposed to the air and wind. The sand at the bed of the stream accrues an unnatural lurid orange colour as the contaminated waters runs across it. As the contaminates come into contact with the sand it would appear that some are transferred leaving the insalubrious orange tinge. Consider the following two pictures:

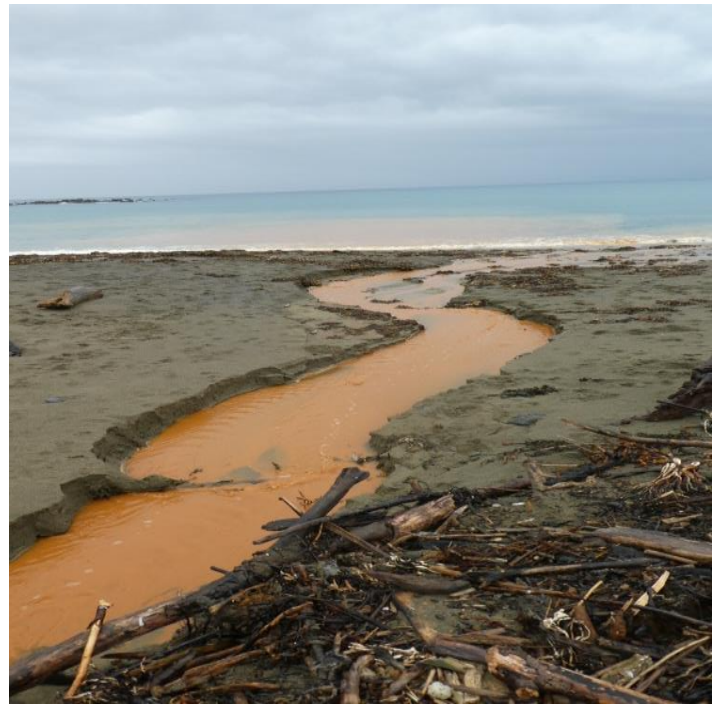

Figure IV: Leachate stream flowing

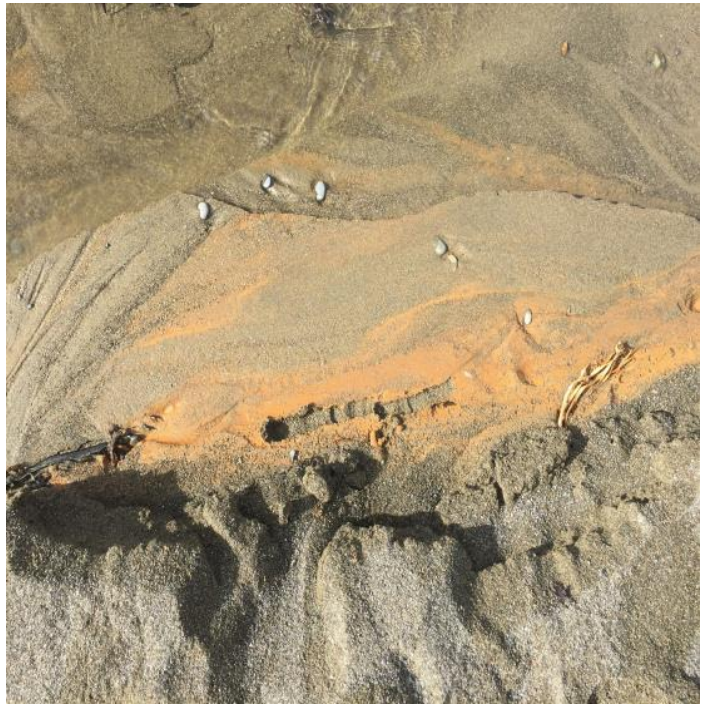

Figure V: Dry sand with orange tinge

What remains are large quantities of the contaminate laden dry sand. Dry sand is prone to being swept around by gusty winds, generating significant concern amongst the community. David said, for example:

"I don't like it when it's in the middle of summer and its really dry and that sand and the dust is blowing around with it being that orange colour, I'm actually more wary about that than getting in the water." (David, 2019) 
When the stream is flowing freely during the cooler months it presents a different set of risks, such as exposure to pollutants absorbed into the water, to those who would use the area than in the summer months. The changing dangers and sources of pollution within the area provide another layer of complexity and adds an element of unpredictability to how the pollution manifests itself as it changes throughout the year. As the risks change, so to do the efforts of those seeking to avoid exposure in order to remain free from the pollution as best they can, efforts that are made increasingly frustrated by the indifferent attitude of the council towards said contamination.

The flexible transformative nature of environmental contamination means residents of $\mathrm{HB}$ must retain an elevated level of environmental awareness to combat the changing manifestations thereby keeping themselves and their families safe from harm. This highlights that environmental victimisation is a dynamic phenomenon and if residents want to avoid it they must also become dynamic actors in their awareness of it to keep themselves safe.

The primary goal of this chapter was to develop an experiential understanding of what it is like to live in an area that is prone to contamination. The testimony of the selected interviewees painted a diverse picture of just how many different types of contamination experiences one can have while living within the area. From corporeal detections of the landfill gases (the most ubiquitous of experiences found) in the backyard or while at the park: to encountering the orange leachate plume from the outfall; to the emotional anguish of suspecting a neighbour's illness is due to the landfill contamination and knowing the hopelessness of trying to connect the two; to turning a blind eye in order to go surfing; to having to be mindful of the an uncertain risk while constantly aware of what manifestation the contamination is taking on.

Importantly, experiences of contamination disrupted the quintessential coastal living that most interviewees believed they'd enjoy by purchasing a house in HB. To depict their level of awareness of the environmental pollution I constructed a spectrum. At one end sits 'idyllic indoctrination' to indicate an unwavering adherence on behalf of an interviewee into the idyllic construction that was established in the last chapter. At the other sits a full awareness of the gas and leachate contaminates from the landfill. All interviewees sat somewhere between these two extremes. What eroded the veneer of idyllic construction was their smelling of the horrid landfill gases or their seeing of the leachate plume. 
Awareness does not necessarily transpire into action, however. Indeed, action can be contrary to awareness, as shown by Bob's reluctance to stop surfing despite his knowledge and understanding of the potential risks. Therefore, it is possible to be fully aware but placidly endorsing or even periodically engaging in the idyllic construction.

Ultimately, there is no 'one size fits all' when it comes to experiencing environmental contamination. Unfortunately for some interviewees, their experiences of harm would precipitate further harmful encounters. The following chapter will explore how regulatory bodies responded to the experiences of contamination of the residents, as individuals and as a group. It will be in this next chapter that WCC can be seen actively pursuing agnosis with respect to the contamination in HB. 


\section{Chapter Six: Orchestrated Agnosis}

This chapter will continue the experiential narrative focusing on the interviewee's experiences within the context of regulatory remediation, the management practices of official bodies and the role of these bodies in creating and perpetuating an agnotological, ainigmological landscape of information surrounding the pollution in HB. This chapter will illustrate how the practices and contamination management (or lack thereof) of regulatory agencies such as WCC, GWRC and Wellington Water, directly and indirectly contribute to the obfuscation and confusion concerning the harms associated with the landfill, further tempting residential attentions away from contamination acknowledgement and back towards the agnotological features of HB.

Unfortunately, suffering though the first-hand experiences of contamination comprises only half of the tumultuous journey for the residents living within the area of HB. The remainder lies in the way their experiences of victimisation were dismissed by the presiding regulatory bodies and institutions, highlighting the regulators' role in directly contributing to the agnotological landscape within $\mathrm{HB}$ in addition to increasing levels of disenfranchisement, contempt, resentment and frustration felt by the residents towards these institutions.

\section{Regulatory Avoidance \& Dismissal}

The first of such experiences comes from Jane, who told of a peculiar phenomenon undoubtedly related to the issues concerning the leachate and the landfill:

"We've had orange water coming out of our faucet twice, and it happens to our neighbour, every time they [the council workers] mess with the faucets down at the bottom, there is a pipe, it's a storm water pipe and anytime they do anything with it their water turns orange and it's happened to ours twice... I know it's related to the tip, it's the same colour." (Jane, 2019)

This quote illustrates the sheer pervasive nature of the contamination in that it is quite literally infiltrating Jane's home, a place where one typically considers themselves safe from most forms of peril, a type of sanctuary. What also makes this experience even more 
egregious is that whenever Jane turns on a tap in her home, she is aware there is a chance that instead of water flowing, there will be pollution instead. One of the most basic services a local council provides to its citizens, clean potable water, has been compromised for Jane due to the mismanagement and inadequate implementation, or lack thereof, of effective strategies for controlling and eventually solving the pollution within the area of HB.

Implementation of various mechanisms to reduce and monitor the contamination within the area have been operative since 1990, beginning with an investigation into the feasibility of creating some form of diversion structure with various other schemes attempted continuing up until the present day (Wellington Water \& WCC, 2018, 2013). The activity the council workers were performing that was noted by Jane is most likely the result of 'flushing' the pipe lines under the landfill in order to remove the encrustations and stalactites that form over time. Left unattended, these encrustations and stalactites will limit the flow of contaminated water and it will eventually block the pipes all together (Wellington Water \& WCC, 2018, 2013). This practice appears to be the most prolific method employed by the council under the guise of supposedly managing the contamination.

Detailed analysis of the agnotological claims made by WCC, GWRC and Wellington Water with regard to landfill contamination management will be made throughout the chapter but for now we shall return to analysing Jane's experience. As undesirable as Jane's experience of the contamination was, the fashion and manner in which Jane's concerns and experiences of contamination where handled by WCC and Wellington Water was abhorrent. Upon having the foul orange-coloured liquid flow from her taps, Jane understandably became very concerned and feared for both the safety of herself and her family, a member of which happens to be an infant, who is more susceptible to the adverse symptoms of contamination exposure than an adult. What follows is Jane's experience of attempting to find some answers and raise some concern for her environmental victimisation:

"I called the council twice, then when I called for a follow-up they said they had no record of my call and I asked them to come down and test the water because I have a baby, they said 'well we won't test it yet, just don't use it for 24 hours and don't bathe your child and don't drink it." (Jane, 2019) 
This flippant dismissal of Jane's concerns is behaviour by an institution charged with ensuring and protecting the wellbeing of the people within their respective jurisdiction. WCC is also the only institution with the legislative, practical and informational monopoly concerning the landfill and its associated complications. The implication of this monopoly is that when concerns regarding the landfill are dismissed, the monopoly means there is little to no other avenues for Jane to seek redress and effect meaningful change concerning the landfill. Jane's experience of environmental pollution precipitated for her acute feelings of frustration, disenfranchisement and outright resentment, as is evidenced in following statement:

"It was just a really disorganised and irresponsible response, I called and they said 'oh we don't have any record of us doing anything around there, we'll pass you on to company [Wellington Waters] that's in charge of the waterworks'... they said 'oh we don't have any record of us doing anything down there, have you contacted the council?'... The next day it happened so I called, the council, they said 'oh we don't' have any record of your call, have you contacted Wellington Water?'... It just went in circles." (Jane, 2019)

The council's blatant disregard towards Jane and her family's environmental concerns is, as I will demonstrate, innately criminal. In NZ the provision of certain responsibilities and services is delegated to specific institutions and regulatory bodies. This includes the responsibility of local councils to provide clean water to those using council infrastructure, the collection and servicing of household wastes in addition to many others (Health Act, 1956; Local Government Act, 2002). Collaboration between these institutions is necessitated by this delegation of responsibility. Collaborative interactions, however, increase and promote risk for their constituents through a process of complex interaction that is referred to as the 'organized irresponsibility principle' (Curran, 2018). That is to say through an increased number of institutional agents working across multiple agencies regarding a phenomenon, like an instance of historical pollution, the less likely the establishment of culpability becomes. I argue this responsibility also extend to acknowledging the mistakes and issues related to the provision of those responsibilities and services, such as Jane's concerns about her fresh water and indirectly, the concerns 
regarding the management of the landfill. A total of four separate phone calls were made to two separate institutions that all parroted the same indifferent response blatantly disregarding Jane's experience as an environmental victim. Unfortunately, other interviewees had experienced similar dismissals in response to their claims of harm.

\section{Institutional Dismissal of Community Science}

During the interview process one of the interviewees recounted events that occurred a few years prior that vividly illustrate the institutional dismissal of a collective experience of environmental victimisation. A number of residents within the area were motivated after encountering the leachate to find out exactly what chemicals and contaminates were present in the outfall flow. They formed an association called 'The Friends of Houghton Bay Association' (that still exists today), and commissioned a company named S.G.S to provide privately funded scientific tests to ascertain the contamination in the stream. The WCC in conjunction with Wellington Water sample the water and sediments quarterly, with data going back to 1994 (Purchas, 1994; WCC \& Wellington Water, 2018; 2013).

The newly collectivised 'Friends of HB Association' published the results of the testing online and it was intended to be presented to WCC as objective evidence of the contamination thereby securing council assistance in alleviating the contamination issues (Corbishley \& Vorster, 2020). The results from those tests by the SGS would finally give residents the objective scientific proof needed to secure the aid of the legal mechanisms capable of delivering redress. A selection of elements was tested and compared with the respective trigger contaminate values established by the ANZECC (2000; Corbishley \& Vorster, 2020). Of the ten tested elements, seven of them breached respective contaminate trigger values (Corbishley \& Vorster, 2020) (see Appendices XI and XII). Trigger values refer to the quantity of contaminates required to adversely impact a set of organisms that inhabit the environment the contaminates infiltrate (MFE, 2020). The percentiles assigned to the level of species protection illustrates the potential impacts when a quantity of a respective contaminate enters that environment. The SGS tests showed that $42 \mathrm{ugL}^{-1}$ of lead $(0.042 \mathrm{mg} / \mathrm{I}$ $x 1000=42 \mathrm{ugL}^{-1}$ ) accounting for the unit conversion, is then compared to the respective trigger value (Corbishley, 2020). The ANZECC trigger values of lead for $99 \%, 95 \%, 90 \%$ and $80 \%$ species protection were all breached with the highest values of $9.4 \mathrm{ugL}^{-1}$ and $12 \mathrm{ugL}^{-1}$ for 
fresh and marine waters respectively pertaining to the $80 \%$ value were also breached, indicating that $20 \%$ of life would be adversely impacted. To put it another way staying with the lead example, the SGS test confirmed the presence of $42 \mathrm{ugL}^{-1}$ compared to the $12 \mathrm{ugL}^{-1}$ limit prescribed by the ANZECC, which indicates $20 \%$ of marine lifeforms would be negatively impacted (ANZECC, 2000). The lead test result was over three times higher than the permissible amount typically expected to adversely impact $20 \%$ of marine life.

The result for cadmium is worth examining because of the metal's toxic nature. Today the use of the metal in general productions is decreasing as we have become more aware of its toxic properties but for the majority of the $20^{\text {th }}$ century, cadmium was used in a wide variety of applications including batteries, electroplating, televisions and nuclear fission (Scoullos et al., 2012). The SGS tests found the presence of cadmium in the HB outfall at a level of $0.68 \mathrm{ugL}^{-1}$ which is enough to breach every freshwater trigger value and breaches the $99 \%$ percentile of the marine water trigger value (Corbishley \& Vorster, 2020). Perhaps the most astounding result is an iron contamination level of $(125 \mathrm{mg} \mid \times 1000)=$ 125,000 ug $^{-1}$ which is a ludicrously high number for test of this constitution (Corbishley \& Vorster, 2020).

Having secured evidence of contamination within the area, the friends of $\mathrm{HB}$ submitted their findings to WCC in 2013. However, WCC rejected the findings as 'inaccurate' and 'incorrect', and claiming that they conduct their own tests and sampling within the area and therefore do not need any third party assistance. As Jane (2019) stated:

“...they said [the council] that they do their own testing and that's [the SGS tests] not correct, the findings weren't correct... that they were irrelevant." (Jane, 2019)

The results of the community funded independent tests were simply dismissed by WCC. McGoey (2012) argues that there are specific organisational and bureaucratic benefits that arise from the confusion and obfuscation of potentially unsetting information. The unsettling aspect of the S.G.S testing are the implications of the results and how this would illustrate the ineffectiveness and incompetence of WCC and Wellington Water management procedures regarding the landfill.

There is much to be said for role of community generated science within legal proceedings concerning environmental crimes and phenomena (Ottinger, 2010; Fischer, 
2000; Scott, 2015). Scott uses the term 'the democratisation of science' to encapsulate the aforementioned notion (Scott, 2015, pg. 272). She, and others, encourage 'citizen science' amongst people without official scientific training and who live in proximity or are exposed to adverse environmental phenomena (Ottinger, 2010; Fischer, 2000; Scott, 2015). There is value in having people who live within the afflicted area become privy to the remedial actions and measures that could be implemented to alleviate the environmental suffering. Locals are "experts at living in their community" (Scott, 2015, pg. 272) which is a factor often overlooked by those in remedial positions.

Legal and institutional perspectives universally exhibit an unhealthy sycophantic devotion to the quantitative forms of scientific evidence within the arena of environmental crime (Scott, 2015). An example comes from a Canadian case concerning the regions downwind of the tar sands operations (Scott, 2015). Ada, a resident of the downwind tar sands region, created a 'pollution log' in the form of a calendar that she updated daily keeping detailed notes regarding the smells, her bodily responses to the smells and anything unusual related to the tar sands operations (Scott, 2015). Updating her 'pollution log' over some time resulted in an impressive collection of what was essentially observational data pertaining to a pressing environmental issue (Scott, 2015). Ada sought to have her 'pollution log' ratified as an affidavit meaning it could be considered accurate and objectively true information reproducible as evidence within a court of law (Scott, 2015). The log was ruled, however, as "inadmissible and struck from the record" (Scott, 2015, pg. 273), and Ada was not able to submit her diligent observations in the forum that stood the greatest chance of enacting some form of change.

I argue that the outcome of those in $\mathrm{HB}$ who rallied behind the acquisition of the scientific data was stifled by the same sycophantic scientific devotion that provided justification for striking Ada's 'pollution logs' from legal proceedings in Canada. What is particularly nefarious is the fact that the friends of $\mathrm{HB}$ did not conduct the tests themselves, but commissioned the assistance of a professional scientific testing company that would presumably employ competent people within their respect fields of expertise. Yet despite this, the WCC still dismissed the evidence on the basis that "they do their own testing" (Jane, 2020). It is awfully convenient that WCC can have a monopoly on the data pertaining to the HB contamination and that they are also the institution that would be held responsible for the environmental situation. It would seem that making the same institution 
the arbiter of what information can be considered legitimate, information that could potentially be used as the basis for litigation against said institution, allows for an avoidance of accountability and responsibility. This is one of the organizational rewards, the avoidance of accountability, that is created by the dismissal of unsettling information and constitutes a case if strategic ignorance (McGoey, 2012, 2019). The environmental situation in HB in its unchanged state is therefore a partial symptom of institutional self-regulation that provides entities like WCC with the autonomy that allows them to dismiss scientific claims and findings that might indict them.

\section{Inadequacies of the Regulatory Standard}

The present research's scientific tests only begin to become impactful when compared to relevant standards set by the respective authorities. There are two issues of significance concerning the ANZECC fresh and marine water contaminate guidelines. The first is the lack of data concerning the actual trigger values themselves (see appendix XII). For a vast majority of the cells where the contaminate trigger values are usually located is instead the acronym 'ID' which stands for 'insufficient data' (ANZECC, 2000).

Without standard values, comparison becomes impossible. Take, for example, the Lanthanum result that can be found under appendicle III. The results show $8.5 \mathrm{ugL}^{1}$ of Lanthanum was present within the sample taken. Lanthanum has the potential to be acutely toxic to humans and to have antimicrobial properties (Barry \& Meehan, 2000). Yet despite this well-documented toxicology there remains no environmental trigger limit for Lanthanum in the ANZECC. This was case for the majority of tested contaminates as shown in the appendices, including: strontium, rubidium, phosphorous, magnesium, and sodium (ANZECC, 2000). Many of these substances have been prolifically used throughout a wide range of industry applications since the post WWII period thereby increasing the chance that those substances are present within materials buried in the landfill (PubChem, 2020d).

The organic contaminate tests conducted by the current research can be found under the appendicle XIII. The tests found the presence of toxic organic compounds from the HB outfall including: Oleamide, Butyric Anhydride, Sulfurous Acid, and Dicyclohexyl phthalate (DCHP). Dicyclohexyl phthalate, which is primarily used to increase the flexibility of plastics, is classified as both a health hazard and as an irritant by the Globally Harmonized System of Classification and Labelling of Chemicals or GHS (PubChem, 2020f). Due to the 
compound's longstanding manufacturing usage DCHP and other phthalates are found ubiquitously in environments near present or historic landfills. An example of this occurred in 1976 when DCHP was detected in the water aquifer underneath an unrestricted Oklahoma landfill thereby illustrating the substances' pervasive nature in breaching the landfill boundaries and contaminating the nearby environments as consequence of their extensive use within manufacturing processes (PubChem, 2020f). The substance has also been shown to cause allergic skin reactions, skin rashes, eye irritations and is known to be acutely toxic to small and unborn children (PubChem, 2020f). Recall from the previous chapter that Graeme has seen a young child playing in the HB outfall where these tests were conducted. This means that the child Graeme saw was probably exposed to DCHP and being a small child means an increased chance for health complications post-exposure. And, like for the non-organic metalloid testing, the trigger values for DCHP, Oleamide, Butyric Anhydride and Sulfurous in addition to all the organic compounds tested were not found in the ANZECC guidelines (ANZECC, 2000). Despite the functional limitations of documents like the ANZECC contaminate trigger guidelines, they can potentially become a source of scientific leverage that environmental victims can use to challenge regulators and their remedial inaction.

The pertinent point here however is that critical information pertaining to environmental safety and personal wellbeing is difficult to access (Shriver et al. 2019). Regulatory procedures eventually grind away the motivations of those who would seek this information out (Shriver et al. 2019). The bar for admissible evidence is also set extraordinarily high. Victims become suspended in a state of uncertainty, or worn down by the enormity of transforming their complex experiences into tidy containers of admissible proof (Trundle, 2020).

This restriction and constraining of the critical information environmental victims need in order to substantiate their experiences further accentuates the development of the agnotological landscape surrounding HB. Erecting barriers to relevant information allows opportunities for alter-narratives to be disseminated, potentially tempting those in search of answers and acknowledgement to embrace these other narratives. A rigid set of informational stipulations also constrains the inclusion of victims' experiences within procedural forums nullifying both the severity of the issue and the human experience of it. 
This is how an inadequate and underdeveloped yet vitally important document with regard to establishing objective environmental harm can become agnotological in function.

\section{Treadmill of Law Protecting the Treadmill of Production}

The discussion will now turn to the 'discharge orders' issued by the Greater Wellington Regional Council (GWRC) which is given legislative authority by NZ's Resource Management Act (RMA) 1991. The RMA is the overarching environmental statute law in NZ, providing clear regulations surrounding sustainable use and protection of the nation's environments (RMA, 1991). The RMA emphasizes 'sustainable management' of NZ's natural environment, which is defined within the Act as "managing the use, development, and protection of natural and physical resource in a way, or at a rate, which enables people and communities to provide for their social, economic and cultural well-being and or their health and safety" (RMA, 1991, pg. 63). It goes on to state that in addition to promoting the sustainable management of NZ's natural and physical resources while "avoiding, remedying, or mitigating any adverse effects of activities on the environment" (RMA, 1991, pg. 63).

Prima facie it would appear the RMA is totally orientated toward protecting the environment with its focus towards on 'sustainable management'. It is also worthwhile to note the sheer scale of the RMA as a piece of legislation as in its entirety stretches over 800 pages in length (RMA, 1991). It would be logical to assume therefore that NZ's environment is protected by a thick web of statutory legislation that clearly lays out the penalties for contravening the RMA's aim of sustainable management. Yet the RMA also creates opportunities to perpetuate instances of environmental harm, such as that in HB. Through the devolving of power to local authorities, the RMA allows powerful corporations and institutions to legalize specific forms of environmental damage thereby freeing them from any potential criminal liability under the statute (RMA, 1991).

The prime example of one the these 'legal devices' can be found under section 15 subsection (d) of the RMA titled 'discharges' (RMA, 1991). Subsections (a) and (b) make it explicitly clear that any form of contaminate discharge into any body of water will constitute a breach of the Act and could be used as an actionable offense in a court of law (RMA, 1991). This means that the residents of Houghton Bay would only need to show that the contents of the outfall contaminating the bay can be considered 'contaminates' per the interpretation section within the Act. There, a contaminant "includes any substance 
(including gasses, odorous compounds, liquids, solids, microorganisms) or energy (excluding noise) or heat, that either by itself or in combination with the same, similar or other substances, energy, or heat that (a) when discharged into water changes or is likely to change the physical, chemical or biological condition of water" (RMA, 1991, pg. 36). Part (b) of the interpretation is the same except for this addition at the beginning which states "when discharged onto or into land or into air" (RMA, 1991, pg. 36) and the phrase "of the land, or air onto or into which it is discharged" (RMA, 1991, pg. 36).

These are comprehensive definitions that seem to possess the legal gamut to include the wide range of different adverse environmental circumstances as an effective piece of environmental legislation ought to do. These definitions appear to fit the leachate and gas pollution occurring within in Houghton Bay rather snuggly in fact. All that remains is for this information to be presented in a legal forum. However, section 15 subsection (d) states "unless the discharge is expressly allowed by a national environmental standard or other regulation, a rule in a regional plan as well as a rule in a proposed regional for the same region (if there is one), or a resource consent" (RMA, 1991, pg. 75). A company or institution simply has to apply for a resource consent application in conjunction with a discharge order that pertains to the situation (i.e. water, land or air discharge) and upon approval of said consent will have no fear of legal indictment from the RMA upon discharging contaminates into the environment. The existence of such legal provisions are nothing short of glorified 'get out of jail free' cards, providing those in positions of power with a means to circumvent the intents and purposes of legislation to protect the environment.

The HB outfall operates under one of four resource consents provided by the GWRC to WCC that grants WCC what is essentially legal immunity from toxic discharges (WCC \& Wellington Water, 2018). In this respect, then, the primary function of the RMA is subverted by its own circular legal mechanisms. Ultimately the RMA offers little in the way of recourse for addressing environmental contamination in HB.

To the Eco-Marxist this is unsurprising as the law is little more than a tool used to protect the accumulated capital of corporations and institutions (Giddens, 1971; Benton, 1996; Foster, 2015). Lynch, Stretesky and Long (2018) argue that the processes of production responsible for corrupting the sustainability of the earth's ecosystems (the ToP) are simultaneously protected by the vast array of legal frameworks (ToL) which are supposedly aimed at combating environmental harm and reducing consumption when in 
reality the ToLs protect the ToPs (Lynch, Stretesky \& Long, 2018). Instead of the rigorous binding environmentally conscience legislation it purports to be, the RMA offers a veneer of environmental sustainability that serves as a façade for capital accumulation. In this vein, it comes as little surprise that the RMA 1991 and Conservation Act 1987 both incorporate legal mechanisms that allow successful capital accumulators the opportunity to avoid legislative lability in the form of 'resources consents' and with regard to the present study, resource consents in the form of discharge orders (RMA, 1991; Conservation Act, 1987).

The flimsy execution of environmental legislation such as the RMA ultimately contributes to the ainigmological, agnotological landscape that afflicts HB. The RMA contributes to this landscape of confusion by having the self-confessed purpose of protecting the sustainability of NZ's environment and those who would use it while it also provides avenues for those who should be held responsible to avoid criminal liability. The RMA is not the only source, however.

\section{Agnotology and Pollution}

The first and most glaring example of agnosis, distinguished from ainigmology by an emphasis on the construction and publication of false information, comes from the documents formulated predominately by WCC, GWRC and Wellington Water (Croissant, 2014; Pinto, 2015; Proctor, 2008; Stanley \& Mihaere, 2018; Stone, 2013, 2014). The previously cited 'annual discharge consent report' unequivocally demonstrates the manufactured inaccuracies espoused by regulators that has had the effect of confusing the informational landscape of HB. The report was filed in 2018. The first example of propagating agnosis, reads: "leachate (contaminates) from the close landfill staining the sand and the water at Houghton Bay beach (this is now eliminated)" (WCC \& Wellington Water, 2018, pg. 120). Yet the stained sand and water have not been eliminated and it is utterly baffling to read such a verifiably incorrect statement concerning this environmental situation be made by the institutions charged with monitoring and solving it. How can the two institutions that ought to the most involved and committed in solving this situation be so far removed from the current reality and state of contamination in the field? The answer is agnotological in nature. Through capitalising on their institutional monopoly over environmental assessment within $\mathrm{HB}, \mathrm{WCC}$ and GWRC are able to skew and manipulate their own monitoring methodologies thereby providing contrived expertise justification for 
agnotological statements like the one above (McGoey, 2019). This production of agnosis helps protect WCC and GWRC by alleviating the need for any admission of responsibility and culpability. This also provides WCC and GWRC with a source of justification to refute contrary scientific information regarding the outfall contamination that may potentially highlight the scientific inadequacy of their own contamination monitoring.

The falseness of this claim can be illustrated with other information sources that directly contradict it. While all interviewees commented on the leachate contamination within the bay, some commented directly on the unsavory colouration of the sand and water, issues that according WCC and Wellington Water were entirely remedied two years ago. They are as follows:

“...particularly after a dry spell, you'll get a big brown stain" (Mathew, 2019), "I don't swim in the Winter and that's of course when you get most the leachate and stuff coming out so." (Sam, 2019)

"...what comes out of the pipe [Houghton Bay outfall] has always concerned me... when it's the middle of summer and it's really dry and that sand and the dust is blowing around with it being that orange colour." (David \& Mary, 2019)

That interviewees made direct references to the discolouration of the sand and the water due to the leachate contamination from the landfill demonstrates the false nature of WCC and Wellington Water's claim that these issues have been "eliminated".

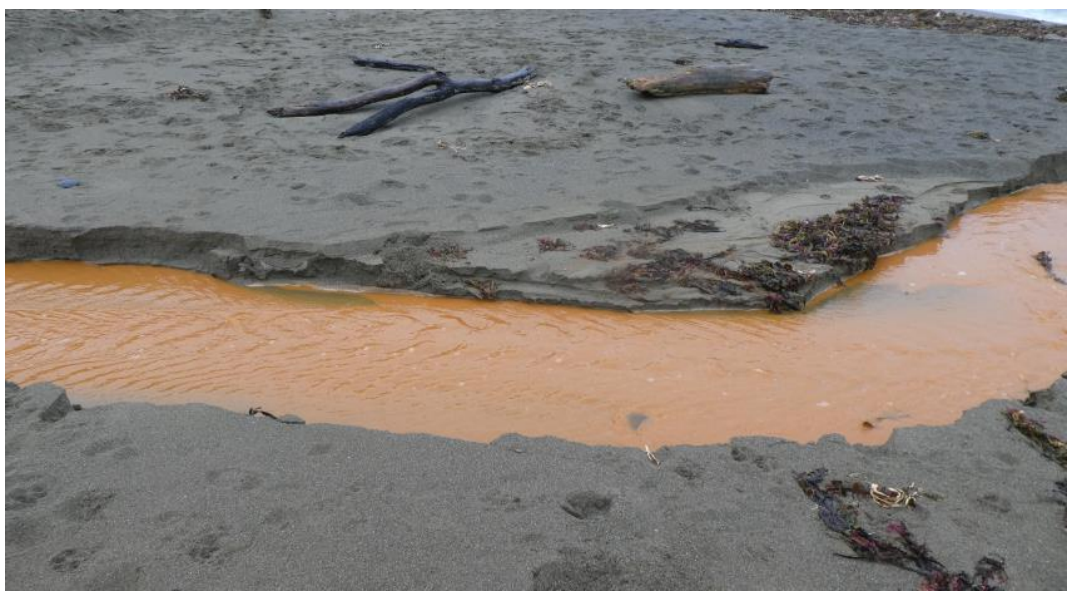

Figure VI: Leachate flowing from the outfall across $H B$ beach 
The photo in Fig VI accurately captures the extent of the discolouration that periodically occurs due to the landfill contamination. The photo is electronically dated as being taken during the month of August 2019, an entire year after the annual stormwater discharge report was submitted claiming to have 'eliminated' the discolouration of the land and water. The images of the stream and orange coloured sand presented in the previous chapter were also taken in August 2019. All three images speak for themselves. The scientific tests commissioned for this research (in August of 2019) showed elevated levels of copper (447ugL ${ }^{-1)}$, zinc $\left(482 \mathrm{ugL}^{-1}\right)$, lead $\left(28.2 \mathrm{ugL}^{-1}\right)$ and a cadmium level of $\left(0.43 \mathrm{ugL}^{-1}\right)$ in addition to a plethora of others (See appendix XIII).

From interviewee testimonials, and visual and scientific evidence, it is almost unfathomable that an institution charged with protecting the community might engage in espousing verifiably incorrect information (WCC \& Wellington Water, 2018). I argue this is a premeditated attempt by WCC and Wellington Water to confuse and obfuscate the gravity of the pollution and thereby undercut any attempts to establish capability between the council entities and consequences of the pollution. Stating the problem has been eliminated also helps to alleviate potential culpability and responsibility. Wellington City Council and Wellington Water retain the option to claim plausible deniability with regard to future instances of contamination.

'Apparently fallacious' statements regarding the noxious landfill gases have also been published and disseminated by WCC and Wellington Water. The 'Houghton Bay Storm Water Management Treatment Options 2013' reads, "It has been noted that the leachate contaminated storm water discharges to the receiving water only during extreme wet weather conditions" (WCC and Wellington Water, 2013, pg. 1). Interviewees in this research purported the exact opposite case. Graeme, for example, said:

"There shouldn't be any pressure on that valve whatsoever but the fact is, even in the middle of summer there is still water trickling down the beach." (Graeme, 2019)

Bob also implied its constant presence in stating: 
"But what I don't let them [his kids] do is play in that stream on the beach, I always keep them away from that, my dogs as well...if something smells like that the you probably don't want to be drinking it." (Bob, 2019)

Similar references to the constant flow of the contamination were also made by David and Mary, who, like Bob, referred to a 'stream':

"...the kids...they often want to play in that [the outfall flow] because it's kind of a little stream." (David \& Mary, 2019)

In addition, the photo below in Fig. VII visually depicts the presence of the flow during what is clearly a dry weather period, as illustrated by the blue skies, sun and dry sand. Nothing that could be considered an 'extreme wet weather event' is depicted below.

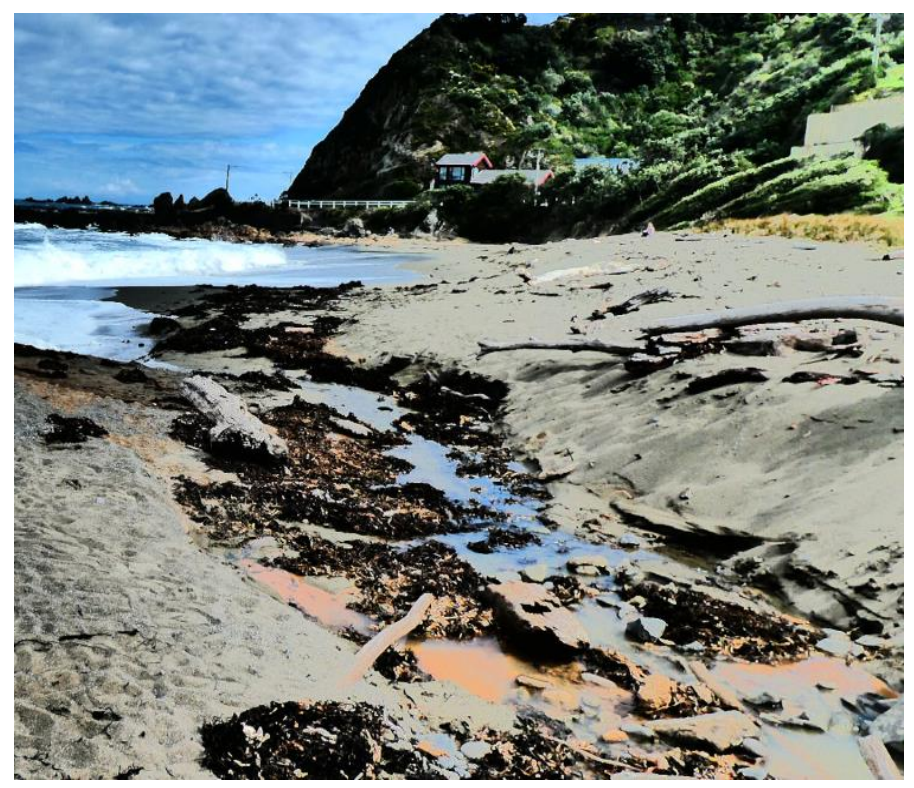

Figure VII: The outflow stream flowing on a dry, sunny day

Therefore, qualitative and visual data give evidence that the statement made by WCC and Wellington Waters that the contamination only occurs during 'extreme wet weather event's' is both inaccurate and incorrect.

It has been well documented within agnotological literature that the production of ignorance helps to justify the continuation of inefficient and inadequate management procedures (Barton, Davis \& White, 2018; McGoey, 2012). If WCC and Wellington Water 
propagate their agnosis to a point where the manufactured narrative is accepted by the residents, this will justify WCC's and Wellington Water's management oriented approach to the contamination rather than a solution orientated approach.

\section{Ainigmology and Pollution}

Complementing the overt agnosis contained within the WCC and Wellington Water documentation regarding the HB landfill, are the subtler more invisible forms of agnosis, bordering on ainigmology, that help to confuse contamination attention and divert thoughts and notions of attributing culpability towards any regulatory institution. What follows is an examination of the subtler forms of ainigmology currently impairing attentions, concerns and thoughts of accountability regarding the landfill contamination. I shall argue that a lack of adequate signage notifying people of the pollution within the area, and the omission of references to the existence of the landfill in 'Land Information Memorandums' (LIM reports) are two key manifestations of ainigmological information that, in addition to the forms of direct agnosis, confuse information regarding the pollution potentially leaving residents and others uniformed, unaware and unknowledgeable of the harms they might encounter.

The distinguishing elements between the two concepts are as follows: Agnosis is typically discussed with an emphasis on both the 'creation' or 'manufacture' of verifiably incorrect 'falsehoods' or 'ignorance's' that are then disseminated within a wider population (Proctor, 2008; Pinto, 2015; Stanley \& Mihaere, 2018). Ainigmology differs from Agnosis with regard to the impact of the disseminated falsehoods, suggesting that the impact of widespread falsehoods does not solely create an untrue narrative or set of falsehoods within society, but can just create confusion and obscure truth (Stone, 2013, 2014). Although this distinction is important, the two concepts are very closely related and there is a noticeable use of similar language in discussions concerning both ideas. For the purposes of this research, the verifiably incorrect statements published by WCC and Wellington Waters in their discharge reports examined previously clearly constitute a case of agnosis as the inaccuracies were formally published in order for those specific falsehoods to become the official narrative concerning the area. The lack of adequate signage and omission of the landfill from LIM reports do not espouse a counter-narrative as there is no manufactured ignorance being propagated in this situation where information is absent. It is the omission of information, rather than the production of false information that compels these 
substantive points of inquiry be included within the realm of ainigmology rather than agnotology.

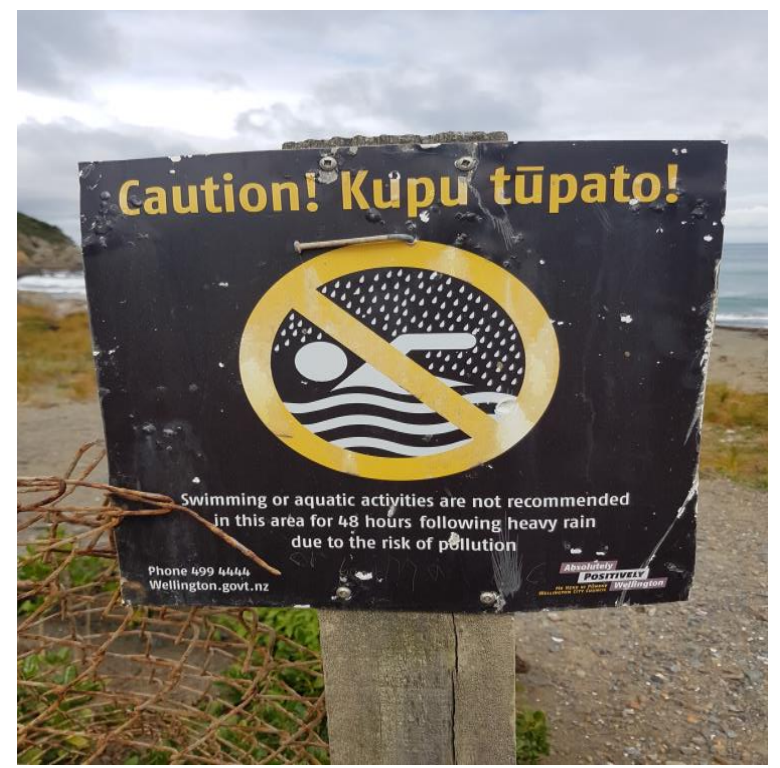

Figure VIII: Caution sign at HB beach

During the initial stages of the research, I spent much time perusing the area within HB observing the visual information available that might possibly indicate the existence of the landfill and any possible implications that it may have on my health and safety. I only managed to successfully locate one sign at the carpark on HB beach that indirectly alluded to the contamination issues within the area (see Fig. VIII). One sign for the entire area that also implies that pollutants are only present in the area after a 'heavy rainfall' event, something that from the previous example of agnosis to be verifiably incorrect. Note how the sign avoids any reference or mention of the landfill, the leachate, the gas, the contaminated outfall stream or the contaminates present within the contaminated water. The sign has also been clearly neglected with rust firmly embedded within the metal work with the paint starting to peel away. The signage available is poorly maintained and overly neglected by WCC that are responsible for its maintenance.

The sign fails to adequately represent or convey the potential harms or risks associated with exposure to the leachate and gas contamination. It draws no attention to the contaminated state of the outfall stream, the section of the beach most visibly contaminated with a near constant flow of orange-tinged water and stained sand, where the risk of exposure is highest. Instead the signs simply blanket the entire area as one that 
may be polluted making no indication that this small highly contaminated section of the area should be avoided. One of the interviewees made specific reference to this peculiarity:

"I think there should be a really big sign saying that kids shouldn't play in it and stuff." (David, 2019)

The sign's use of the phrase 'not recommended' also fails to accurately convey the severity of potential contamination exposure and is closer to a suggestion than something more imperative. Wellington City Council evidently do not deem the contamination occurring within the area to be of sufficient risk to people's health and therefore are not prepared to adopt a more stringent approach in restricting people's engagement with the environment.

The sign is also located at the bottom of the valley and appears to be one of only two within the entire area. The lack of signage was a point discussed by the interviewees, who stated:

"...they should at least have a sign or something!" (Stella, 2019)

"...the only signs I am aware of are the dangerous swimming." (Mathew, 2019)

"...there is no discretionary signage there to inform people about the fact that the valley was a landfill." (Sam, 2019)

"...the way I see it is that sign is there because you aren't meant to take anything from a marine reserve...So the message for me is about not taking rather than pollutants from this stream." (Charlie, 2019)

There is an element of absurdity with regard to something as physically large, corporally invasive and potentially harmful as a landfill that somehow warrants no notification other than two measly neglected signs. Interestingly, the Department of Conservation or (DoC) have erected ample signage throughout the area notifying the public of the pest control work being conducted within $\mathrm{HB}$ as pictured in Fig. IX. 


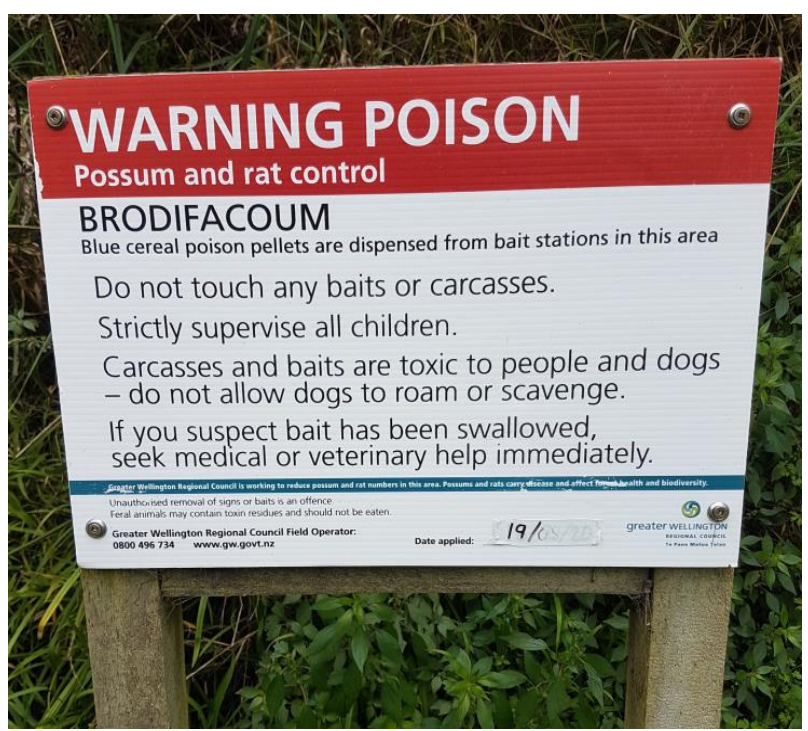

Figure IX: DoC's pest control signage in $H B$

These signs are posted at the bottom of the bush reserve that straddles the west bank of the valley. They overtly warn passersby of Brodifacoum's toxicology while also stating who one should contact in a situation where some of the poison is ingested, either by an animal or a human. In addition to this information, the sign is also dated at the bottom left hand corner thereby conveying to those who read it that it is actively maintained by those who placed it there. The level of information successfully conveyed in this pest control sign above greatly surpasses the informative quality of the pollution sign at HB beach. This is despite the fact that the risk of exposure to pollution posed by the landfill is arguably greater than that of ingesting Brodifacoum. Yet the only signs that can be seen in the steplike valley refer to the pest control and there is absolutely no signage regarding either the leachate or gas contamination. This lack of landfill risk-related signage compounded with the proliferation of Brodifacoum signage, is potentially confusing for those living within the area as attentions are disproportionally directed towards noticing the visual cues regarding Brodifacoum, while omission of landfill related signage prevents attention from being direct towards the landfill's capacity for harm. This constitutes a form of ainigmology as attention that should be directed towards the risks associated with the landfill are confused and obfuscated by both the general lack of landfill signage and the disproportionate level of pest control signage. 
Since writing the above passage, there has been a development within HB. On the $19^{\text {th }}$ of August 2020, two news stories were published online in response to a particularly nasty spout of the leachate contamination (Campbell, 2020; Quinlivin, 2020). According to anecdotal reports from people living near the area, a swarm of WCC and Wellington Water equipment, vehicles and maintenance workers were concentrated at the outfall for a couple of days following the spout of contamination.

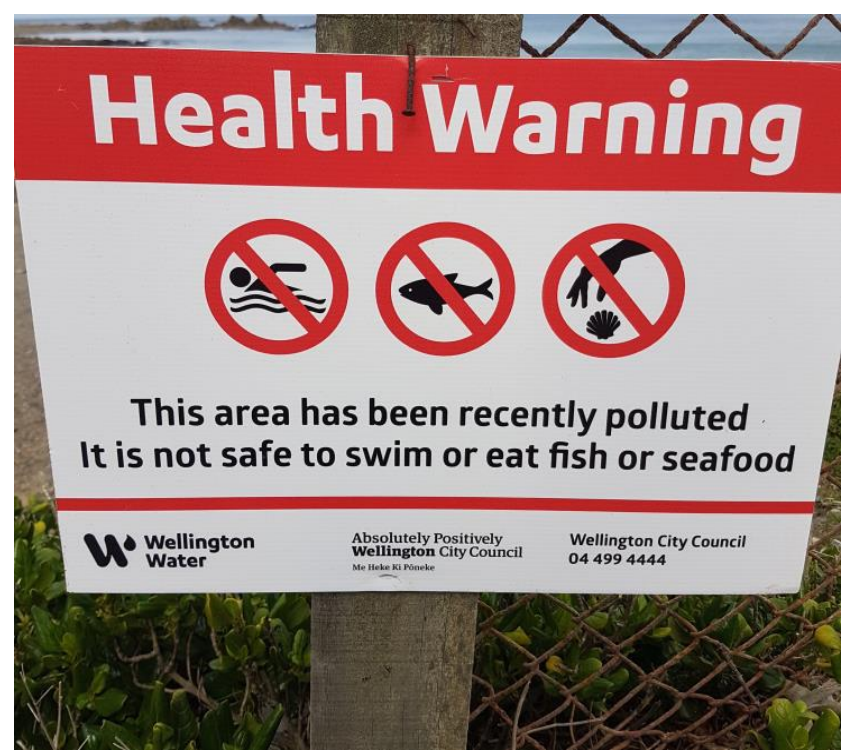

Figure $X$ : New temporary warning sign in $H B$

There has since been a new sign erected at HB beach warning people of the pollution pictured here in Fig. X. This sign employs more appropriate terminology for conveying the potential risks of the landfill than its older counterpart, in using phrases such as 'it is not safe' and 'health warning' that leaves less room for interpretation and confusion concerning the potential health implications of the landfill. However, this sign is transient in nature as it only conveys a temporary warming illustrated by the use of the word 'recently' with regard to the particularly nasty contamination spout which precipitated the media coverage. This leads one to safely assume that without this particularly heinous instance of leachate pollution occurring and without the ensuing media attention, WCC and Wellington Water would not have implemented the sign.

Another example of how the omission of information can contribute to an ainigmological, agnotological informational landscape comes from the failure to include reference to the landfill in resident's LIM reports. A LIM or (Land Information Memorandum) is a paid service offered by WCC designed to provide people with a 
'comprehensive report' of either a commercial or residential property, typically used by people either buying or selling land (WCC, 2020). According to the WCC website, a LIM report should include rates information, the presence of any underlying storm water or sewage infrastructure but most importantly, is meant to include "historical and current information" (WCC, 2020, para. 1) with regard to the property and makes specific reference to "any special feature of the land Council knows about including the downhill movement, gradual sinking or wearing away of any land, the falling or rock or earth, flooding of any type and possible contamination or hazardous substances" (WCC, 2020, para. 2). I draw explicit attention to the final phrase of the paragraph which states 'possible contamination' and 'hazardous substances'.

These phrases indicate that if one was to purchase a section of land in proximity to the old HB landfill then mention of the gas and leachate contamination would definitely be included in a LIM report. This inclusion would be simply because the manifestations of environmental harm occurring within HB would certainly qualify as 'hazardous substances', and from the experiential testimonies such as Derek and Graeme's, instances of 'possible contamination' have been known to occur. One would think that obviously the LIM reports for sections in proximity to the landfill would mention the area's prolific history of contamination. This assertion, while logical, would be incorrect. When interviewees were asked about the inclusion on landfill references with LIM reports, those who could remember commissioning a LIM report said there was no mention of the landfill or the contamination:

"We didn't know about it [the landfill or its contamination] when we bought the house." (Derek, 2019)

"...we had to get tick-boxes and LIM reports to get our own pieces of mind but no, nothing for sure as that goes." (Charlie, 2019)

"No, we did pay for a LIM Report and all that it picked up was some kind of shady boundary that had stuck up so it literally didn't pick up anything about environmental hazards or the dump..." (Stella, 2019) 
Despite proclaiming to include reference to 'hazardous substances' and 'possible contamination' on the WCC website, any mention of the landfill and its associated complications were not included in the LIM reports for houses of the interviewees. Perhaps the most poignant example comes from Derek, someone that has vents in their backyard that allow landfill gases to directly emanate onto their property and still, there was no mention of this made by either then real-estate corporation or WCC in the form of a LIM report. Such blatant omission of important information contributes to the informational confusion afflicting the area of $\mathrm{HB}$ inhibiting acknowledgement of the contamination and thereby stifling any link of causality the residents might draw between the harms of the landfill contamination and those who ought to be held responsible. For something as verifiably toxic, potentially harmful and geographically imposing as a landfill the size of a valley to be somehow omitted from such a report is nothing short of deceptive. Such an egregious omission suggests that WCC are deliberately and covertly redacting mention of the landfill in LIM reports so as to not dissuade potential buyers from purchasing within the area.

It is the omission of key information from sources that should discuss the landfill, such as the lack of general signage, the proliferation of non-landfill related signage and the disregard of the landfill from LIM reports that work together in tandem creating an ainigmological environment surrounding the area of HB. This ainigmological confusion is then compounded by the direct statements of agnosis made by institutions such as WCC and Wellington Water, entrenching the already developed confusion concerning the landfill and its potential for harm via pollution exposure. Underdeveloped technical documents sorely needed by environmental victims to objectively prove their suffering within forums plagued by a devotion to quantitative scientific evidence remain elusive, further stifling and confusing the efforts of those motivated to attempt some form of meaningful change (Scott, 2016; Trundle, 2020). All while environmental legislation offers a thin veneer of sustainable management as it provides those who rapaciously profiteered from the process which precipitated the landfill's existence with an avenue to escape legal responsibility. It is the confluence of the above factors that when combined, confuse and obfuscate the concerns of environmental victims, frustrate the accommodation of these experiences within the legal system and finally provides the institutions most likely to be held accountable with plausible deniability and the ability to adopt a strategy of inadequate management rather 
than a strategy of permanent solution. The issue of historical pollution is thereby compounded by contemporary forms of agnosis and ainigmology. In fact, it is the contemporary nature of these agnotological and ainigmological processes that offer one answer to question at the centre of studies of historical pollution. That will be discussed in the conclusion, next. 


\section{Chapter Seven: Concluding Discussions}

Who is responsible for the historical pollution in HB? Before addressing this question, I will briefly recount the conceptual journey and the conclusions reached in the discussions across Chapters Four, Five and Six.

Chapter Four sought to examine the reasons people were attracted to HB despite the pollution occurring there. It was found that there existed an 'idyllic construction' of the area within the minds of the residents. This constructed interpretation of reality is a result of a combination of factors that work in tandem to manufacture the idyllic construction. This begins with the internalisation of 'factors of environmental attraction', which are the beautiful and natural aspects of an environment, that in a NZ context include but are not strictly limited to native bush, native wildlife (both terrestrial and aquatic), natural coastlines, a rural-esque school and a general bucolic typography. Houghton Bay's unique geographical location offering both the conveniences of an urban setting and a country aesthetic contribute to this idyllic construction. These factors of environmental attraction are then romanticised and marketed by corporations and government subsidiaries which primarily focus on advertising those factors of environmental attraction within the wider community. The HVS also contributes the idyllic construction as the school's unique geolocation within an urban setting accrues a sense of prestige and desirability amongst parents that in-turn reinforces the idyllic construction of the area. NZ's 'clean and green' marketing strategy acts as the social and cultural binding agent which solidifies the idyllic construction of HB within the minds of residents.

Chapter Five sought to examine how the idyllic construction of HB can be disturbed through encountering manifestations of landfill pollution, primarily the leachate and gas contamination. The chapter sought to investigate how the idyllic construction impacts the acknowledgement of contamination and following, whether the idyllic construction inhibits the amendment of personal behaviors regarding the contamination. The selected interviewee experiences of Derek, Graeme, Bob and Sam illustrated how responses were not consistent within the sample. It was found that interviewees were harmed across each of the five recognised avenues of environmental victimisation: health, economic, social, cultural and environmental security (Hall, 2013; Skinnider, 2011) confirming that instances 
of historical pollution in an urban setting share commonalities with other environmental victims.

The 'scale of contamination awareness' was created to represent the impact that experiencing the landfill pollution has on the idyllic construction. For most interviewees, encountering pollution destabilized the idyllic construction. Bob, however, despite being aware of the presence of leachate contaminates within the bay, temporarily suspended his awareness and contamination acknowledgment in favour of engaging in recreational surfing. Bob made no attempt to deny the presence of the pollution or even the possibility of health complications from exposure to it. His desire to surf simply came first. Bob's encounter with the pollution and his reluctance to amend his personal behaviour illustrates that the idyllic construction may be employed to one's benefit if and when harmful pollution becomes inconvenient. Bob slides toward the left region of the spectrum in such instances.

Graeme's and Derek's experiences illustrated the social and cultural dimensions of environmental victimisation. Upon encountering the pollution, Graeme and Derek amended their personal behaviours while remaining strongly tied to the factors of environmental attraction. Despite their open appreciation for HB's factors of environmental attraction, the idyllic construction was not of significant strength to subvert their concerns regarding the pollution. Sam, however, displayed much more movement and variance along the spectrum. Upon encountering the pollution, Sam oscillated between states of critical awareness regarding the contamination and favorable appreciation towards the factors of environmental attraction. As the latter happened, the idyllic construction appeared to behave as a neutralizing agent absolving his potential acknowledgment towards the implications of pollution exposure. I conclude, then, that the idyllic construction can both temper and neutralize concerns regarding the implications of the pollution, alternatively, it can be actively dipped into, and out again, when it suits.

Chapter Six examined the interviewee experience of engaging with institutions, such as WCC, GWRC and Wellington Water, and identified the agnotological and ainigmological methods employed by the aforementioned institutions to confuse and obfuscate concerns and the potential for harm that interviewees made claim to. It was found that environmental victims of historical pollution, like Jane, struggled to have their concerns 
acknowledged seriously by institutions charged with ensuring the provision of basic utilities to its constituents.

I suggested that the dismissal of victim experiences was possibly a factor behind the collectivisation of the HB community members in commissioning private scientific tests in an attempt to conform to quantitative, scientific evidence with regard to instances of environmental degradation. The information contained within the privately funded S.G.S testing illustrated the severity of the pollution entering the environment of $\mathrm{HB}$. That being so, the release and public acknowledgment of the tests had potential to incur significant criticism and other institutional consequences for WCC, GWRC and Wellington Water. I proposed that by deeming the results irrelevant, WCC, GWRC and Wellington Water employed acts of 'strategic ignorance' (McGoey, 2012, 2019) in order to counter the 'unsettling qualities' of the S.G.S tests.

This aside, another potential barrier for the residents in HB seeking accountability lay with the lack of comprehensive contamination trigger limits in the ANZECC. The incomplete data sets pertaining to the impacts of pollution found within the ANZECC makes it unnecessarily difficult for environmental victims to objectively prove their experiences of victimisation (Shriver et al. 2019). Tests, like the S.G.S, that quantitatively illustrate the potential for harm, only become relevant when compared to the established national standard found in the ANZECC. However, many of the results found within the test commissioned by the HB residents, such as Iron, Chromium (III), Methyl Mercury and Selenium (IV), have no prescribed ANZECC limits (ANZECC, 2000) thus preventing any comparison between what was found in HB and the national standard.

Nor would the RMA 1991 or the Conservation Act 1987 offer any recourse. Like the ANZECC, the RMA 1991 and Conservation Act 1987 initially look to be powerful legal tools able to provide protection to the myriad of situations in which the natural world's environment is currently under siege. Yet, despite the S.G.S. tests clearly satisfying a breach of contamination discharge according to the statutes, they are of no use to environmental victims of HB. This is because they offer capital accumulators the facility to obtain resource consents in the form of 'discharge orders', such as the one allowing the WCC and Wellington Water to let the leachate continue to seep its ugly contaminates into Houghton Bay. In this vein, the RMA 1991 and Conservation Act 1987 operate as manifestations of the ToL 
(Treadmill of laws) that serve to protect the continuation of the ToP (Treadmill of production), confusing the impact of the legislation and undermining its efficacy.

Further compounding the situation was the engagement in agnotological and ainigmological practices by GWRC, WCC and Wellington Water. It was found that these three institutions, through the publication of verifiably false information and the omission of key information regarding the landfill, sought to deliberately obscure not only the harms associated with the leachate and gas pollution, but the subsequent experiences of human victimisation incurred as a result. This research clearly demonstrated with scientific testing, photographs, and from in-depth accounts of residents living alongside the landfill, the fallacious nature of the claims made by the authorities regarding the apparent 'elimination of all sand discoloration' and the low frequency of contamination apparently restricted to 'wet weather events'. These statements evidence the agnotological inclinations of WCC, GWRC, and Wellington Water that serve to obfuscate the concerns of environmental victims and frustrate the process of formal acknowledgement and meaningful redress.

The agnotological statements are compounded by the omission of key information regarding the pollution and comprise the ainigmological confusion propagated by the three institutions. Only one sign informing people of the potential harms from pollution exposure was found within the entire area of HB. Moreover, that single sign was in a state of clear neglect and employed ambiguous language that did not fully convey the risks associated with pollution exposure. The lack of information is misleading and may mean people incur harm from interacting with the HB environment.

There was additionally a lack of information in the LIM (Land Information Memorandum) reports for housing within the area. LIM reports are used to provide a potential home buyer with comprehensive information regarding the property and typically one will include mention of any longstanding, historical issues or oddities. According to WCC themselves, LIM reports are to include reference to any 'hazardous substances' and instances of 'possible contamination' (WCC, 2020). Yet not a single interviewee that had acquired a LIM report when purchasing their property could recall any mention of the landfill, the leachate or the gas pollution. With decades of frequent pollution within the area, alongside media coverage, official reports and other documentation that unequivocally prove the existence of what should clearly constitutes a 'hazardous substance' there was still no mention of the landfill, the leachate or gasses within any LIM 
reports. The omission of this crucial information contributes to the informational confusion concerning the risks posed by the landfill on behalf of local authorities.

The final state of manufactured confusion regarding both the pollution risks and the victimisation experiences of $\mathrm{HB}$ residents is realised when each of the aforementioned agnotological and ainigmological contributors work in tandem to create a 'veil of ignorance' serving to perpetuate the continuation of this particular case of historical pollution. The inadequate signage; the omission of any landfill notification in LIM reports for property within the area; the agnotological statements from WCC and Wellington Water, all compound the ainigmological confusion. Avenues that might be of great use to environmental victims, such as the ANZECC, the RMA 1991, and the Conservation Act 1987, omit key limits; permit some polluting activities; and are written in inaccessible and overly complex language (Shriver et al. 2019; Scott, 2016; Trundle, 2020). It is the combination of these different sources of confusion that obfuscate the perception of harms associated with the HB landfill. As a result, WCC, GWRC and Wellington Water, the presiding local authorities (Natali, 2017), can claim to be 'ignorant' (McGoey, 2012, 2019), and plausibly deny any environmental issue that materializes in HB. Perhaps the greatest harm is that the confusion inhibits the official acknowledgement of environmental victim experiences within forums that stand the greatest chance to give effect to meaningful change.

My findings have important implications for the issue of historical pollution. As discussed in the literature review, the role of authorities in confusing the impacts of historical pollution is something that has been already established (Natali, 2017). This thesis has expanded on this connection through researching the exact mechanisms by which authorities can manufacture this confusion in an urban setting.

Following, this thesis also concludes that when researching instances of historical pollution, the agnotological and ainigmological bodies of literature ought to be included. Agnotology and ainigmology provide comprehensive scholarship and research concerning the generation and function of ignorance and confusion within society. Such confusion compliments the creeping nature of historical pollution as harms associated with the pollution take time to materialise, time which also provides organisations with the opportunities to develop a state of confusion and ignorance regarding that pollution. The adoption of an agnotological and ainigmological framework for research into historical pollution provides researchers with the tools necessary for determining the level at which 
local and national authorities might be obscuring an instance of historical pollution. Determining the influence of such obfuscation, and the level to which it is entrenched, is crucial before determining how the experiences of those victimised by instances of historically pollution, like those in $\mathrm{HB}$, might become formally acknowledged.

There is also something to be said of the relationship between successful confusion propagation (agnotology/ainigmology) and the notion of the metabolic rift and the alienation from nature. Capitalism confuses and obscures the natural relationship between humanity and the earth's ecosystems through characterising environmental 'withdrawals' and toxic additions as a normal and sustainable. Yet it is this capitalistic relationship to our environment that is responsible for instances like the HB legacy landfill. This relationship is far from natural, a relationship that without obfuscation would be reconsidered and reverted. This highlights a potential relationship between capitalistic environmental relations and the propagation of ainigmology and agnotology.

Returning to the question of responsibility, this thesis argues a contemporary element must be incorporated in studies of historical pollution. As discussed in the literature review, the 'historic' element of historical pollution is what inhibits the establishment of responsibility and culpability (and potential redress). Over the course of time, a myriad of different agents are employed by institutions presiding over such environmental instances and in addition to changes in bureaucratic responsibility, portfolio and evolving societal and cultural frameworks ultimately attribute the establishment of responsibility to a single actor (Natali, 2017). This thesis argues that the mechanisms of obfuscation engaged in by presiding institutions constitute the contemporary component of responsibility. Despite having no relation to the genesis of a particular instance of historical pollution, contemporary actors who engage in obscuring the harms associated with that particular instance of historical pollution should be held responsible for the harm stemming from ignorant interactions with the environment on behalf of their constituents. Presentday actors who deliberately obfuscate information regarding instances of historical pollution aid in the dismissal of environmental victims' experiences and are instrumental in allowing the continuation of victimisation. It is in this respect, a significant portion of research dedicated to understanding and solving the issue of 'historical' pollution must incorporate discussions on the 'contemporary' mechanisms used to the extent that they may confuse or dismiss the concerns of potential and actual environmental victims. It may be that, in turn, 
criminal justice systems can (and will) attribute responsibility for harm stemming from historical pollution, perhaps as acts of 'grievous bodily harm'.

Recognising a contemporary component of responsibility does introduce a confounding factor, however. Residents of polluted areas such as HB may exercise a choice to move away to escape their risk of encountering harm. They may, alternatively, find a way to live alongside it. But whether they leave or stay, residents will find themselves implicated in propagating a state of agnosis with regards to historical pollution in an urban setting. How? If they move away, they must first sell their house. Selling to receive a market value in somewhere like $\mathrm{HB}$ will require engaging in practices of obfuscating the buyer, or at least turning a blind eye as the real estate company does so on their behalf. Staying entails obfuscating by default, to those who are not yet residents but are attracted to the area, by silently assuring them through their own residency that it is a safe and enjoyable one. Future research into historical pollution might therefore consider the intersections that appear between victimisation and offending that pose to complicate the question: who is responsible? 


\section{References:}

Agency for Toxic Substances and Disease Registry. (1999). Toxicological Profile for Hydrogen Sulphide (pp. 27-98). Atlanta: US Department of Health and Human Services. Retrieved from https://www.atsdr.cdc.gov/toxprofiles/tp114.pdf

Agency for Toxic Substances and Disease Registry. (2001). Landfill Gas Primer: An Overview for Environmental Health Professionals (pp. 1-31). Atlanta: Department of Health and Human Services. Retrieved from https://www.atsdr.cdc.gov/HAC/landfill/PDFs/cover_2001_bar.pdf

Andrady, A., \& Neal, M. (2009). Applications and societal benefits of plastics. Philosophical Transactions Of The Royal Society B: Biological Sciences, 364(1526), 1977-1984. doi: $10.1098 /$ rstb.2008.0304

Australian and New Zealand Environment and Conservation Council. (2000). Australian and New Zealand Guidelines for Fresh and Marine Water Quality. Retrieved 4 August 2019, from https://www.waterquality.gov.au/anz-guidelines/resources/previousguidelines/anzecc-armcanz-2000

Auyero, J., \& Swistun, D. (2009). Flammable. New York: Oxford University Press.

Bain, C., \& Dandachi, T. (2015). "100\% Pure"? Private Governance efforts to mitigate the effects of dirty dairying on New Zealand's environment. In A. Bonanno \& L. Busch, Handbook of the International Political Economy of Agriculture and Food (pp. 4058). Edward Elgar Publishing.

Barry, M., \& Meehan, B. (2000). The acute and chronic toxicity of lanthanum to Daphnia carinata. Chemosphere, 41(10), 1669-1674. doi: 10.1016/s0045-6535(00)00091-6

Barton, A., Davis, H., \& White, H. (2018). Agnotology and the Criminological Imagination. In A. Barton \& H. Davis, Power, Ignorance and Harm (1st ed., pp. 12-35). Cham: Palgrave Macmillan. Retrieved from https://link.springer.com/book/10.1007/978-3-319-97343-2

Beirne, P. (1995). The Use and Abuse of Animals in Criminology: A Brief History and Current Review. Social Justice, 1(59), 5-31. 
Beirne, P. (1999). For a Nonspeciesist Criminology: Animal Abuse As An Object Of Study. Criminology, 37(1), 117-148. doi: 10.1111/j.1745-9125.1999.tb00481.x

Benton, T. (1996). The greening of Marxism (pp. 103-241). New York: Guilford Press.

Benton, T. (1996). The greening of Marxism (pp. 103-241). New York: Guilford Press.

Boyatzis, R. (1998). Transforming Qualitative Information: Thematic Analysis and Code Development. Thousand Oaks, California: Sage.

Braun, V., \& Clarke, V. (2006). Using thematic analysis in psychology. Qualitative Research In Psychology, 3(2), 77-101. doi: 10.1191/1478088706qp063oa

Campbell, G. (2020). 'Rank' brown plume emerges at Wellington's Houghton Bay. Retrieved 10 September 2020, from https://www.nzherald.co.nz/nz/news/article.cfm?c_id=1\&objectid=12357985

Centonze, F., \& Manacorda, S. (2017). Historical Pollution: Comparative Legal Responses to Environmental Crimes (1st ed., pp. 1-50). Springer International Publishing.

Christensen, T., Cossu, R., \& Stegmann, R. (1992). Landfilling of Waste (1st ed., pp. 17-75). London: E \& FN SPON.

Christensen, T., Cossu, R., \& Stegmann, R. (2012). Sanitary landfilling (1st ed.). London: Academic Press.

Christensen, T., Kjeldsen, P., Bjerg, P., Jensen, D., Christensen, J., \& Baun, A. et al. (2001). Biogeochemistry of landfill leachate plumes. Applied Geochemistry, 16(7-8), 659-718. doi: $10.1016 / \mathrm{s} 0883-2927(00) 00082-2$

Christie, N. (1977). Conflicts As Property. The British Journal Of Criminology, 17(1), 1-15. doi: 10.1093/oxfordjournals.bjc.a046783

Clayton, S. (2003). Environmental Identity: A Conceptual and an Operational Definition. In S. Clayton \& S. Opotow, Identity and the natural environment: The psychological significance of nature (pp. 45-65). Cambridge: MIT Press. Retrieved from https://psycnet.apa.org/record/2004-14744-003 
Cohen, S. (2001). States of Denial: Knowing about Atrocities and Suffering (1st ed., pp. 1154). Cambirdge: Polity.

Corbishley, G., Vorster, J. (2020). Houghton Valley's web. Retrieved 8 July 2020, from http://houghtonvalley.org.nz/playing/Leachate/leachate.html

Coyle, F., \& Fairweather, J. (2005). Challenging a place myth: New Zealand's clean green image meets the biotechnology revolution. Area, 37(2), 148-158. doi: 10.1111/j.14754762.2005.00617.x

Cresswell, J. (2014). Research Design; qualitative, quantitative and mixed methods approaches (4th ed., pp. 3-23). Washington, United States of America: Sage.

Creswell, J., \& Poth, C. (2018). Qualitative Inquiry and Research Design: Choosing Among Five Approaches (4th ed., pp. 1-69). United States of America, Washington DC: Sage Publications.

Croissant, J. (2014). Agnotology: Ignorance and Absence or Towards a Sociology of Things That Aren't There. Social Epistemology, 28(1), 4-25. doi: $10.1080 / 02691728.2013 .862880$

Crotty, M. (1998). The foundations of social research : Meaning and perspective in the research process. St Leonards, NSW: Allen \& Unwin.

Curran, D. (2018). The Organized Irresponsibility Principle and Risk Arbitrage. Critical Criminology, 26(4), 595-610. doi: 10.1007/s10612-018-9415-x

Department of Conservation (DoC). (2015). Taputeranga Marine Reserve. Retrieved 4 September 2020, from https://www.doc.govt.nz/parks-and-recreation/places-togo/wellington-kapiti/places/taputeranga-marine-reserve/

Derrida, J. (1993). Spectres of Marx (pp. 1-60). Abingdon, Oxon: Routledge.

Dew, K. (1999). National identity and controversy: New Zealand's clean green image and pentachlorophenol. Health \& Place, 5(1), 45-57. doi: 10.1016/s1353-8292(98)00040-9 
Donnelly, J., Scarpino, P., \& Brunner, D. (1982). The Survival of Bacterial Indicators in Lysimeters and Landfills. Water Science And Technology, 14(9-11), 1558-1559. doi: 10.2166/wst.1982.0202

Fischer, F. (2000). Citizens, Experts, and the Environment. Durham NC: Duke University Press Books.

Foster, J. (1999). The Vulnerable Planet: A Short Economic History of the Environment. New York, USA: Monthly Review Press.

Foster, J. (2000). Marx's Ecology: Materialism and Nature (p. 158). New York: Monthly Review Press.

Foster, J. (2015). Marxism and Ecology: Common Fonts of a Great Transition. Monthly Review, 67(7), 1. doi: 10.14452/mr-067-07-2015-11_1

Foster, J., Clark, B., \& York, R. (2010). The ecological rift. New York: Monthly Review Press.

Giddens, A. (1971). Capitalism and modern social theory. Cambridge, Angleterre: Cambridge University Press.

Hall, M. (2013). Victims of Environmental Harm: Rights, Recognition and Redress under National and International Law (1st ed., pp. 1-72). Abingdon Oxon: Routledge.

Hall, M. (2017). Exploring the cultural dimensions of environmental victimization. Palgrave Communications, 3(1), 1-10. doi: 10.1057/palcomms.2017.76

Harrell, M., \& Bradley, M. (2009). Data Collection Methods: Semi Structured Interviews and Focus Groups. Santa Monica, California: RAND National Defense Research Institute.

Houghton Valley Progressive Association. (2020). Houghton Valley (the Valley of the Wild) I Wellington South Coast. Retrieved 2 September 2020, from http://www.houghtonvalley.org.nz/forum/

Houghton Valley School. (2019). Houghton Valley School (HVS). Retrieved 4 August 2020, from https://houghton.school.nz/ 
Jaram, D. (2009). Joe Harawira: the emergence of a mātauranga Māori environmentalist. MAI Review, (1), 1-16. doi: https://www.dioxinnz.com/swap/pdf/mai-rpt-2009-swap.pdf

Jayaratne, R., Williamson, B., Idris, I., Wood, N., Bhula, J., \& Wilson, A. (2015). Our Capital Beaches - Effect of Stormwater Discharges (pp. 1,2,5 -7). Wellington: Water New Zealand Organisation. Retrieved from https://www.waternz.org.nz/Attachment?Action=Download\&Attachment_id=685 Jayaratne, R., Williamson, B., Idris, I., Wood, N., Bhula, J., \& Wilson, A. (2015). Our Capital Beaches, Effects of Stormwater Discharges. Retrieved 29 May 2019, from https://www.waternz.org.nz/Attachment?Action=Download\&Attachment_id=685

Jordan, J. (2012). Silencing Rape, Silencing Women. In J. Brown \& S. Walklate, The Handbook on Sexual Violence (1st ed., pp. 253-287). Spinger International. Retrieved from https://ebookcentral-proquestcom.helicon.vuw.ac.nz/lib/vuw/reader.action?doclD=957739

Lievens, M. (2010). Towards an Eco-Marxism. Radical Philosophy Review, 13(1), 1-17. doi: 10.5840/radphilrev20101312

Lisk, D. (1991). Environmental effects of landfills. Science Of The Total Environment, 100(1), 415-468. doi: 10.1016/0048-9697(91)90387-t

Lynch, M. (1990). The greening of criminology: A perspective on the 1990s. The Critical Criminologist, 2(3), 1-12.

Lynch, M. (2019). Green Criminology and Environmental Crime: Criminology That Matters in the Age of Global Ecological Collapse. Journal Of White Collar And Corporate Crime, 1(1), 50-61. doi: 10.1177/2631309×19876930

Lynch, M., \& Stretesky, P. (2014). Exploring Green Criminology (1st ed., pp. 1-28, 51-102). Farnham: Ashgate Publishing Limited.

Lynch, M., Stretesky, P., \& Long, M. (2018). The Treadmill of Production and the Treadmill of Law: Propositions for Analyzing Law, Ecological Disorganization and Crime. Capitalism Nature Socialism, 31(1), 107-122. doi: 10.1080/10455752.2018.1545241 
Maguire, M. (1991). The Needs and Rights of Victims of Crime. Crime And Justice, 14, 363433. doi: $10.1086 / 449190$

Manzo, L. (2005). For better or worse: Exploring multiple dimensions of place meaning. Journal Of Environmental Psychology, 25(1), 67-86. doi: 10.1016/j.jenvp.2005.01.002

Marx, K. (1974). Capital Volume 1 (p. 474). Moscow: Progress Publishers.

Marx, K. (1978). Capital Volume 3 (p. 813). Moscow: Progress Publishers.

Marx, K., Engels, F., Mandel, E., \& Fernbach, D. (1991). Capital. London: Penguin Books in association with New Left Review.

Maynard, M. (1994). Methods, Practice and epistemology. In M. Maynard \& J. Purvis, Researching Women's Lives from a Feminist Perspective (pp. 10-26). London: Taylor \& Francis.

McGoey, L. (2012). Strategic unknowns: towards a sociology of ignorance. Economy And Society, 41(1), 1-16. doi: 10.1080/03085147.2011.637330

McGoey, L. (2019). The Unknowers: How Strategic Ignorance Rules the World (pp. 1-22, 249270). Zed Books.

MFE. (2020). "Trigger" values for New Zealand rivers | Ministry for the Environment. Retrieved 9 July 2020, from https://www.mfe.govt.nz/publications/fresh-waterenvironmental-reporting/trigger-values-rivers-may00/trigger-values-rivers

Ministry for the Environment. (2018). Types of landfills | Ministry for the Environment. Retrieved 25 March 2019, from http://www.mfe.govt.nz/waste/waste-guidance-andtechnical-information/types-of-landfills

Moustakas, C. (1994). Phenomenological Research Methods. Thousand Oaks California: Sage.

Nagle, J. (2009). The Idea of Pollution. The UC Davis Law Review, 43, 1-78. 
Natali, L. (2017). The Contribution of Green Criminology to the Analysis of Historical Pollution. In F. Centonze \& S. Manacorda, Historical Pollution (1st ed., pp. 21-55). Springer International Publishing.

Natali, L. (2019). Visually exploring social perceptions of environmental harm in global urban contexts. Current Sociology, 67(5), 650-668. doi: 10.1177/0011392118823842

Natali, L., \& McClanahan, B. (2017). Perceiving and Communicating Environmental Contamination and Change: Towards a Green Cultural Criminology with Images. Critical Criminology, 25(2), 199-214. doi: 10.1007/s10612-017-9356-9

New Zealand Government. Conservation Act (1987). New Zealand.

New Zealand Government. Health Act (1956).

New Zealand Government. Local Government Act (2002).

New Zealand Government. Resource Management Act (1991).

OneRoof. (2020). Houghton Bay. Retrieved 4 August 2020, from https://www.oneroof.co.nz/suburb/6-view-houghton-bay-1570

Ottinger, G. (2009). Buckets of Resistance: Standards and the Effectiveness of Citizen Science. Science, Technology, \& Human Values, 35(2), 244-270. doi: $10.1177 / 0162243909337121$

Pahren, H., \& Clark, C. (1987). Microorganisms in municipal solid waste and public health implications. Critical Reviews In Environmental Control, 17(3), 187-228. doi: $10.1080 / 10643388709388334$

Peterson, M. (1974). Soiled disposable diapers: a potential source of viruses. American Journal Of Public Health, 64(9), 912-914. doi: 10.2105/ajph.64.9.912

Pinto, M. (2015). Tensions in agnotology: Normativity in the studies of commercially driven ignorance. Social Studies Of Science, 45(2), 294-315. doi: 10.1177/0306312714565491

Plotkin, S., \& Ram, N. (1984). Multiple bioassays to assess the toxicity of a sanitary landfill leachate. Archives Of Environmental Contamination And Toxicology, 13(2), 197-206. doi: $10.1007 / \mathrm{bf01055877}$ 
Proctor, R. (2008). Agnotology: A Missing Term to Describe the Cultural Production of Ignorance. In R. Proctor \& L. Schiebinger, Agnotology: The Making and Unmaking of Ignorance (1st ed.). Stanford: Stanford University Press.

PubChem. (2020a). Lithium. Retrieved 4 September 2020, from https://pubchem.ncbi.nlm.nih.gov/compound/3028194\#section=Methods-ofManufacturing

PubChem. (2020b). Benzyl butyl phthalate. Retrieved 4 September 2020, from https://pubchem.ncbi.nlm.nih.gov/compound/2347

PubChem. (2020c). Butyric anhydride. Retrieved 4 September 2020, from https://pubchem.ncbi.nlm.nih.gov/compound/7798

PubChem. (2020d). About PubChem. Retrieved 4 August 2020, from https://pubchemdocs.ncbi.nlm.nih.gov/about

PubChem. (2020e). Nonanal. Retrieved 6 August 2020, from https://pubchem.ncbi.nlm.nih.gov/compound/31289

PubChem. (2020f). Dicyclohexyl phthalate. Retrieved 4 September 2020, from https://pubchem.ncbi.nlm.nih.gov/compound/6777

Purchas, C. (1998). Landfills in the Wellington Region (pp. 2-4, 250-251). Wellington: Wellington Regional Council.

Quinlivan, M. (2020). Orange sludge seeps into the water at Wellington's Houghton Bay. Retrieved 10 September 2020, from https://www.newshub.co.nz/home/newzealand/2020/08/orange-sludge-seeps-into-the-water-at-wellington-s-houghtonbay.html

Rogers, H. (2010). Green Gone Wrong: How our Economy is Undermining the Environmental Revolution. New York: Scribner.

Rotolo, G. (2017). Historical Pollution: In Search of a Legal Definition. In F. Centonze \& S. Manacorda, Historical Pollution (1st ed., pp. 1-89). Cham: Spinger International AG. Retrieved from https://link-springer-com.helicon.vuw.ac.nz/chapter/10.1007/978-3319-56937-6_3 
Ryan, G., \& Bernard, H. (2000). Data Management and Analysis Methods (2nd ed., pp. 769802). Thousand Oaks, California: Sage.

Saldaña, J. (2009). The Coding Manual for Qualitative Researchers (pp. 1-31). Thousand Oaks California: Sage.

Scannell, L., \& Gifford, R. (2010). The relations between natural and civic place attachment and pro-environmental behavior. Journal Of Environmental Psychology, 30(3), 289-297. doi: 10.1016/j.jenvp.2010.01.010

Schanbacher, W. (2010). The Politics of Food: The Global Conflict between Food Security and Food Sovereignty (1st ed.). Santa Barbara: Praeger Security International.

Schnaiberg, A. (1980). The Environment: From Surplus to Scarcity. New York: Oxford University Press.

Schnaiberg, A., Pellow, D., \& Weinberg, A. (2000). The treadmill of production and the environmental state. Research In Social Problems And Public Policy, 15-32. doi: 10.1016/s0196-1152(02)80004-7

Scott, D. (2016). 'We Are the Monitors Now'. Social \& Legal Studies, 25(3), 261-287. doi: $10.1177 / 0964663915601166$

Scoullos, M., Vonkeman, G., Thornton, I., \& Makuch, Z. (2012). Mercury Cadmium Lead Handbook for Sustainable Heavy Metals Policy and Regulation. Dordrecht: Springer Netherlands.

Shriver, T., Messer, C., Whittington, J., \& Adams, A. (2019). Industrial pollution and acquiescence: living with chronic remediation. Environmental Politics, 1-20. doi: 10.1080/09644016.2019.1654239

Skinnider, E. (2011). Victims of Environmental Crimes - Mapping the Issues (pp. 23-41). Vancouver British Columbia: The International Center for Criminal Law Reform and Criminal Justice Policy.

Smithson, M. (1990). Ignorance and Disasters. International Journal Of Mass Emergencies And Disasters, 8(3), 207-235. 
South, N. (2016). Green Criminology and Brown Crime: Despoliation, Disposal and Demanufacturing in Global Resource Industries. In T. Wyatt, Hazardous Waste and Pollution(1st ed., pp. 11-25). Cham, Switzerland: Springer International.

South, N., Eman, K., \& Mesko, G. (2014). History of Green Criminology. In G. Bruinsma \& D. Weisburd, Encyclopedia of Criminology and Criminal Justice. New York: Springer.

Sparkman, O., Penton, Z., Kitson, F., \& Kitson, F. (2011). Gas Chromatography and Mass Spectrometry: A Practical Guide (1st ed.). Burlington, MA: Elsevier/Academic Press.

Stanely, E., \& Mihaere, R. (2018). Managing Ignorance About Maori Imprisonment. In A. Barton \& H. Davis, Power Ignorance and Harm (1st ed., pp. 113-138). Cham: Palgrave Macmillan. Retrieved from https://link.springer.com/book/10.1007/978-3-319-97343-2

Stokols, D., \& Shumaker, S. (1981). The Relations Between Natural and Civic Place Attachment and Pro-environmental Behavior. In J. Harvey, Cognition, social behavior, and the environment (pp. 441-448). Hillsdale: Erlbaum.

Stone, G. (2013). A Response to Herring and Rao. Economic And Political Weekly, 48(33), 7072. Retrieved from https://www-jstororg.helicon.vuw.ac.nz/stable/23528093?seq=1\#metadata_info_tab_contents

Stone, G. (2014). Biosecurity in the Age of Genetic Engineering. In N. Chen \& L. Sharp, Bioinsecurity and Vulnerability (1st ed., pp. 71-86). Santa Fe, New Mexico: School for Advanced Research Press. Retrieved from https://d1wqtxts1xzle7.cloudfront.net/36461679/Stone_2014_Bioinsecurity_1_.pdf?14 $22722875=\&$ response-content -

disposition=inline\%3B+filename\%3DBiosecurity_in_the_Age_of_Genetic_Engine.pdf\&E xpires=1595370975\&Signature=gCag2glO7EXufUWJmveWImcnx6M72WmyGn 8GckV WGzvdhNUQaD4D--

JzHYyxvZBWO1ud5Q537izQ22dLjnQuWFdWg910pV0Odj90UoVq 9ypTeKODj2tLH4sta5p4DrhCBCYxzLWYghuqYgL9MZm06jsn0GsHx6LDjHU1xkLKL3D1hh1Xa2BAIVR yw3LfQd7gZxLD5SRRf431Gk11JewkRK8qR3OLL5cXQPpvKKgRPGjcQxCC8Dnfu2E6zQZ0o 5 yMZSsPoyDjRhj13AV5Z2xrBPyPf2uLi84oAPEWZVQP098XjeBpoRWs2PVdqpMLOxBrefd e1JD1b P3VxYOMg_\&Key-Pair-Id=APKAJLOHF5GGSLRBV4ZA 
Sze, J. (2007). Noxious New York. Cambridge MA: MIT Press.

The Greater Wellington Regional Council. (2013). Houghton Bay Stormwater Management Treatment Options (pp. 1-14). Wellington: The Greater Wellington Regional Council.

Tommys. (2019). Free property data for 245 Houghton Bay Road, Houghton Bay, Wellington - homes.co.nz. Retrieved 4 September 2020, from https://homes.co.nz/address/wellington/houghton-bay/245-houghton-bay$\mathrm{road} / \mathrm{DPYn} 2$

Trundle, C. (2020). Translating Proof: Contested Illness, Radiation Exposure, and the Health Claims of Nuclear Test Veterans. In M. Leeuw \& S. Wichelen, Personhood in the Age of Biolegality, Biolegalities (pp. 75-90). Palgrave Macmillan.

Tucker, C. (2017). Clean, Green Aotearoa New Zealand?. In A. Bell, V. Elizabeth, T. McIntosh \& M. Wynyard, A Land of Milk and Honey?: Making Sense of Aotearoa New Zealand (pp. 278-289). Auckland, New Zealand: Auckland University Press.

United Nations. (2019). Globally Harmonized System of Classification and Labelling of Chemicals (GHS). United Nations. Retrieved from https://pubchem.ncbi.nlm.nih.gov/ghs/\#_prec

Van Duijvenbooden, W., \& Kooper, W. (1981). Effects on groundwater flow and groundwater quality of a waste disposal site in Noordwijk, The Netherlands. Science of The Total Environment, 21(1), 85-92. doi: 10.1016/0048-9697(81)90141-8

WCC \& GWRC. (2013). Houghton Bay Stormwater Management Treatment Options (pp. 13). Wellington: GWRC.

WCC \& Wellington Water. (2018). Stormwater Discharge Consent Annual Report (pp. 1-3, 26-28). Wellington: Wellington Water.

WCC. (2020). Property - Land Information Memorandum (LIM) - Wellington City Council. Retrieved 14 September 2020, from https://wellington.govt.nz/services/rates-andproperty/property/reports/lim 
Wellington City Council. (2019). Enjoy the outdoors - Houghton Bay Beach - Wellington City Council. Retrieved 12 August 2020, from https://wellington.govt.nz/recreation/enjoythe-outdoors/beaches-and-coast/southern-suburbs/houghton-bay-beach

Wellington Water. (2015). Houghton Bay leachate - Wellington Water. Retrieved 25 March 2019, from https://www.wellingtonwater.co.nz/your-water/stormwater/stormwaterin-the-wellington-region/houghton-bay-leachate/

White, R. (2008). Crimes Against Nature: Environmental Criminology and Ecological Justice(1st ed.). Devon: Willan Publishing.

White, R. (2010). Environmental Victims and Resistance to State Crime Through Transnational Activism. Social Justice, 36(3), 46-60. Retrieved from https://www-jstororg.helicon.vuw.ac.nz/stable/pdf/29768548.pdf

White, R., \& Heckenberg, D. (2011). Key Vulnerabilities and Limitations in the Management of Hazardous Waste and Its Disposal: A Checklist Assessment Tool. Journal Of Environmental Protection, 02(09), 1257-1263. doi: 10.4236/jep.2011.29145

White, R., \& Heckenberg, D. (2014). Green Criminology An Introduction to the Study of Environmental Harm (1st ed., pp. 24-275). Abingdon: Routledge.

WHO. (2019). Lead poisoning and health. Retrieved 26 October 2020, from https://www.who.int/news-room/fact-sheets/detail/lead-poisoning-and-health

Williams, C. (1996). An Environmental Victimology. Social Science, 23(1), 16-40.

Wyatt, T. (2016). Hazardous Waste and Pollution (1st ed., pp. 1-45). Cham, Switzerland: Springer International Publishing.

Zaykowski, H., \& Campagna, L. (2014). Teaching Theories of Victimology. Journal Of Criminal Justice Education, 25(4), 452-467. doi: 10.1080/10511253.2014.965410

Zheng, Q., Feng, M., \& Dai, Y. (2013). Comparative antioxidant responses in liver of Carassius auratus exposed to phthalates: An integrated biomarker approach. Environmental Toxicology And Pharmacology, 36(3), 741-749. doi: 10.1016/j.etap.2013.07.008 


\section{Appendices:}

I) Figure I,

Leachate flow into HB.

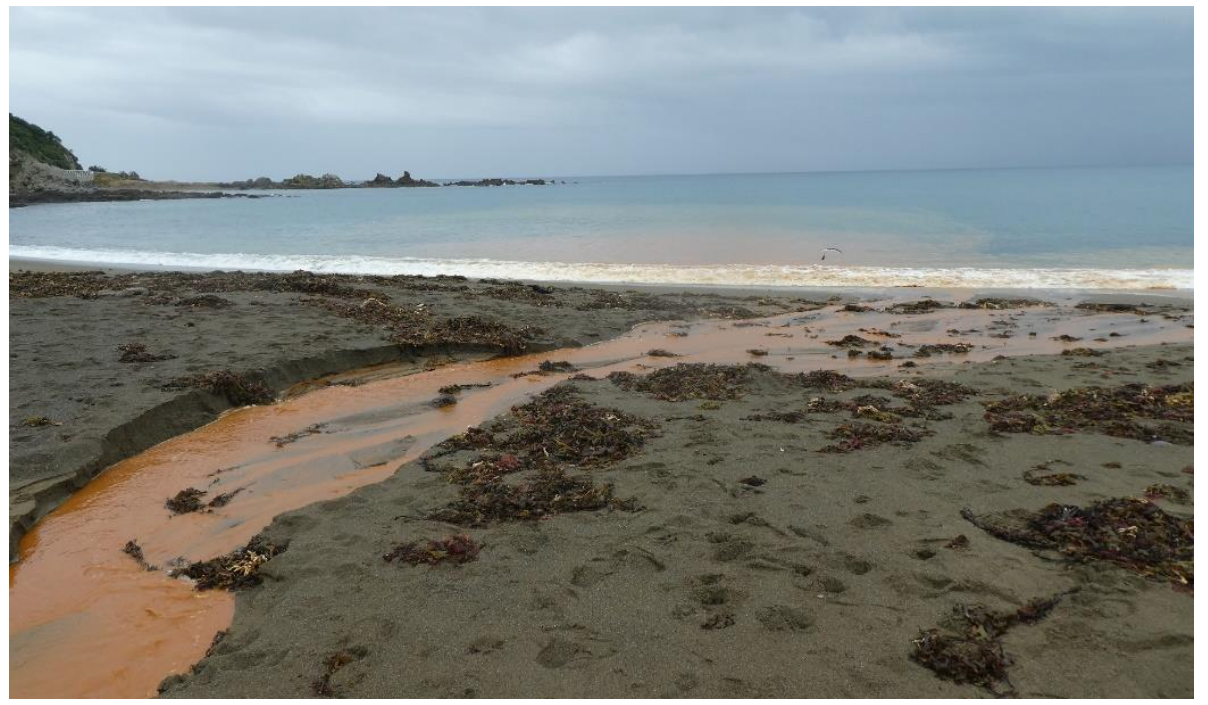

II) Figure II, GCMS chromatograms for water sample \#1.

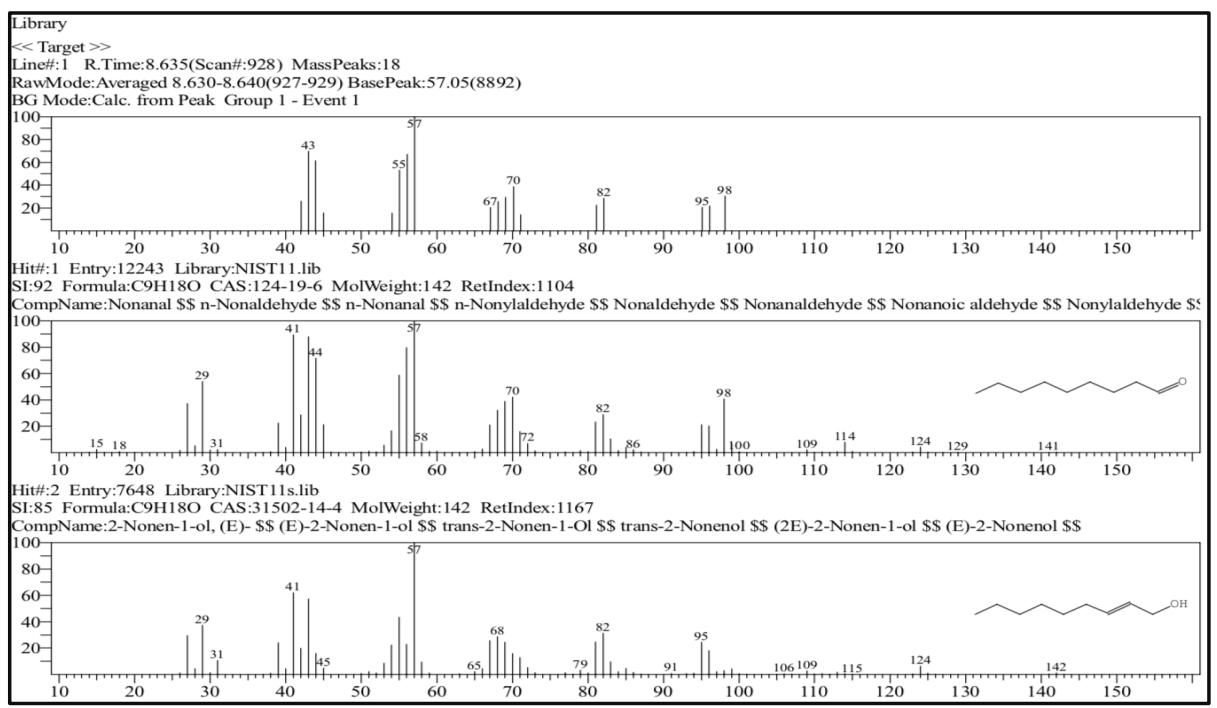

III) Figure III, The Contaminated Environment Spectrum of Awareness.

The Contaminated Environment Spectrum of Awareness

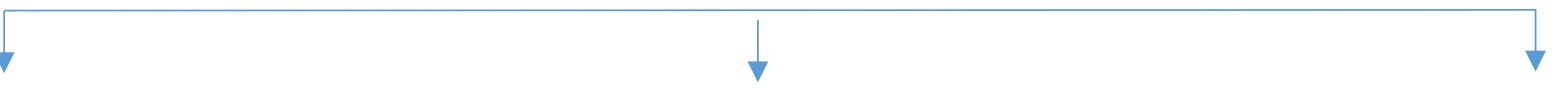

Idyllic Indoctrination

Partial Awareness Contamination Acknowledgement 
IV) Figure IV, Leachate stream flowing.

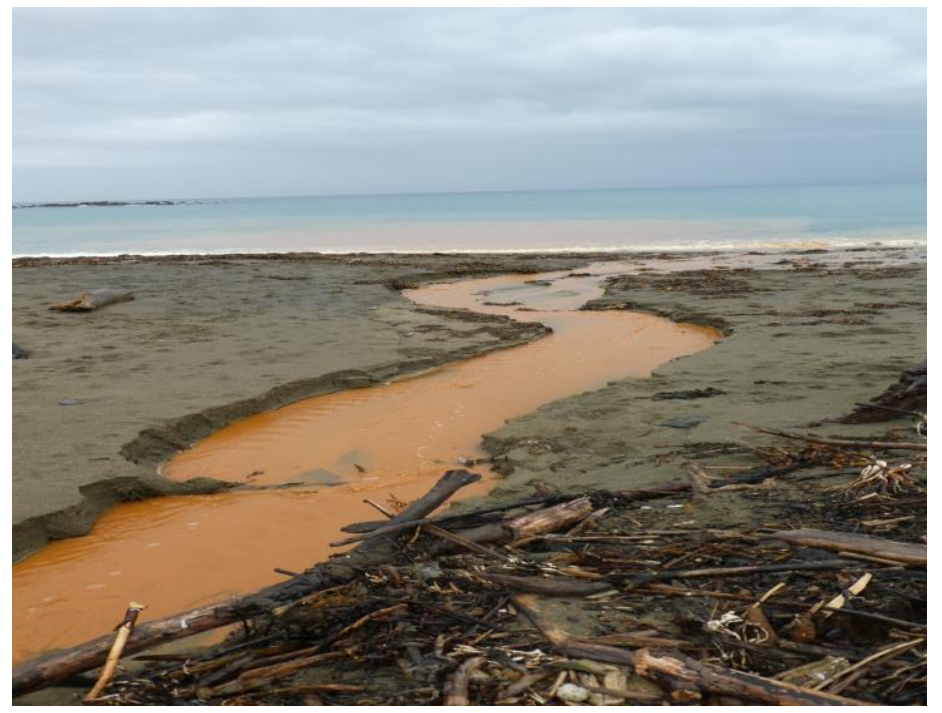

V) Figure V, Sand with orange discolouration.

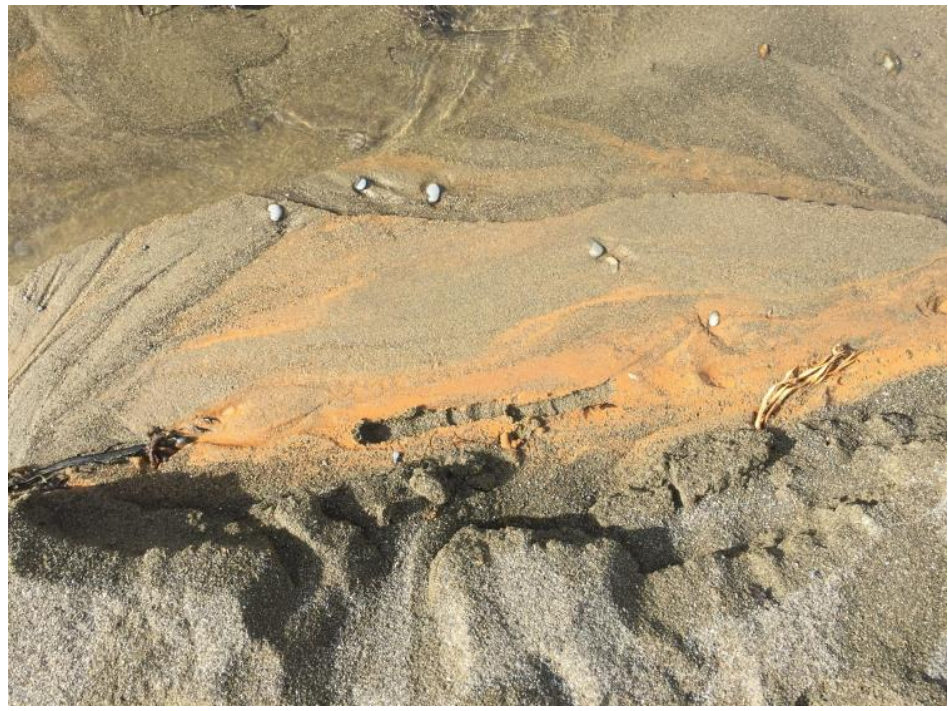

VI) Figure VI, Leachate flowing from the outfall across HB beach.

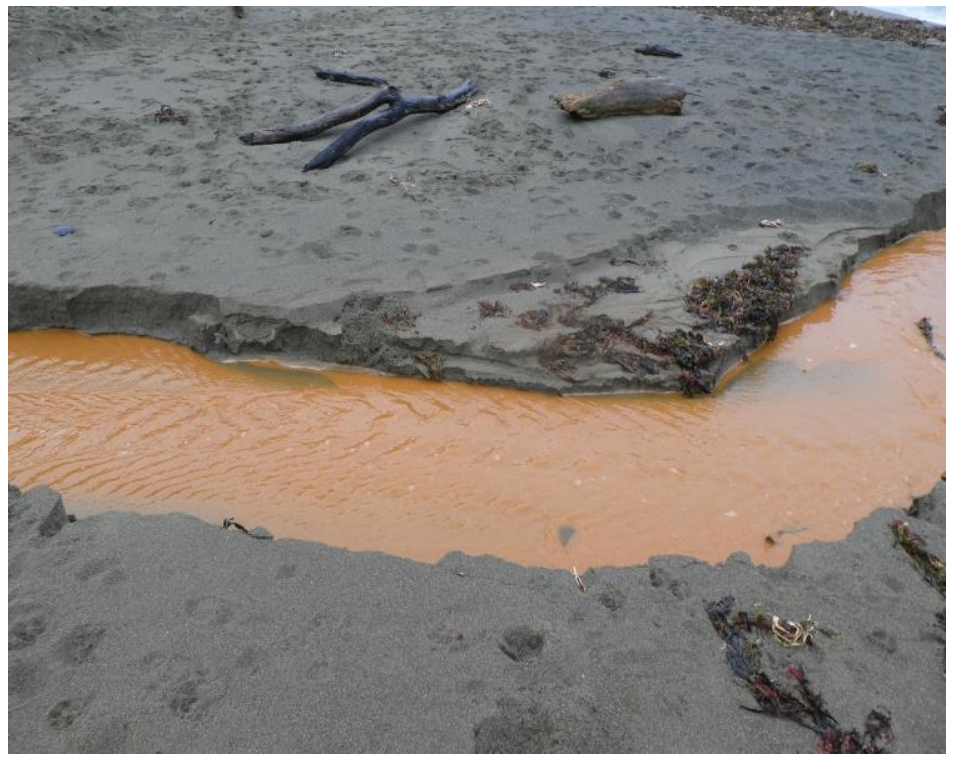


VII) Figure VII, The outflow stream flowing on a dry, sunny day.

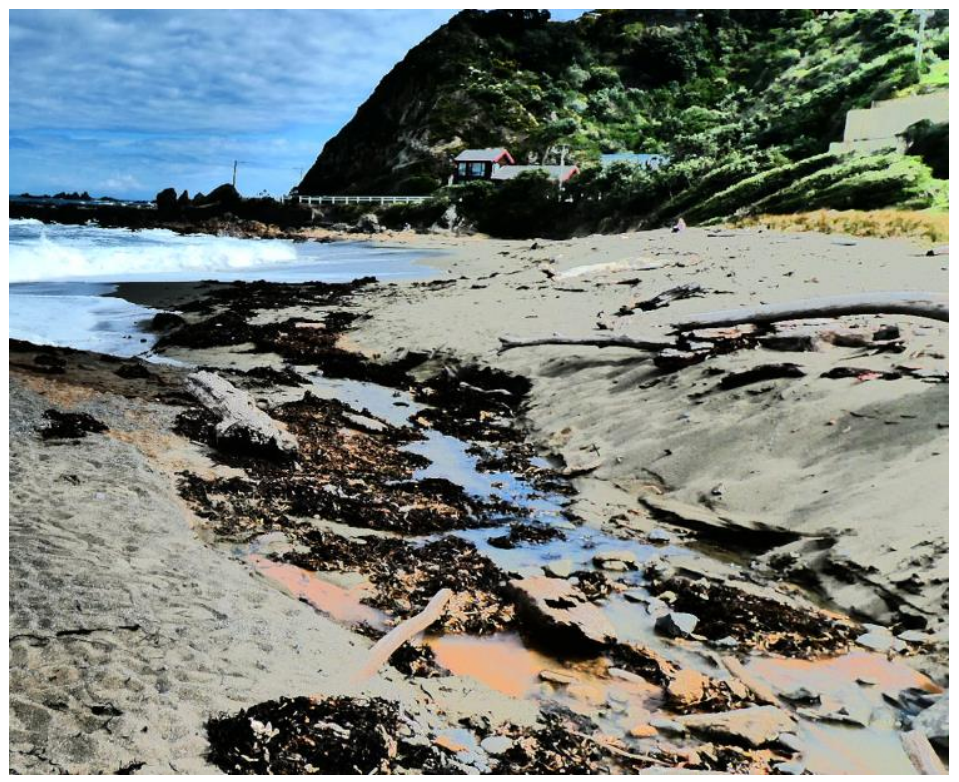

VIII) Figure VIII, Caution sign at HB beach.

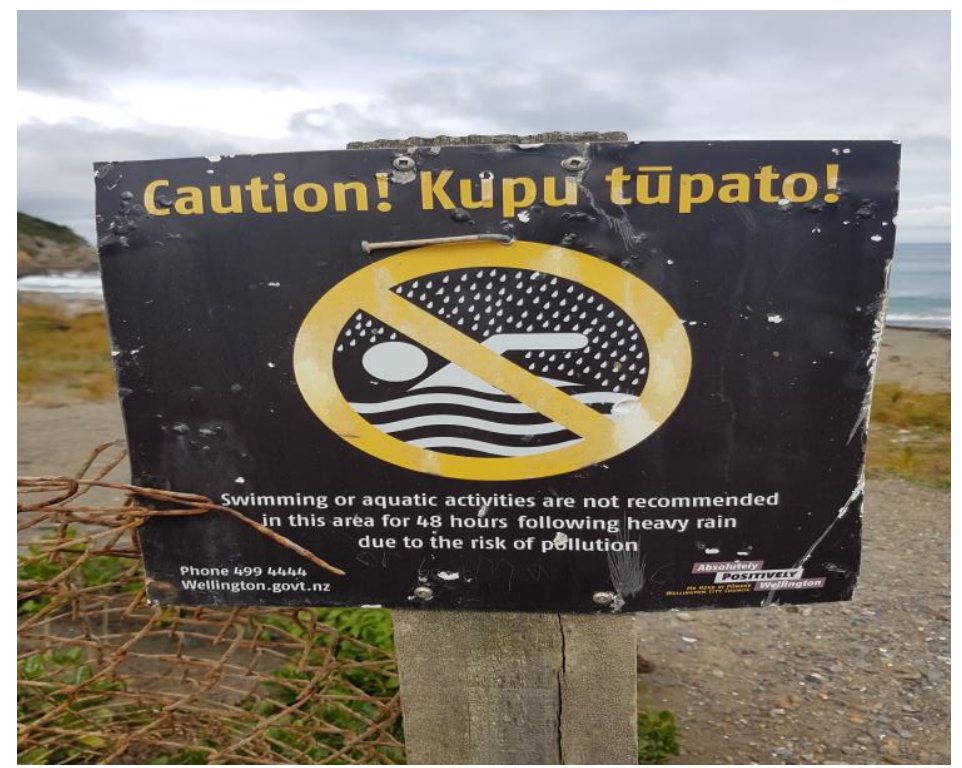

IX) Figure IX, DoC's pest control signage in $\mathrm{HB}$

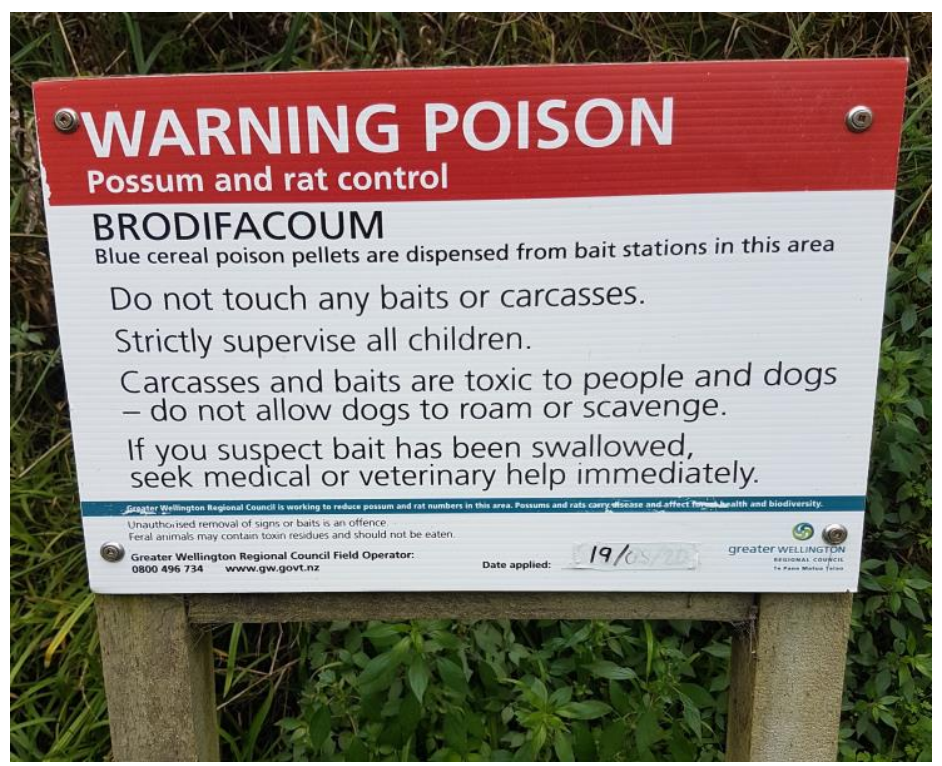


X) Figure $X$, New temporary warning sign in $\mathrm{HB}$.

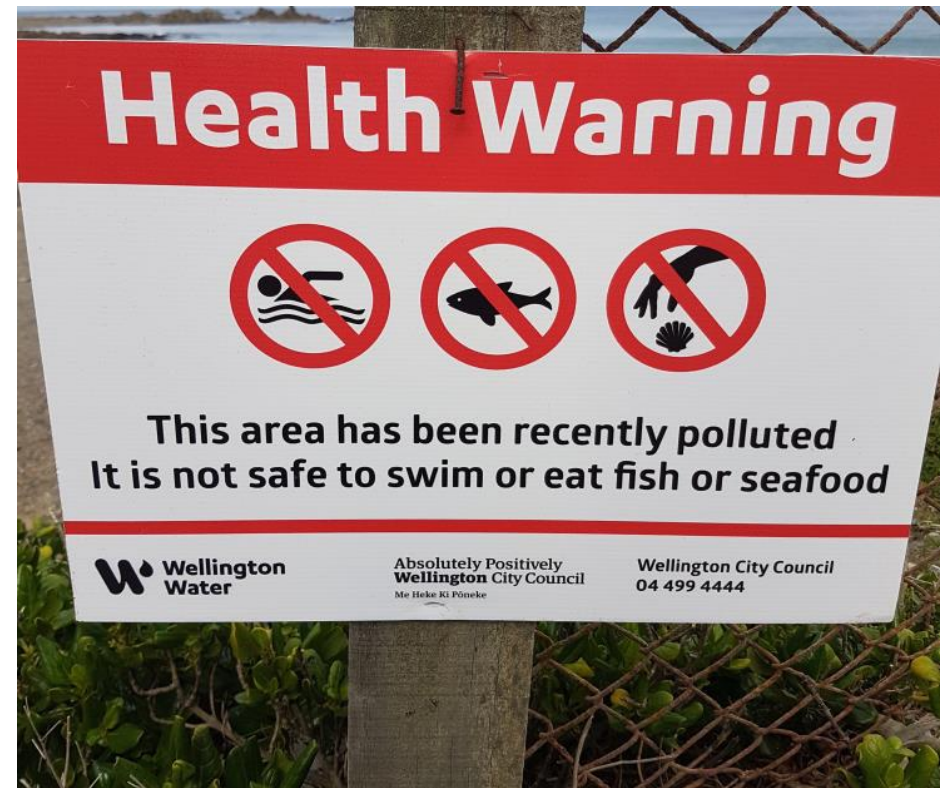


XI) Figure XI, Australia and New Zealand Environment Conservation Council (ANZECC) Contaminate Trigger Values.

\begin{tabular}{|c|c|c|c|c|c|c|c|c|c|}
\hline \multirow{3}{*}{\multicolumn{2}{|c|}{ Chemical }} & \multirow{2}{*}{\multicolumn{4}{|c|}{\begin{tabular}{|c|}
$\begin{array}{c}\text { Trigger values for freshwater } \\
\left(\mu \mathrm{LL}^{-1}\right)\end{array}$ \\
Level of protection (\% species)
\end{tabular}}} & \multicolumn{4}{|c|}{$\begin{array}{l}\text { Trigger values for marine water } \\
\left(\mu \mathrm{gL}^{-1}\right)\end{array}$} \\
\hline & & & & & & \multicolumn{4}{|c|}{ Level of protection (\% species) } \\
\hline & & $99 \%$ & $95 \%$ & $90 \%$ & $80 \%$ & $99 \%$ & $95 \%$ & $90 \%$ & $80 \%$ \\
\hline \multicolumn{10}{|c|}{ METALS \& METALLOIDS } \\
\hline Aluminium & $\mathrm{pH}>6.5$ & 27 & 55 & 80 & 150 & ID & ID & ID & ID \\
\hline Aluminium & $\mathrm{pH}<6.5$ & ID & ID & ID & ID & ID & ID & ID & ID \\
\hline Antimony & & ID & ID & ID & ID & ID & ID & ID & ID \\
\hline Arsenic (As III) & & 1 & 24 & $94^{\mathrm{C}}$ & $360^{\mathrm{C}}$ & ID & ID & ID & ID \\
\hline Arsenic (AsV) & & 0.8 & 13 & 42 & $140^{\mathrm{C}}$ & ID & ID & ID & ID \\
\hline Beryllium & & ID & ID & ID & ID & ID & ID & ID & ID \\
\hline Bismuth & & ID & ID & ID & ID & ID & ID & ID & ID \\
\hline Boron & & 90 & $370^{c}$ & $680^{c}$ & $1300^{c}$ & ID & ID & ID & ID \\
\hline Cadmium & $\mathrm{H}$ & 0.06 & 0.2 & 0.4 & $0.8^{\mathrm{C}}$ & $0.7^{8}$ & $5.5^{\mathrm{B}, \mathrm{C}}$ & $14^{\mathrm{B}, \mathrm{C}}$ & $36^{\mathrm{B}, \mathrm{A}}$ \\
\hline Chromium (Cr III) & $\mathrm{H}$ & ID & ID & ID & ID & 7.7 & 27.4 & 48.6 & 90.6 \\
\hline Chromium (CrVI) & & 0.01 & $1.0^{\mathrm{C}}$ & $6^{A}$ & $40^{A}$ & 0.14 & 4.4 & $20^{\mathrm{C}}$ & $85^{c}$ \\
\hline Cobalt & & ID & ID & ID & ID & 0.005 & 1 & 14 & $150^{c}$ \\
\hline Copper & $\mathrm{H}$ & 1.0 & 1.4 & $1.8^{\mathrm{C}}$ & $2.5^{\mathrm{C}}$ & 0.3 & 1.3 & $3^{c}$ & $8^{A}$ \\
\hline Gallium & & ID & ID & ID & ID & ID & ID & ID & ID \\
\hline Iron & & ID & ID & ID & ID & ID & ID & ID & ID \\
\hline Lanthanum & & ID & ID & ID & ID & ID & ID & ID & ID \\
\hline Lead & $\mathrm{H}$ & 1.0 & 3.4 & 5.6 & $9.4^{\mathrm{C}}$ & 2.2 & 4.4 & $6.6^{c}$ & $12^{\mathrm{C}}$ \\
\hline Manganese & & 1200 & $1900^{C}$ & $2500^{\mathrm{C}}$ & $3600^{\mathrm{C}}$ & ID & ID & ID & ID \\
\hline Mercury (inorganic) & $\mathrm{B}$ & 0.06 & 0.6 & $1.9^{\mathrm{C}}$ & $5.4^{\mathrm{A}}$ & 0.1 & $0.4^{\mathrm{C}}$ & $0.7^{\mathrm{C}}$ & $1.4^{\mathrm{C}}$ \\
\hline Mercury (methyl) & & ID & ID & ID & ID & ID & ID & ID & ID \\
\hline Molybdenum & & ID & ID & ID & ID & ID & ID & ID & ID \\
\hline Nickel & $\mathrm{H}$ & 8 & 11 & 13 & $17^{c}$ & 7 & $70^{c}$ & $200^{A}$ & $560^{A}$ \\
\hline Selenium (Total) & $\mathrm{B}$ & 5 & 11 & 18 & 34 & ID & ID & ID & ID \\
\hline Selenium (SelV) & $\mathrm{B}$ & ID & ID & ID & ID & ID & ID & ID & ID \\
\hline Silver & & 0.02 & 0.05 & 0.1 & $0.2^{\mathrm{C}}$ & 0.8 & 1.4 & 1.8 & $2.6^{\mathrm{C}}$ \\
\hline Thallium & & ID & ID & ID & ID & ID & ID & ID & ID \\
\hline Tin (inorganic, SnIV) & & ID & ID & ID & ID & ID & ID & ID & ID \\
\hline Tributyltin (as $\mu \mathrm{g} / \mathrm{L} \mathrm{Sn}$ ) & & ID & ID & ID & ID & 0.0004 & $0.006^{c}$ & $0.02^{\mathrm{C}}$ & $0.05^{\mathrm{C}}$ \\
\hline Uranium & & ID & ID & ID & ID & ID & ID & ID & ID \\
\hline Vanadium & & ID & ID & ID & ID & 50 & 100 & 160 & 280 \\
\hline Zinc & $\mathrm{H}$ & 2.4 & $8.0^{c}$ & $15^{c}$ & $31^{c}$ & 7 & $15^{c}$ & $23^{c}$ & $43^{c}$ \\
\hline \multicolumn{10}{|c|}{ NON-METALLIC INORGANICS } \\
\hline Ammonia & $\mathrm{D}$ & 320 & $900^{\mathrm{C}}$ & $1430^{\mathrm{C}}$ & $2300^{A}$ & 500 & 910 & 1200 & 1700 \\
\hline Chlorine & $\mathrm{E}$ & 0.4 & 3 & $6^{\mathrm{A}}$ & $13^{\mathrm{A}}$ & ID & ID & ID & ID \\
\hline Cyanide & $\mathrm{F}$ & 4 & 7 & 11 & 18 & 2 & 4 & 7 & 14 \\
\hline Nitrate & $\mathrm{J}$ & 17 & 700 & $3400^{\mathrm{C}}$ & $17000^{\mathrm{A}}$ & ID & ID & ID & ID \\
\hline Hydrogen sulfide & G & 0.5 & 1.0 & 1.5 & 2.6 & ID & ID & ID & ID \\
\hline \multicolumn{10}{|l|}{ ORGANIC ALCOHOLS } \\
\hline Ethanol & & 400 & 1400 & $2400^{\mathrm{C}}$ & $4000^{c}$ & ID & ID & ID & ID \\
\hline Ethylene glycol & & ID & ID & ID & ID & ID & ID & ID & ID \\
\hline Isopropyl alcohol & & ID & ID & ID & ID & ID & ID & ID & ID \\
\hline \multicolumn{10}{|c|}{ CHLORINATED ALKANES } \\
\hline \multicolumn{10}{|l|}{ Chloromethanes } \\
\hline Dichloromethane & & ID & ID & ID & ID & ID & ID & ID & ID \\
\hline Chloroform & & ID & ID & ID & ID & ID & ID & ID & ID \\
\hline Carbon tetrachloride & & ID & ID & ID & ID & ID & ID & ID & ID \\
\hline \multicolumn{10}{|l|}{ Chloroethanes } \\
\hline 1,2-dichloroethane & & ID & ID & ID & ID & ID & ID & ID & ID \\
\hline 1,1,1-trichloroethane & & ID & ID & ID & ID & ID & ID & ID & ID \\
\hline
\end{tabular}




\begin{tabular}{|c|c|c|c|c|c|c|c|c|c|}
\hline \multirow[t]{3}{*}{ Chemical } & & \multirow{2}{*}{\multicolumn{4}{|c|}{\begin{tabular}{|c}
$\begin{array}{r}\text { Trigger values for freshwater } \\
\left(\mu \mathrm{gL}^{-1}\right)\end{array}$ \\
Level of protection $(\%$ species $)$
\end{tabular}}} & \multicolumn{4}{|c|}{$\begin{array}{l}\text { Trigger values for marine water } \\
\left(\mu \mathrm{gL}^{-1}\right)\end{array}$} \\
\hline & & & & & & \multicolumn{4}{|c|}{ Level of protection (\% species) } \\
\hline & & $99 \%$ & $95 \%$ & $90 \%$ & $80 \%$ & $99 \%$ & $95 \%$ & $\mathbf{9 0 \%}$ & $80 \%$ \\
\hline 1,1,2-trichloroethane & & 5400 & 6500 & 7300 & 8400 & 140 & 1900 & $5800^{c}$ & $18000^{\circ}$ \\
\hline 1,1,2,2-tetrachloroethane & & ID & ID & ID & ID & ID & ID & ID & ID \\
\hline Pentachloroethane & & ID & ID & ID & ID & ID & ID & ID & ID \\
\hline Hexachloroethane & B & 290 & 360 & 420 & 500 & ID & ID & ID & ID \\
\hline \multicolumn{10}{|l|}{ Chloropropanes } \\
\hline 1,1-dichloropropane & & ID & ID & ID & ID & ID & ID & ID & ID \\
\hline 1,2-dichloropropane & & ID & ID & ID & ID & ID & ID & ID & ID \\
\hline 1,3-dichloropropane & & ID & ID & ID & ID & ID & ID & ID & ID \\
\hline \multicolumn{10}{|l|}{ CHLORINATED ALKENES } \\
\hline Chloroethylene & & ID & ID & ID & ID & ID & ID & ID & ID \\
\hline 1,1-dichloroethylene & & ID & ID & ID & ID & ID & ID & ID & ID \\
\hline 1,1,2-trichloroethylene & & ID & ID & ID & ID & ID & ID & ID & ID \\
\hline 1,1,2,2-tetrachloroethylene & & ID & ID & ID & ID & ID & ID & ID & ID \\
\hline 3-chloropropene & & ID & ID & ID & ID & ID & ID & ID & ID \\
\hline 1,3-dichloropropene & & ID & ID & ID & ID & ID & ID & ID & ID \\
\hline \multicolumn{10}{|l|}{ ANILINES } \\
\hline Aniline & & 8 & $250^{A}$ & $1100^{A}$ & $4800^{\mathrm{A}}$ & ID & ID & ID & ID \\
\hline 2,4-dichloroaniline & & 0.6 & 7 & 20 & $60^{c}$ & ID & ID & ID & ID \\
\hline 2,5-dichloroaniline & & ID & ID & ID & ID & ID & ID & ID & ID \\
\hline 3,4-dichloroaniline & & 1.3 & 3 & $6^{\mathrm{c}}$ & $13^{\mathrm{c}}$ & 85 & 150 & 190 & 260 \\
\hline 3,5-dichloroaniline & & ID & ID & ID & ID & ID & ID & ID & ID \\
\hline Benzidine & & ID & ID & ID & ID & ID & ID & ID & ID \\
\hline Dichlorobenzidine & & ID & ID & ID & ID & ID & ID & ID & ID \\
\hline \multicolumn{10}{|c|}{ AROMATIC HYDROCARBONS } \\
\hline Benzene & & 600 & 950 & 1300 & 2000 & $500^{\mathrm{C}}$ & $700^{c}$ & $900^{c}$ & $1300^{c}$ \\
\hline Toluene & & ID & ID & ID & ID & ID & ID & ID & ID \\
\hline Ethylbenzene & & ID & ID & ID & ID & ID & ID & ID & ID \\
\hline o-xylene & & 200 & 350 & 470 & 640 & ID & ID & ID & ID \\
\hline$m$-xylene & & ID & ID & ID & ID & ID & ID & ID & ID \\
\hline$p$-xylene & & 140 & 200 & 250 & 340 & ID & ID & ID & ID \\
\hline$m+p$-xylene & & ID & ID & ID & ID & ID & ID & ID & ID \\
\hline Cumene & & ID & ID & ID & ID & ID & ID & ID & ID \\
\hline \multicolumn{10}{|c|}{ Polycyclic Aromatic Hydrocarbons } \\
\hline Naphthalene & & 2.5 & 16 & 37 & 85 & $50^{c}$ & $70^{\mathrm{C}}$ & $90^{\mathrm{C}}$ & $120^{c}$ \\
\hline Anthracene & $\mathrm{B}$ & ID & ID & ID & ID & ID & ID & ID & ID \\
\hline Phenanthrene & $\mathrm{B}$ & ID & ID & ID & ID & ID & ID & ID & ID \\
\hline Fluoranthene & $\mathrm{B}$ & ID & ID & ID & ID & ID & ID & ID & ID \\
\hline Benzo(a)pyrene & $\mathrm{B}$ & ID & ID & ID & ID & ID & ID & ID & ID \\
\hline \multicolumn{10}{|l|}{ Nitrobenzenes } \\
\hline Nitrobenzene & & 230 & 550 & 820 & 1300 & ID & ID & ID & ID \\
\hline 1,2-dinitrobenzene & & ID & ID & ID & ID & ID & ID & ID & ID \\
\hline 1,3-dinitrobenzene & & ID & ID & ID & ID & ID & ID & ID & ID \\
\hline 1,4-dinitrobenzene & & ID & ID & ID & ID & ID & ID & ID & ID \\
\hline 1,3,5-trinitrobenzene & & ID & ID & ID & ID & ID & ID & ID & ID \\
\hline 1-methoxy-2-nitrobenzene & & ID & ID & ID & ID & ID & ID & ID & ID \\
\hline 1-methoxy-4-nitrobenzene & & ID & ID & ID & ID & ID & ID & ID & ID \\
\hline 1-chloro-2-nitrobenzene & & ID & ID & ID & ID & ID & ID & ID & ID \\
\hline 1-chloro-3-nitrobenzene & & ID & ID & ID & ID & ID & ID & ID & ID \\
\hline 1-chloro-4-nitrobenzene & & ID & ID & ID & ID & ID & ID & ID & ID \\
\hline 1-chloro-2,4-dinitrobenzene & & ID & ID & ID & ID & ID & ID & ID & ID \\
\hline 1,2-dichloro-3-nitrobenzene & & ID & ID & ID & ID & ID & ID & ID & ID \\
\hline 1,3-dichloro-5-nitrobenzene & & ID & ID & ID & ID & ID & ID & ID & ID \\
\hline 1,4-dichloro-2-nitrobenzene & & ID & ID & ID & ID & ID & ID & ID & ID \\
\hline 2,4-dichloro-2-nitrobenzene & & ID & ID & ID & ID & ID & ID & ID & ID \\
\hline
\end{tabular}




\begin{tabular}{|c|c|c|c|c|c|c|c|c|}
\hline \multirow[t]{3}{*}{ Chemical } & \multirow{2}{*}{\multicolumn{4}{|c|}{\begin{tabular}{|c|}
$\begin{array}{c}\text { Trigger values for freshwater } \\
\left(\mu \mathrm{gL}^{-1}\right)\end{array}$ \\
Level of protection (\% species)
\end{tabular}}} & \multirow{2}{*}{\multicolumn{4}{|c|}{$\begin{array}{l}\begin{array}{c}\text { Trigger values for marine water } \\
(\mu \mathrm{gL}-1)\end{array} \\
\text { Level of protection }(\% \text { species })\end{array}$}} \\
\hline & & & & & & & & \\
\hline & $99 \%$ & $95 \%$ & $90 \%$ & $80 \%$ & $99 \%$ & $95 \%$ & $90 \%$ & $80 \%$ \\
\hline 1,2,4,5-tetrachloro-3-nitrobenzene & ID & ID & ID & ID & ID & ID & ID & ID \\
\hline 1,5-dichloro-2,4-dinitrobenzene & ID & ID & ID & ID & ID & ID & ID & ID \\
\hline 1,3,5-trichloro-2,4-dinitrobenzene & ID & ID & ID & ID & ID & ID & ID & ID \\
\hline 1-fluoro-4-nitrobenzene & ID & ID & ID & ID & ID & ID & ID & ID \\
\hline \multicolumn{9}{|l|}{ Nitrotoluenes } \\
\hline 2-nitrotoluene & ID & ID & ID & ID & ID & ID & ID & ID \\
\hline 3-nitrotoluene & ID & ID & ID & ID & ID & ID & ID & ID \\
\hline 4-nitrotoluene & ID & ID & ID & ID & ID & ID & ID & ID \\
\hline 2,3-dinitrotoluene & ID & ID & ID & ID & ID & ID & ID & ID \\
\hline 2,4-dinitrotoluene & 16 & $65^{c}$ & $130^{\mathrm{C}}$ & $250^{c}$ & ID & ID & ID & ID \\
\hline 2,4,6-trinitrotoluene & 100 & 140 & 160 & 210 & ID & ID & ID & ID \\
\hline 1,2-dimethyl-3-nitrobenzene & ID & ID & ID & ID & ID & ID & ID & ID \\
\hline 1,2-dimethyl-4-nitrobenzene & ID & ID & ID & ID & ID & ID & ID & ID \\
\hline 4-chloro-3-nitrotoluene & ID & ID & ID & ID & ID & ID & ID & ID \\
\hline Chlorobenzenes and Chloronaphth & nes & & & & & & & \\
\hline Monochlorobenzene & ID & ID & ID & ID & ID & ID & ID & ID \\
\hline 1,2-dichlorobenzene & 120 & 160 & 200 & 270 & ID & ID & ID & ID \\
\hline 1,3-dichlorobenzene & 160 & 260 & 350 & $520^{\mathrm{C}}$ & ID & ID & ID & ID \\
\hline 1,4-dichlorobenzene & 40 & 60 & 75 & 100 & ID & ID & ID & ID \\
\hline 1,2,3-trichlorobenzene & 3 & 10 & 16 & $30^{\mathrm{c}}$ & ID & ID & ID & ID \\
\hline 1,2,4-trichlorobenzene & 85 & $170^{c}$ & $220^{\mathrm{C}}$ & $300^{\mathrm{C}}$ & 20 & 80 & 140 & 240 \\
\hline 1,3,5-trichlorobenzene & ID & ID & ID & ID & ID & ID & ID & ID \\
\hline 1,2,3,4-tetrachlorobenzene & ID & ID & ID & ID & ID & ID & ID & ID \\
\hline 1,2,3,5-tetrachlorobenzene & ID & ID & ID & ID & ID & ID & ID & ID \\
\hline 1,2,4,5-tetrachlorobenzene & ID & ID & ID & ID & ID & ID & ID & ID \\
\hline Pentachlorobenzene & ID & ID & ID & ID & ID & ID & ID & ID \\
\hline Hexachlorobenzene & ID & ID & ID & ID & ID & ID & ID & ID \\
\hline 1-chloronaphthalene & ID & ID & ID & ID & ID & ID & ID & ID \\
\hline Polychlorinated Biphenyls (PCBs) & ioxins & & & & & & & \\
\hline Capacitor 21 & ID & ID & ID & ID & ID & ID & ID & ID \\
\hline Aroclor 1016 & ID & ID & ID & ID & ID & ID & ID & ID \\
\hline Aroclor 1221 & ID & ID & ID & ID & ID & ID & ID & ID \\
\hline Aroclor 1232 & ID & ID & ID & ID & ID & ID & ID & ID \\
\hline Aroclor 1242 & 0.3 & 0.6 & 1.0 & 1.7 & ID & ID & ID & ID \\
\hline Aroclor 1248 & ID & ID & ID & ID & ID & ID & ID & ID \\
\hline Aroclor 1254 & 0.01 & 0.03 & 0.07 & 0.2 & ID & ID & ID & ID \\
\hline Aroclor 1260 & ID & ID & ID & ID & ID & ID & ID & ID \\
\hline Aroclor 1262 & ID & ID & ID & ID & ID & ID & ID & ID \\
\hline Aroclor 1268 & ID & ID & ID & ID & ID & ID & ID & ID \\
\hline 2,3,4'-trichlorobiphenyl & ID & ID & ID & ID & ID & ID & ID & ID \\
\hline 4,4'-dichlorobiphenyl & ID & ID & ID & ID & ID & ID & ID & ID \\
\hline 2,2',4,5,5'-pentachloro-1,1'-biphenylB & ID & ID & ID & ID & ID & ID & ID & ID \\
\hline $2,4,6,2^{\prime}, 4^{\prime}, 6^{\prime}$-hexachlorobiphenyl B & ID & ID & ID & ID & ID & ID & ID & ID \\
\hline Total PCBs & ID & ID & ID & ID & ID & ID & ID & ID \\
\hline $2,3,7,8-\mathrm{TCDD}$ & ID & ID & ID & ID & ID & ID & ID & ID \\
\hline PHENOLS and XYLENOLS & & & & & & & & \\
\hline Phenol & 85 & 320 & 600 & $1200^{c}$ & 270 & 400 & 520 & 720 \\
\hline 2,4-dimethylphenol & ID & ID & ID & ID & ID & ID & ID & ID \\
\hline Nonylphenol & ID & ID & ID & ID & ID & ID & ID & ID \\
\hline 2-chlorophenol & $340^{c}$ & $490^{c}$ & $630^{c}$ & $870^{c}$ & ID & ID & ID & ID \\
\hline 3-chlorophenol & ID & ID & ID & ID & ID & ID & ID & ID \\
\hline 4-chlorophenol & 160 & 220 & $280^{C}$ & $360^{\circ}$ & ID & ID & ID & ID \\
\hline 2,3-dichlorophenol & ID & ID & ID & ID & ID & ID & ID & ID \\
\hline 2,4-dichlorophenol & 120 & $160^{c}$ & $200^{C}$ & $270^{c}$ & ID & ID & ID & ID \\
\hline
\end{tabular}




\begin{tabular}{|c|c|c|c|c|c|c|c|c|}
\hline \multirow[t]{3}{*}{ Chemical } & \multirow{2}{*}{\multicolumn{4}{|c|}{$\begin{array}{c}\begin{array}{c}\text { Trigger values for freshwater } \\
(\mu \mathrm{gL}-1)\end{array} \\
\text { Level of protection (\% species) }\end{array}$}} & \multicolumn{4}{|c|}{$\begin{array}{c}\text { Trigger values for marine water } \\
\left(\mu g \mathrm{~L}^{-1}\right)\end{array}$} \\
\hline & & & & & \multicolumn{4}{|c|}{ Level of protection (\% species) } \\
\hline & $99 \%$ & $95 \%$ & $90 \%$ & $80 \%$ & $99 \%$ & $95 \%$ & $90 \%$ & $80 \%$ \\
\hline 2,5-dichlorophenol & ID & ID & ID & ID & ID & ID & ID & ID \\
\hline 2,6-dichlorophenol & ID & ID & ID & ID & ID & ID & ID & ID \\
\hline 3,4-dichlorophenol & ID & ID & ID & ID & ID & ID & ID & ID \\
\hline 3,5-dichlorophenol & ID & ID & ID & ID & ID & ID & ID & ID \\
\hline 2,3,4-trichlorophenol & ID & ID & ID & ID & ID & ID & ID & ID \\
\hline 2,3,5-trichlorophenol & ID & ID & ID & ID & ID & ID & ID & ID \\
\hline 2,3,6-trichlorophenol & ID & ID & ID & ID & ID & ID & ID & ID \\
\hline 2,4,5-trichlorophenol & ID & ID & ID & ID & ID & ID & ID & ID \\
\hline 2,4,6-trichlorophenol & 3 & 20 & 40 & 95 & ID & ID & ID & ID \\
\hline 2,3,4,5-tetrachlorophenol & ID & ID & ID & ID & ID & ID & ID & ID \\
\hline 2,3,4,6- tetrachlorophenol & 10 & 20 & 25 & 30 & ID & ID & ID & ID \\
\hline $2,3,5,6$ - tetrachlorophenol & ID & ID & ID & ID & ID & ID & ID & ID \\
\hline Pentachlorophenol & 3.6 & 10 & 17 & $27^{\mathrm{A}}$ & 11 & 22 & 33 & $55^{\mathrm{A}}$ \\
\hline \multicolumn{9}{|l|}{ Nitrophenols } \\
\hline 2-nitrophenol & ID & ID & ID & ID & ID & ID & ID & ID \\
\hline 3-nitrophenol & ID & ID & ID & ID & ID & ID & ID & ID \\
\hline 4-nitrophenol & ID & ID & ID & ID & ID & ID & ID & ID \\
\hline 2,4-dinitrophenol & 13 & 45 & 80 & 140 & ID & ID & ID & ID \\
\hline 2,4,6-trinitrophenol & ID & ID & ID & ID & ID & ID & ID & ID \\
\hline \multicolumn{9}{|l|}{ ORGANIC SULFUR COMPOUNDS } \\
\hline Carbon disulfide & ID & ID & ID & ID & ID & ID & ID & ID \\
\hline Isopropyl disulfide & ID & ID & ID & ID & ID & ID & ID & ID \\
\hline n-propyl sulfide & ID & ID & ID & ID & ID & ID & ID & ID \\
\hline Propyl disulfide & ID & ID & ID & ID & ID & ID & ID & ID \\
\hline Tert-butyl sulfide & ID & ID & ID & ID & ID & ID & ID & ID \\
\hline Phenyl disulfide & ID & ID & ID & ID & ID & ID & ID & ID \\
\hline Bis(dimethylthiocarbamyl)sulfide & ID & ID & ID & ID & ID & ID & ID & ID \\
\hline Bis(diethylthiocarbamyl)disulfide & ID & ID & ID & ID & ID & ID & ID & ID \\
\hline $\begin{array}{l}\text { 2-methoxy-4H-1,3,2- } \\
\text { benzodioxaphosphorium-2-sulfide }\end{array}$ & ID & ID & ID & ID & ID & ID & ID & ID \\
\hline \multicolumn{9}{|l|}{ Xanthates } \\
\hline Potassium amyl xanthate & ID & ID & ID & ID & ID & ID & ID & ID \\
\hline Potassium ethyl xanthate & ID & ID & ID & ID & ID & ID & ID & ID \\
\hline Potassium hexyl xanthate & ID & ID & ID & ID & ID & ID & ID & ID \\
\hline Potassium isopropyl xanthate & ID & ID & ID & ID & ID & ID & ID & ID \\
\hline Sodium ethyl xanthate & ID & ID & ID & ID & ID & ID & ID & ID \\
\hline Sodium isobutyl xanthate & ID & ID & ID & ID & ID & ID & ID & ID \\
\hline Sodium isopropyl xanthate & ID & ID & ID & ID & ID & ID & ID & ID \\
\hline Sodium sec-butyl xanthate & ID & ID & ID & ID & ID & ID & ID & ID \\
\hline \multicolumn{9}{|l|}{ PHTHALATES } \\
\hline Dimethylphthalate & 3000 & 3700 & 4300 & 5100 & ID & ID & ID & ID \\
\hline Diethylphthalate & 900 & 1000 & 1100 & 1300 & ID & ID & ID & ID \\
\hline Dibutylphthalate & 9.9 & 26 & 40.2 & 64.6 & ID & ID & ID & ID \\
\hline Di(2-ethylhexyl)phthalate & ID & ID & ID & ID & ID & ID & ID & ID \\
\hline \multicolumn{9}{|c|}{ MISCELLANEOUS INDUSTRIAL CHEMICALS } \\
\hline Acetonitrile & ID & ID & ID & ID & ID & ID & ID & ID \\
\hline Acrylonitrile & ID & ID & ID & ID & ID & ID & ID & ID \\
\hline $\begin{array}{l}\text { Poly(acrylonitrile-co-butadiene-co- } \\
\text { styrene) }\end{array}$ & 200 & 530 & $800^{c}$ & $1200^{c}$ & 200 & 250 & 280 & 340 \\
\hline Dimethylformamide & ID & ID & ID & ID & ID & ID & ID & ID \\
\hline 1,2-diphenylhydrazine & ID & ID & ID & ID & ID & ID & ID & ID \\
\hline Diphenylnitrosamine & ID & ID & ID & ID & ID & ID & ID & ID \\
\hline Hexachlorobutadiene & ID & ID & ID & ID & ID & ID & ID & ID \\
\hline Hexac & ID & ID & ID & ID & ID & ID & ID & ID \\
\hline
\end{tabular}




\begin{tabular}{|c|c|c|c|c|c|c|c|c|c|}
\hline \multirow[t]{3}{*}{ Chemical } & & \multirow{2}{*}{\multicolumn{4}{|c|}{$\begin{array}{c}\begin{array}{r}\text { Trigger values for freshwater } \\
\left(\mu \mathrm{gL}^{-1}\right)\end{array} \\
\text { Level of protection (\% species) }\end{array}$}} & \multicolumn{4}{|c|}{$\begin{array}{l}\text { Trigger values for marine water } \\
\left(\mu g \mathrm{~L}^{-1}\right)\end{array}$} \\
\hline & & & & & & \multicolumn{4}{|c|}{ Level of protection (\% species) } \\
\hline & & $\mathbf{9 9} \%$ & $95 \%$ & $90 \%$ & $80 \%$ & $99 \%$ & $95 \%$ & $90 \%$ & $80 \%$ \\
\hline Isophorone & & ID & ID & ID & ID & ID & ID & ID & ID \\
\hline \multicolumn{10}{|c|}{ ORGANOCHLORINE PESTICIDES } \\
\hline Aldrin & $\mathrm{B}$ & ID & ID & ID & ID & ID & ID & ID & ID \\
\hline Chlordane & B & 0.03 & 0.08 & 0.14 & $0.27^{\mathrm{c}}$ & ID & ID & ID & ID \\
\hline $\mathrm{DDE}$ & B & ID & ID & ID & ID & ID & ID & ID & ID \\
\hline DDT & $\mathrm{B}$ & 0.006 & 0.01 & 0.02 & 0.04 & ID & ID & ID & ID \\
\hline Dicofol & B & ID & ID & ID & ID & ID & ID & ID & ID \\
\hline Dieldrin & B & ID & ID & ID & ID & ID & ID & ID & ID \\
\hline Endosulfan & $\mathrm{B}$ & 0.03 & $0.2^{\mathrm{A}}$ & $0.6^{\mathrm{A}}$ & $1.8^{\mathrm{A}}$ & 0.005 & 0.01 & 0.02 & $0.05^{\mathrm{A}}$ \\
\hline Endosulfan alpha & $\mathrm{B}$ & ID & ID & ID & ID & ID & ID & ID & ID \\
\hline Endosulfan beta & $\mathrm{B}$ & ID & ID & ID & ID & ID & ID & ID & ID \\
\hline Endrin & $\mathrm{B}$ & 0.01 & 0.02 & $0.04^{\mathrm{C}}$ & $0.06^{\mathrm{A}}$ & 0.004 & 0.008 & 0.01 & 0.02 \\
\hline Heptachlor & B & 0.01 & 0.09 & 0.25 & $0.7^{\mathrm{A}}$ & ID & ID & ID & ID \\
\hline Lindane & & 0.07 & 0.2 & 0.4 & $1.0^{\mathrm{A}}$ & ID & ID & ID & ID \\
\hline Methoxychlor & B & ID & ID & ID & ID & ID & ID & ID & ID \\
\hline Mirex & $\mathrm{B}$ & ID & ID & ID & ID & ID & ID & ID & ID \\
\hline Toxaphene & $\mathrm{B}$ & 0.1 & 0.2 & 0.3 & 0.5 & ID & ID & ID & ID \\
\hline \multicolumn{10}{|c|}{ ORGANOPHOSPHORUS PESTICIDES } \\
\hline Azinphos methyl & & 0.01 & 0.02 & 0.05 & $0.11^{\mathrm{A}}$ & ID & ID & ID & ID \\
\hline Chlorpyrifos & $\mathrm{B}$ & 0.00004 & 0.01 & $0.11^{\mathrm{A}}$ & $1.2^{\mathrm{A}}$ & 0.0005 & 0.009 & $0.04^{\mathrm{A}}$ & $0.3^{\mathrm{A}}$ \\
\hline Demeton & & ID & ID & ID & ID & ID & ID & ID & ID \\
\hline Demeton-S-methyl & & ID & ID & ID & ID & ID & ID & ID & ID \\
\hline Diazinon & & 0.00003 & 0.01 & $0.2^{\mathrm{A}}$ & $2^{A}$ & ID & ID & ID & ID \\
\hline Dimethoate & & 0.1 & 0.15 & 0.2 & 0.3 & ID & ID & ID & ID \\
\hline Fenitrothion & & 0.1 & 0.2 & 0.3 & 0.4 & ID & ID & ID & ID \\
\hline Malathion & & 0.002 & 0.05 & 0.2 & $1.1^{\mathrm{A}}$ & ID & ID & ID & ID \\
\hline Parathion & & 0.0007 & $0.004^{c}$ & $0.01^{\mathrm{c}}$ & $0.04^{\mathrm{A}}$ & ID & ID & ID & ID \\
\hline Profenofos & B & ID & ID & ID & ID & ID & ID & ID & ID \\
\hline Temephos & $\mathrm{B}$ & ID & ID & ID & ID & 0.0004 & 0.05 & 0.4 & $3.6^{\mathrm{A}}$ \\
\hline \multicolumn{10}{|c|}{ CARBAMATE \& OTHER PESTICIDES } \\
\hline Carbofuran & & 0.06 & $1.2^{\mathrm{A}}$ & $4^{\mathrm{A}}$ & $15^{\mathrm{A}}$ & ID & ID & ID & ID \\
\hline Methomyl & & 0.5 & 3.5 & 9.5 & 23 & ID & ID & ID & ID \\
\hline S-methoprene & & ID & ID & ID & ID & ID & ID & ID & ID \\
\hline \multicolumn{10}{|l|}{ PYRETHROIDS } \\
\hline Deltamethrin & & ID & ID & ID & ID & ID & ID & ID & ID \\
\hline Esfenvalerate & & ID & $0.001^{*}$ & ID & ID & ID & ID & ID & ID \\
\hline \multicolumn{10}{|c|}{ HERBICIDES \& FUNGICIDES } \\
\hline \multicolumn{10}{|c|}{ Bypyridilium herbicides } \\
\hline Diquat & & 0.01 & 1.4 & 10 & $80^{\mathrm{A}}$ & ID & ID & ID & ID \\
\hline Paraquat & & ID & ID & ID & ID & ID & ID & ID & ID \\
\hline \multicolumn{10}{|c|}{ Phenoxyacetic acid herbicides } \\
\hline MCPA & & ID & ID & ID & ID & ID & ID & ID & ID \\
\hline 2,4-D & & 140 & 280 & 450 & 830 & ID & ID & ID & ID \\
\hline $2,4,5-\mathrm{T}$ & & 3 & 36 & 100 & $290^{A}$ & ID & ID & ID & ID \\
\hline \multicolumn{10}{|c|}{ Sulfonylurea herbicides } \\
\hline Bensulfuron & & ID & ID & ID & ID & ID & ID & ID & ID \\
\hline Metsulfuron & & ID & ID & ID & ID & ID & ID & ID & ID \\
\hline \multicolumn{10}{|c|}{ Thiocarbamate herbicides } \\
\hline Molinate & & 0.1 & 3.4 & 14 & 57 & ID & ID & ID & ID \\
\hline Thiobencarb & & 1 & 2.8 & 4.6 & $8^{\mathrm{c}}$ & ID & ID & ID & ID \\
\hline Thiram & & 0.01 & 0.2 & $0.8^{\mathrm{C}}$ & $3^{A}$ & ID & ID & ID & ID \\
\hline \multicolumn{10}{|l|}{ Triazine herbicides } \\
\hline Amitrole & & ID & ID & ID & ID & ID & ID & ID & ID \\
\hline Atrazine & & 0.7 & 13 & $45^{c}$ & $150^{c}$ & ID & ID & ID & ID \\
\hline
\end{tabular}




\begin{tabular}{|c|c|c|c|c|c|c|c|c|}
\hline \multirow[t]{3}{*}{ Chemical } & \multicolumn{4}{|c|}{$\begin{array}{c}\text { Trigger values for freshwater } \\
\left(\mu \mathrm{gL}^{-1}\right)\end{array}$} & \multicolumn{4}{|c|}{$\begin{array}{l}\text { Trigger values for marine water } \\
\left(\mu \mathrm{LL}^{-1}\right)\end{array}$} \\
\hline & \multicolumn{4}{|c|}{ Level of protection (\% species) } & \multicolumn{4}{|c|}{ Level of protection (\% species) } \\
\hline & $99 \%$ & $95 \%$ & $90 \%$ & $80 \%$ & $99 \%$ & $95 \%$ & $90 \%$ & $80 \%$ \\
\hline Hexazinone & ID & ID & ID & ID & ID & ID & ID & ID \\
\hline Simazine & 0.2 & 3.2 & 11 & 35 & ID & ID & ID & ID \\
\hline \multicolumn{9}{|l|}{ Urea herbicides } \\
\hline Diuron & ID & ID & ID & ID & ID & ID & ID & ID \\
\hline Tebuthiuron & 0.02 & 2.2 & 20 & $160^{c}$ & ID & ID & ID & ID \\
\hline \multicolumn{9}{|l|}{ Miscellaneous herbicides } \\
\hline Acrolein & ID & ID & ID & ID & ID & ID & ID & ID \\
\hline Bromacil & ID & ID & ID & ID & ID & ID & ID & ID \\
\hline Glyphosate & 370 & 1200 & 2000 & $3600^{A}$ & ID & ID & ID & ID \\
\hline Imazethapyr & ID & ID & ID & ID & ID & ID & ID & ID \\
\hline loxynil & ID & ID & ID & ID & ID & ID & ID & ID \\
\hline Metolachlor & ID & ID & ID & ID & ID & ID & ID & ID \\
\hline Sethoxydim & ID & ID & ID & ID & ID & ID & ID & ID \\
\hline Trifluralin & 2.6 & 4.4 & 6 & $9^{A}$ & ID & ID & ID & ID \\
\hline \multicolumn{9}{|l|}{ GENERIC GROUPS OF CHEMICALS } \\
\hline \multicolumn{9}{|l|}{ Surfactants } \\
\hline Linear alkylbenzene sulfonates (LAS) & 65 & 280 & $520^{c}$ & $1000^{c}$ & ID & ID & ID & ID \\
\hline Alcohol ethoxyolated sulfate (AES) & 340 & 650 & $850^{c}$ & $1100^{c}$ & ID & ID & ID & ID \\
\hline Alcohol ethoxylated surfactants (AE) & 50 & 140 & 220 & $360^{c}$ & ID & ID & ID & ID \\
\hline Oils \& Petroleum Hydrocarbons & ID & ID & ID & ID & ID & ID & ID & ID \\
\hline \multicolumn{9}{|l|}{ Oil Spill Dispersants } \\
\hline BP $1100 X$ & ID & ID & ID & ID & ID & ID & ID & ID \\
\hline Corexit 7664 & ID & ID & ID & ID & ID & ID & ID & ID \\
\hline Corexit 8667 & & ID & ID & ID & ID & ID & ID & ID \\
\hline Corexit 9527 & ID & ID & ID & ID & 230 & 1100 & 2200 & $4400^{A}$ \\
\hline Corexit 9550 & ID & ID & ID & ID & ID & ID & ID & ID \\
\hline
\end{tabular}

Notes: Where the final water quality guideline to be applied to a site is below current analytical practical quantitation limits, see Section 3.4 .3 .3 for guidance.

Most trigger values listed here for metals and metalloids are High reliability figures, derived from field or chronic NOEC data (see 3.4 .2 .3 for reference to Volume 2). The exceptions are Moderate reliability for freshwater aluminium ( $\mathrm{pH}>6.5$ ), manganese and marine chromium (III).

Most trigger values listed here for non-metallic inorganics and organic chemicals are Moderate reliability figures, derived from acute $\mathrm{LC}_{50}$ data (see 3.4.2.3 for reference to Volume 2). The exceptions are High reliability for freshwater ammonia, 3,4-DCA, endosulfan, chlorpyrifos, esfenvalerate, tebuthiuron, three surfactants and marine for 1,1,2-TCE and chlorpyrifos.

* = High reliability figure for esfenvalerate derived from mesocosm NOEC data (no alternative protection levels available).

$A=$ Figure may not protect key test species from acute toxicity (and chronic) - check Section 8.3.7 for spread of data and its significance. 'A' indicates that trigger value $>$ acute toxicity figure; note that trigger value should be $<1 / 3$ of acute figure (Section 8.3 .4 .4 ).

$\mathrm{B}=$ Chemicals for which possible bioaccumulation and secondary poisoning effects should be considered (see Sections 8.3.3.4 and 8.3.5.7).

$\mathrm{C}=$ Figure may not protect key test species from chronic toxicity (this refers to experimental chronic figures or geometric mean for species) - check Section 8.3.7 for spread of data and its significance. Where grey shading and 'C' coincide, refer to text in Section 8.3.7.

$\mathrm{D}=\mathrm{Ammonia}$ as TOTAL ammonia as $\left[\mathrm{NH}_{3}-\mathrm{N}\right]$ at $\mathrm{pH}$ 8. For changes in trigger value with $\mathrm{pH}$ refer to Section 8.3.7.2.

$\mathrm{E}=$ Chlorine as total chlorine, as [Cl]; see Section 8.3.7.2.

$\mathrm{F}=$ Cyanide as un-ionised $\mathrm{HCN}$, measured as [CN]; see Section 8.3.7.2.

$\mathrm{G}=$ Sulfide as un-ionised $\mathrm{H}_{2} \mathrm{~S}$, measured as [S]; see Section 8.3.7.2.

$\mathrm{H}=$ Chemicals for which algorithms have been provided in table 3.4 .3 to account for the effects of hardness. The values have been calculated using a hardness of $30 \mathrm{mg} / \mathrm{L} \mathrm{CaCO}_{3}$. These should be adjusted to the site-specific hardness (see Section 3.4.3).

$\mathrm{J}=$ Figures protect against toxicity and do not relate to eutrophication issues. Refer to Section 3.3 if eutrophication is the issue of concern.

$\mathrm{ID}=$ Insufficient data to derive a reliable trigger value. Users advised to check if a low reliability value or an ECL is given in Section 8.3.7.

$\mathrm{T}=$ Tainting or flavour impairment of fish flesh may possibly occur at concentrations below the trigger value. See Sections $4.4 .5 .3 / 3$ and 8.3.7 . 
XII) Figure XII, S.G.S HB outfall test results.

\section{SGS}

\section{Analysis Report}

11 February 2013

Page 1 of 1

Date Received: $\quad 7 / 02 / 13$

Lab Number: $\quad 68534$

Wellington

Temperature:

Ambient

Order NumberiRef: $\quad 07 / 0222013$

Attention:

Date Completed:

$11 / 02 / 13$

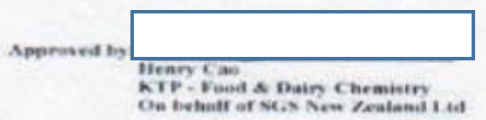

The Results of analysis on the sample/s as received from Paterson Engineering andDesign and described below, are as follows. The Sample/s were received in good condition. Analysis of the sample/s commenced on 7/02/2013

\begin{tabular}{|c|c|c|c|}
\hline Test & Method & ResultUnit & $\begin{array}{c}1 \\
\text { Tip Leachate } \\
\text { Sample }\end{array}$ \\
\hline Cadmium & APHA 3125 & $\mathrm{mgl}$ & 0.00068 \\
\hline Chromium & APHA 3125 & $\mathrm{~mol}$ & 0.010 \\
\hline Copper & APHA 3125 & $\mathrm{mgl}$ & 0.050 \\
\hline Iron & APHA 3125 & $\mathrm{mgl}$ & 125 \\
\hline Lead & APHA 3125 & $\mathrm{~mol}$ & 0.042 \\
\hline Mercury & APHA 3125 & $\mathrm{~mol}$ & $<0.0002$ \\
\hline Selenium & APHA 3125 & $\mathrm{mot}$ & 0.0040 \\
\hline Zinc & APHA 3125 & $\mathrm{mgl}$ & 0.82 \\
\hline
\end{tabular}

Legend: < = less than limit of detection, > = greater than, $[\mathrm{ND}]=$ not detected, $s=$ sub contracted

As: $0.0082 \mathrm{mg} /$ litre

Ni $0.0072 \mathrm{mg} /$ litre.

This document is issued by the Company subject to its General Condisions of Service available on request and accessible at wmw. sgs.com. Attention is drawn to the limitations of liability, indemnification and jurisdictional issues defined therein. Uniess otherwise stated the results shown in this test report refer only to the sample(s) tested. The document cannot be reproduced except in full, without prior approval of the Company.

Any unauthorised alteration, forgery or falsification of the content or appearance of this report is unlawtul and offenders may be prosecuted to the fullest extent of the law.

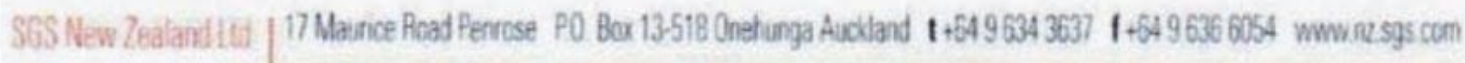


XIII) Figure XIII, Non-organic Water Sample test results.

\begin{tabular}{|l|l|l|}
\hline \multicolumn{1}{|c|}{ Analyte } & \multicolumn{1}{|c|}{ Unit Conversion } & \multicolumn{1}{c|}{ Highest Converted Amount Detected } \\
\hline Arsenic & $0.016 \mathrm{~g} / \mathrm{m}^{3} \times 1000=16 \mathrm{ug} / \mathrm{L}$ & $16 \mathrm{ug} / \mathrm{L}$ \\
\hline Aluminium & $6.2 \mathrm{~g} / \mathrm{m}^{3} \times 1000=6200 \mathrm{ug} / \mathrm{L}$ & $6200 \mathrm{ug} / \mathrm{L}$ \\
\hline Barium & $1.95 \mathrm{~g} / \mathrm{m}^{3} \times 1000=1950 \mathrm{ug} / \mathrm{L}$ & $1950 \mathrm{ug} / \mathrm{L}$ \\
\hline Beryllium & $0.00045 \mathrm{~g} / \mathrm{m}^{3} \times 1000=0.45 \mathrm{ug} / \mathrm{L}$ & $0.45 \mathrm{ug} / \mathrm{L}$ \\
\hline Bismuth & $0.001 \mathrm{~g} / \mathrm{m}^{3} \times 1000=1 \mathrm{ug} / \mathrm{L}$ & $1 \mathrm{ug} / \mathrm{L}$ \\
\hline Boron & $0.664 \mathrm{~g} / \mathrm{m}^{3} \times 1000=664 \mathrm{ug} / \mathrm{L}$ & $664 \mathrm{ug} / \mathrm{L}$ \\
\hline Calcium & $89.6 \mathrm{~g} / \mathrm{m}^{3} \times 1000=89,600 \mathrm{ug} / \mathrm{L}$ & $89,600 \mathrm{ug} / \mathrm{L}$ \\
\hline Cadmium* & $0.00034 \mathrm{~g} / \mathrm{m}^{3} \times 1000=0.34 \mathrm{ug} / \mathrm{L}$ & $0.34 \mathrm{ug} / \mathrm{L}$ \\
\hline Cobalt & $0.00046 \mathrm{~g} / \mathrm{m}^{3} \times 1000=0.46 \mathrm{ug} / \mathrm{L}$ & $0.46 \mathrm{ug} / \mathrm{L}$ \\
\hline Chromium & $0.0092 \mathrm{~g} / \mathrm{m}^{3} \times 1000=9.2 \mathrm{ug} / \mathrm{L}$ & $9.2 \mathrm{ug} / \mathrm{L}$ \\
\hline Caesium & $0.00142 \mathrm{~g} / \mathrm{m}^{3} \times 1000=1.42 \mathrm{ug} / \mathrm{L}$ & $1.42 \mathrm{ug} / \mathrm{L}$ \\
\hline Copper* & $0.0447 \mathrm{~g} / \mathrm{m}^{3} \times 1000=447 \mathrm{ug} / \mathrm{L}$ & $447 \mathrm{ug} / \mathrm{L}$ \\
\hline Iron & $215 \mathrm{~g} / \mathrm{m}^{3} \times 1000=215,000 \mathrm{ug} / \mathrm{L}$ & $215,000 \mathrm{ug} / \mathrm{L}$ \\
\hline Germanium & $0.00861 \mathrm{~g} / \mathrm{m}^{3} \times 1000=8.61 \mathrm{ug} / \mathrm{L}$ & $8.61 \mathrm{ug} / \mathrm{L}$ \\
\hline Mercury & $<0.001 \mathrm{~g} / \mathrm{m}^{3} \times 1000=<1 \mathrm{ug} / \mathrm{L}$ & $<1 \mathrm{ug} / \mathrm{L}$ \\
\hline Potassium & $11.1 \mathrm{~g} / \mathrm{m}^{3} \times 1000=11,100 \mathrm{ug} / \mathrm{L}$ & $11,100 \mathrm{ug} / \mathrm{L}$ \\
\hline Lanthanum & $0.00815 \mathrm{~g} / \mathrm{m}^{3} \times 1000=8.15 \mathrm{ug} / \mathrm{L}$ & $8.15 \mathrm{ug} / \mathrm{L}$ \\
\hline Lithium & $0.0182 \mathrm{~g} / \mathrm{m}^{3} \times 1000=18.2 \mathrm{ug} / \mathrm{L}$ & $18.2 \mathrm{ug} / \mathrm{L}$ \\
\hline Manganese & $1.09 \mathrm{~g} / \mathrm{m}^{3} \times 1000=1090 \mathrm{ug} / \mathrm{L}$ & $1090 \mathrm{ug} / \mathrm{L}$ \\
\hline Magnesium & $26.0 \mathrm{~g} / \mathrm{m}^{3} \times 1000=26,000 \mathrm{ug} / \mathrm{L}$ & $26,000 \mathrm{ug} / \mathrm{L}$ \\
\hline Sodium & $132 \mathrm{~g} / \mathrm{m}^{3} \times 1000=132,000 \mathrm{ug} / \mathrm{L}$ & $132,000 \mathrm{ug} / \mathrm{L}$ \\
\hline Nickel & $0.0052 \mathrm{~g} / \mathrm{m}^{3} \times 1000=5.2 \mathrm{ug} / \mathrm{L}$ & $5.2 \mathrm{ug} / \mathrm{L}$ \\
\hline Phosphorus & $4.73 \mathrm{~g} / \mathrm{m}^{3} \times 1000=4730 \mathrm{ug} / \mathrm{L}$ & $4730 \mathrm{ug} / \mathrm{L}$ \\
\hline Lead* & $0.0282 \mathrm{~g} / \mathrm{m}^{3} \times 1000=28.2 \mathrm{ug} / \mathrm{L}$ & $28.2 \mathrm{ug} / \mathrm{L}$ \\
\hline Rubidium & $0.0152 \mathrm{~g} / \mathrm{m}^{3} \times 100015.2 \mathrm{ug} / \mathrm{L}$ & $15.2 \mathrm{ug} / \mathrm{L}$ \\
\hline Strontium & $1.01 \mathrm{~g} / \mathrm{m}^{3} \times 1000=1010 \mathrm{ug} / \mathrm{L}$ & $1010 \mathrm{ug} / \mathrm{L}$ \\
\hline Uranium & $0.00033 \mathrm{~g} / \mathrm{m}^{3} \times 1000=0.33 \mathrm{ug} / \mathrm{L}$ & $0.33 \mathrm{ug} / \mathrm{L}$ \\
\hline Vanadium & $0.013 \mathrm{~g} / \mathrm{m}^{3} \times 100=13 \mathrm{ug} / \mathrm{L}$ & $13 \mathrm{ug} / \mathrm{L}$ \\
\hline Yttrium & $0.00796 \mathrm{~g} / \mathrm{m}^{3} \times 1000=7.96 \mathrm{ug} / \mathrm{L}$ & $7.96 \mathrm{ug} / \mathrm{L}$ \\
\hline Zinc* & $0.482 \mathrm{~g} / \mathrm{m}^{3} \times 1000=482 \mathrm{ug} / \mathrm{L}$ & $482 \mathrm{ug} / \mathrm{L}$ \\
\hline & & \\
\hline
\end{tabular}


XIV) Figure XIV, Organic Water \& Solid test results.

\begin{tabular}{|c|c|c|c|c|c|}
\hline \multicolumn{6}{|c|}{ Water Test \#1 } \\
\hline Line Number $\nabla$ & Height & $\nabla$ & Highest S.I. \% $\nabla$ & Compound Name & $\nabla$ \\
\hline 11 & 3738188 & & 91 & 2,2,4-Trimethyl-1,3-pentanediol diisobutyrate & \\
\hline 24 & 7107389 & & 92 & Diisobutyl Phthalate & \\
\hline 37 & 6784192 & & 82 & Benzyl butyl phthalate & \\
\hline 42 & 7433369 & & 90 & Dicyclohexyl Phthalate & \\
\hline \multicolumn{6}{|c|}{ Water Test \#2 } \\
\hline 11 & 1662331 & & 92 & Tetrahydrofurfuryl Acetate & \\
\hline 39 & 1448655 & & 92 & Heptadecane & \\
\hline 44 & 7176525 & & 92 & Diisobutyl Phthalate & \\
\hline 51 & 3531500 & & 90 & Isopropyl Palmitate & \\
\hline 68 & 1559416 & & 94 & Heneicosane & \\
\hline 80 & 6671183 & & 76 & Benzyl butyl phthalate & \\
\hline 94 & 7063599 & & 88 & Dicyclohexyl Phthalate & \\
\hline \multicolumn{6}{|c|}{ Water Test \#3 } \\
\hline 9 & 1750845 & & 92 & Tetrahydrofurfuryl Acetate & \\
\hline 38 & 7147753 & & 92 & Diisobutyl Phthalate & \\
\hline 60 & 1448954 & & 94 & 2-Bromododecane & \\
\hline 72 & 6203029 & & 78 & Benzyl butyl phthalate & \\
\hline 83 & 6940944 & & 88 & Dicyclohexyl Phthalate & \\
\hline \multicolumn{6}{|c|}{ Water Test \#4 } \\
\hline 8 & 1943659 & & 92 & Butyric Anhydride & \\
\hline 26 & 7244717 & & 90 & Diisobutyl Phthalate & \\
\hline 31 & 1468237 & & 94 & Tetradecane & \\
\hline 38 & 5069149 & & 74 & Benzyl butyl phthalate & \\
\hline 42 & 7044609 & & 87 & Di(Z)-hex-3-enyl phthalate & \\
\hline \multicolumn{6}{|c|}{ Water test \#5 } \\
\hline 18 & 6474230 & & 91 & Diisobutyl Phthalate & \\
\hline 22 & 723933 & & 94 & Sulfurous acid, 2-ethylhexyl isohexyl ester & \\
\hline 26 & 1567649 & & 77 & Benzyl carbazate & \\
\hline 30 & 3149181 & & 81 & Di(E)-hex-3-enyl-phthalate & \\
\hline \multicolumn{6}{|c|}{ Water Test \#6 } \\
\hline 19 & 7144538 & & 91 & Diisobutyl Phthalate & \\
\hline 23 & 1019272 & & 94 & Sulfurous acid, 2-ethylhexyl isohexyl ester & \\
\hline 28 & 7900109 & & 92 & Oleamide & \\
\hline 30 & 1383397 & & 88 & Dioctyl Ether & \\
\hline 32 & 5468538 & & 85 & Di(E)-hex-3-enyl-phthalate & \\
\hline
\end{tabular}




\begin{tabular}{|l|l|l|l|}
\hline \multicolumn{2}{|c|}{ Orange Sheen (Water) } \\
\hline 13 & 2572230 & 92 & Butyric Anhydride \\
\hline 33 & 7776413 & 90 & Butyl 2-ethylhexyl phthalate \\
\hline 38 & 1512736 & 94 & Tetradecane \\
\hline 41 & 1347031 & & Heptadecane \\
\hline 44 & 6786110 & 84 & Benzyl butyl phthalate \\
\hline 46 & 1199689 & 90 & Oxalic acid, 2-ethylhexyl hexyl ester \\
\hline 48 & 7679304 & 86 & Dicyclohexyl phthalate \\
\hline & & Sea Retraction Water Sample \\
\hline 8 & 1032869 & 93 & Butyric Anhydride \\
\hline 23 & 7082727 & 91 & Diisobutyl Phthalate \\
\hline 36 & 6061041 & 85 & Dicyclohexyl phthalate \\
\hline 58 & 7103034 & 91 & Diisobutyl Phthalate \\
\hline 93 & 1402285 & 83 & O-Benzylhydroxylamine \\
\hline & & & Sediment \#1 \\
\hline 4 & 88893386 & 93 & Propanoic Acid \\
\hline 14 & 19466705 & 94 & 2,2,4-Trimethyl-1,3-pentanediol diisobutyrate \\
\hline 15 & 17869179 & 90 & Propanoic Acid \\
\hline 37 & 5963050 & 92 & Dibutyl Phthalate \\
\hline 40 & 4751928 & 91 & Octathiocane \\
\hline & & & Sediment \#2 \\
\hline 6 & 1001764 & 92 & Butyric Anhydride \\
\hline 34 & 7270729 & 91 & Diisobutyl Phthalate \\
\hline 42 & 1211740 & 94 & 2-Bromododecane \\
\hline & & & \\
\hline
\end{tabular}


Figure XV, Sampling Information.

\section{Non-organic Pollutant Testing:}

This thesis commissioned the scientific analysis of the pollutants found within HB listed in appendicle XIII from Analytica Laboratories, a private company based in Hamilton, NZ. These test are by no means conclusive, as there are a range of factors not accounted for, such as flow rates, temperatures and seasonal that prevent these tests from being absolutely definitive regarding the exact quantity of the pollutant present. These test do provide a snapshot, an indication as to the quantity of pollutants present within the samples taken from the HB outfall. As indicted in the methodology, these where compared the ANZECC contaminate trigger guidelines reprinted under appendicle XI. Note that the sampling employed was conducted by the research halfway submerging small jars that were pre-prepared by Analytica Laboratories and a roughly even distance moving from the base of the outfall towards the sea. What these tests illustrate is that there are pollutants entering the environment of $\mathrm{HB}$ that have the capacity to cause harm to humans, nonhumans and the physical environment itself upon repeated exposure.

\section{Organic Pollutant Testing:}

This thesis was generous enough to have the organic sample testing conducted free of charge by an organic chemist at Victoria University of Wellington located under appendicle XIV. These tests are not comprehensive and serve as presence or absence indicators that provide likely suggestions as to what organic pollutants may be present in HB. These were also compared to the ANZECC contaminate trigger guidelines in addition to the PubChem online database. Water Test \#1 through to \#6 were conducted by submerging small glass jars until almost full into the outfall stream that were then stored in a polystyrene case before being transported to the laboratory for analysis. The Orange sheen sample was taken from a layer of orange sediment that gathered at the base of the stream. The sea retraction sample was taken at the point where the landfill outflow meets the sea in HB. The final two sediment samples were taken halfway down the outfall stream one from each side of the stream although, due to the constraints on this thesis, were unable to be included. The samples were run through a gas chromatography-mass spectrometry (GCMS) machine producing chromatograms that were then interpreted by the researcher. 